\title{
John Stuart MILL (1859)
}

\section{De la liberté}

Traduit de l'anglais par Laurence Lenglet à partir de la traduction de Dupond White (en 1860)

\author{
Un document produit en version numérique par Jean-Marie Tremblay, \\ professeur de sociologie au Cégep de Chicoutimi \\ Courriel:jmt_sociologue@videotron.ca \\ Site web: http://pages.infinit.net/sociojmt
}

Dans le cadre de la collection: "Les classiques des sciences sociales"

Site web: http://www.uqac.uquebec.ca/zone30/Classiques_des_sciences_sociales/index.html

Une collection développée en collaboration avec la Bibliothèque

Paul-Émile-Boulet de l'Université du Québec à Chicoutimi

Site web: http://bibliotheque.uqac.uquebec.ca/index.htm 
Cette édition électronique a été réalisée par Jean-Marie Tremblay, professeur de sociologie au Cégep de Chicoutimi à partir de :

\section{John Stuart Mill (1859)}

DE LA LIBERTÉ.

Une édition électronique réalisée à partir du livre de John Stuart Mill (1859), De la liberté. Traduit de l'anglais par Laurence Lenglet à partir de la traduction de Dupond White en 1860.

Polices de caractères utilisée :

Pour le texte: Times, 12 points.

Pour les citations : Times 10 points.

Pour les notes de bas de page : Times, 10 points.

Édition électronique réalisée avec le traitement de textes Microsoft Word 2001 pour Macintosh.

Mise en page sur papier format

LETTRE (US letter), 8.5’’ x 11'’)

Édition complétée le 19 mai 2002 à Chicoutimi, Québec.

\section{f. Fait avec}

Macintosh 


\title{
Table des matières
}

\author{
I. Introduction \\ II. De la liberté de pensée et de discussion \\ III. De l'individualité comme l'un des éléments du bien-être \\ IV. Des limites de l'autorité de la société sur l'individu \\ V. Applications
}




\section{John Stuart Mill :}

De la liberté

Traduit de l'anglais par Laurence Lenglet à partir de la traduction de Dupond White

« Le sujet de cet essai est la liberté sociale ou civile : la nature et les limites du pouvoir que la société peut légitimement exercer sur l'individu. Cette question, bien que rarement posée ou théorisée, influence profondément les controverses pratiques de notre époque par sa présence latente et devrait bientôt s'imposer comme la question vitale de l'avenir. ( ... )

Je considère l'utilité comme le critère absolu dans toutes les questions éthiques ; mais ici l'utilité doit être prise dans son sens le plus large : se fonder sur les intérêts permanents de l'homme en tant qu'être susceptible de progrès. Je soutiens que ces intérêts autorisent la sujétion de la spontanéité individuelle à un contrôle extérieur uniquement pour les actions de chacun qui touchent l'intérêt d'autrui. »

\section{J. S. M.}




\section{Chapitre I}

\section{Introduction}

$\underline{\text { Retour à la table des matières }}$

Le sujet de cet essai n'est pas ce qu'on appelle le libre arbitre - doctrine opposée à tort à la prétendue nécessité philosophique -, mais la liberté sociale ou civile : la nature et les limites du pouvoir que la société peut légitimement exercer sur l'individu. Cette question, bien que rarement posée ou théorisée, influence profondément les controverses pratiques de notre époque par sa présence latente et devrait bientôt s'imposer comme la question vitale de l'avenir. En un certain sens, elle divise depuis toujours l'humanité; aussi est-elle loin d'être neuve. Mais étant donné le niveau de progrès atteint aujourd'hui par les peuples les plus civilisés, elle se présente sous des formes nouvelles et nécessite un traitement différent et plus fondamental.

La lutte entre liberté et autorité est le trait le plus remarquable de ces périodes historiques qui nous sont familières dès l'enfance, comme la Grèce, la Rome antique et l'Angleterre notamment. Mais autrefois, c'était une dispute qui opposait le souverain à ses sujets, ou à certaines classes de ses sujets. Par liberté, on entendait protection contre la tyrannie des souverains ; gouvernants et gouvernés tenaient alors des positions nécessairement antagonistes. Le pouvoir était aux mains d'un individu, d'une tribu ou d'une caste qui avaient acquis leur autorité soit par héritage, soit par conquête, mais 
ne la tenait en aucun cas du peuple; et nul n'osait, ni ne désirait peut-être, contester leur suprématie, quelles que fussent les précautions à prendre contre l'exercice oppressif qu'ils en faisaient. Le pouvoir des gouvernants était ressenti à la fois comme nécessaire et extrêmement dangereux: comme une arme qu'ils pouvaient à loisir retourner et contre leurs sujets et contre leurs ennemis extérieurs. Pour éviter que d'innombrables vautours ne fondent sur les membres les plus faibles de la communauté, il avait bien fallu charger un aigle, plus puissant celui-là, de les tenir en respect. Mais comme le roi des oiseaux n'était pas moins enclin que les charognards inférieurs à fondre sur le troupeau, on vivait perpétuellement dans la crainte de son bec et de ses serres. Aussi le but des patriotes était-il d'imposer des limites, supportables pour la communauté, au pouvoir du gouvernant: c'est cette limitation qu'ils nommaient liberté. Il y avait deux façons d'y parvenir. Tout d'abord, en obtenant la reconnaissance de certaines immunités, appelées libertés ou droits politiques, que le gouvernant ne pouvait transgresser sans manquer à son devoir et déclencher une résistance spécifique ou une rébellion générale, alors tout à fait justifiée. Le second expédient, généralement plus récent, fut l'établissement de freins constitutionnels : le consentement de la communauté - ou d'un corps quelconque censé représenter ses intérêts - devenait la condition nécessaire de certains actes les plus importants du gouvernement. Au premier de ces modes de restriction, les gouvernants de la plupart des pays d'Europe furent plus ou moins contraints de se soumettre. Il n'en fut pas ainsi du second: l'instaurer - ou achever de l'instaurer lorsqu'il n'existait encore que partiellement - devint partout le but à atteindre des amoureux de la liberté. Et tant que l'humanité se contenta de combattre un ennemi par l'autre, et de se laisser diriger par un maître à condition d'être garantie plus ou moins efficacement contre sa tyrannie, elle n'aspira à rien de plus.

Mais dans la marche des affaires humaines vint le temps où les hommes cessèrent de considérer qu'une loi naturelle conférait à leurs gouvernants un pouvoir indépendant, opposé à leurs propres intérêts. Il fallait que les différents magistrats de l'État fussent pour eux des tenants, des délégués, révocables à leur gré. C'était, leur semblait-il, la seule façon de se prémunir complètement contre les abus de pouvoir du gouvernement. Peu à peu, cette revendication - ce besoin nouveau de gouvernants électifs et temporaires - devint l'objet principal des efforts du parti démocratique partout où un tel parti existait et se substitua très largement à l'ancienne volonté de limiter le pouvoir des gouvernants. Tandis qu'on luttait pour placer le pouvoir des gouvernants sous la tutelle des gouvernés, certains se mirent à penser qu'on avait attaché trop d'importance à la limitation du pouvoir lui-même. C'était une ressource uniquement (semblait-il) lorsque les dirigeants avaient des intérêts opposés à ceux du peuple. A présent, ce qu'on voulait, c'était que les dirigeants fussent identifiés au peuple : que leurs intérêts et leur volonté devinssent les intérêts et la volonté de la nation. La nation n'avait nul besoin d'être protégée contre sa propre volonté; il n'y avait aucun risque qu'elle ne se tyrannisât elle-même. Si les gouvernants étaient effectivement responsables devant elle, promptement révocables par elle, elle serait alors en mesure de leur confier un pouvoir dont elle dicterait elle-même l'usage. Leur pouvoir ne serait plus que celui de la nation, concentré sous une forme propice à son 
exercice. Cette façon de penser - de sentir peut-être - était répandue dans la dernière génération du libéralisme européen et semble prédominer encore dans sa section continentale. Ceux qui admettent une limite à ce que peut faire un gouvernement, sauf s'il s'agit selon eux d'un gouvernement illégitime, font figure de brillantes exceptions parmi les penseurs politiques du Continent. Et aujourd'hui même, une tendance similaire se serait imposée chez, nous si les circonstances qui l'encouragèrent un temps ne s'étaient pas modifiées depuis.

Mais, dans les théories politiques et philosophiques comme chez les personnes, le succès révèle des fautes et des infirmités que l'échec eût peut-être dérobées à l'observation. L'idée que les peuples n'ont pas besoin de limiter leur pouvoir sur eux-mêmes pouvait sembler axiomatique lorsqu'un gouvernement démocratique n'existait encore que dans nos rêves ou nos livres d'histoires. Mais cette idée ne se laisse pas pour autant amoindrir par les aberrations passagères de la Révolution française dont les plus graves furent le fait d'une minorité usurpatrice et qui, par ailleurs, ne trouvèrent pas de légitimité dans les institutions démocratiques, mais dans une explosion de révolte soudaine et convulsive contre le despotisme aristocratique et monarchique. Cependant, avec le temps, une république démocratique vint occuper une grande partie de la surface de la terre et s'imposa comme l'un des membres les plus puissants de la communauté des nations; dès lors, le gouvernement électif et responsable devint l'objet de ces observations et de ces critiques qu'on adresse à tout grand fait existant. C'est alors qu'on s'aperçut que des expressions telles que « l'autonomie politique » et « le pouvoir du peuple sur lui-même » n'exprimaient pas un véritable état de choses. Les " gens du peuple » qui exercent le pouvoir ne sont pas toujours les mêmes que ceux sur qui il s'exerce; et « l'autonomie politique » en question n'est pas le gouvernement de chacun par soi-même, mais celui de chacun par tous les autres. Bien plus, la volonté du peuple signifie en pratique la volonté du plus grand nombre ou de la partie la plus active du peuple: de la majorité, ou ceux qui parviennent à s'imposer en tant que majorité. Il est donc possible que les « gens du peuple » soient tentés d'opprimer une partie des leurs ; aussi est-ce un abus de pouvoir dont il faut se prémunir au même titre qu'un autre. C'est pourquoi il demeure primordial de limiter le pouvoir du gouvernement sur les individus, même lorsque les détenteurs du pouvoir sont régulièrement responsables devant la communauté, c'est-à-dire devant son parti le plus fort. Si cette conception est devenue réalité, c'est qu'elle s'est imposée d'elle-même tant à l'intelligence des penseurs qu'aux inclinations de ces classes importantes de la société européenne qui, à tort ou à raison, voient en la démocratie une menace pour leurs intérêts. Ainsi range-t-on aujourd'hui, dans les spéculations politiques, « la tyrannie de la majorité » au nombre de ces maux contre lesquels la société doit se protéger.

De même que les autres tyrannies, la tyrannie de la majorité inspirait - et inspire encore généralement - de la crainte d'abord parce qu'elle transparaissait dans les actes des autorités publiques. Mais les gens réfléchis s'aperçurent que, lorsque la société devient le tyran - lorsque la masse en vient à opprimer l'individu - ses moyens de tyranniser ne se limitent pas aux actes qu'elle impose à ses fonctionnaires politiques. La société applique les décisions qu'elle prend. Si elle en prend de mauvaises, si elle veut 
ce faisant s'ingérer dans des affaires qui ne sont pas de son ressort, elle pratique une tyrannie sociale d'une ampleur nouvelle - différente des formes d'oppression politique qui s'imposent à coups de sanctions pénales - tyrannie qui laisse d'autant moins d'échappatoire qu'elle va jusqu'à se glisser dans les plus petits détails de la vie, asservissant ainsi l'âme elle-même. Se protéger contre la tyrannie du magistrat ne suffit donc pas. Il faut aussi se protéger contre la tyrannie de l'opinion et du sentiment dominants, contre la tendance de la société à imposer, par d'autres moyens que les sanctions pénales, ses propres idées et ses propres pratiques comme règles de conduite à ceux qui ne seraient pas de son avis. Il faut encore se protéger contre sa tendance à entraver le développement - sinon à empêcher la formation - de toute individualité qui ne serait pas en harmonie avec ses mœurs et à façonner tous les caractères sur un modèle préétabli. Il existe une limite à l'ingérence légitime de l'opinion collective dans l'indépendance individuelle : trouver cette limite - et la défendre contre tout empiétement éventuel - est tout aussi indispensable à la bonne marche des affaires humaines que se protéger contre le despotisme politique.

Mais si cette question n'est guère contestable en théorie, celle de savoir où placer cette limite dans la pratique - trouver le juste milieu entre indépendance individuelle et contrôle social - est un domaine où presque tout reste à explorer. Tout ce qui donne sa valeur à notre existence repose sur les restrictions posées aux actions d'autrui. Il est donc nécessaire d'imposer certaines règles de conduite, par la loi d'abord; puis, pour les nombreuses questions qui ne sont pas de son ressort, par l'opinion. Ce que doivent être ces règles est le problème majeur des sociétés humaines. C'est un problème qui n'a pas encore trouvé de solution véritable. Il n'y a pas deux époques, voire deux pays, qui l'aient tranché de la même façon; et la solution adoptée par une époque ou un pays donné a toujours été une source d'étonnement pour les autres. Pourtant, l'humanité n'a jamais accordé à ce problème qu'une attention limitée, comme s'il y avait toujours eu consensus sur la question. Les règles qui ont cours dans les différents pays sont si évidentes pour leurs habitants qu'elles semblent naturelles. Cette illusion universelle est un exemple de l'influence magique de l'habitude qui, comme le dit le proverbe, devient non seulement une seconde nature, mais se confond constamment avec la première. La coutume, qui neutralise toute critique éventuelle des règles de conduite que l'humanité s'impose à elle-même, est une arme d'autant plus efficace que nul n'éprouve généralement le besoin de la remettre en question, que ce soit collectivement ou individuellement. Les gens ont pris l'habitude de croire - et ceux qui passent pour des philosophes les ont encouragés dans ce sens - que leur opinion personnelle sur ce genre de questions rendait superflue toute remise en question globale. Dans la pratique, le principe qui détermine leur opinion sur la conduite à adopter provient de l'idée qu'il existe en chacun la même volonté de se comporter en modèle pour son voisin et de se conformer au modèle que représentent ses amis. Personne ne conçoit en effet qu'un choix puisse être le résultat d'une inclination personnelle. En revanche, un avis péremptoire sur la conduite à adopter dans telle ou telle situation, voilà ce qui tait office d'inclination personnelle,, que l'on en vienne à expliquer les raisons de ce choix, et l'on constate qu'il est le plus souvent motivé par l'inclination du plus grand nombre. Cependant, que l'inclination de l'homme ordinaire 
soit régie par celle du plus grand nombre est pour lui non seulement un critère tout à fait satisfaisant, mais celui qui détermine toutes ses notions de moralité, de goût ou de convenance, autant de questions qui ne sont pas expressément abordées par sa religion - le critère qui détermine même l'interprétation de sa foi. En conséquence, les opinions des hommes sur ce qui est louable ou blâmable sont le produit de causes multiples - tantôt la raison, tantôt les préjugés ou les superstitions ; souvent la sociabilité, assez fréquemment les penchants antisociaux, l'envie ou la jalousie, l'arrogance ou le mépris ; mais surtout l'ambition ou la peur de perdre: l'intérêt, légitime ou illégitime - autant de causes qui influencent leurs désirs concernant la conduite d'autrui ou toute autre question. Partout où existe une classe dominante, la moralité du pays émane dans une large mesure des intérêts et du sentiment de supériorité de cette classe. Spartiates et Ilotes, planteurs et esclaves, princes et sujets, nobles et roturiers, hommes et femmes : la morale est d'abord issue des intérêts et des sentiments de classe. Et les sentiments ainsi engendrés agissent à leur tour sur les conceptions morales de la classe dominante dans les relations entre ses membres. En revanche, lorsqu'une classe autrefois dominante perd son influence, ou lorsque cette position dominante devient impopulaire, la morale qui prévaut porte fréquemment l'empreinte d'une vive aversion de toute supériorite. L'autre grand principe, imposé par la loi ou l'opinion, qui détermine les règles de conduite en matière d'intolérance et de tolérance est la servilité de l'humanité envers les préférences et aversions supposées de ses maîtres temporels, c'est-à-dire de ses dieux. Ouoique essentiellement égoïste, cette servilité n'est pas de l'hypocrisie; elle provoque d'authentiques sentiments de répulsion, et c'est elle qui pousse les hommes à brûler les magiciens et les hérétiques. Au nombre des influences les plus viles, les intérêts généraux et évidents de la société ont naturellement eu une part - une large part - dans l'orientation des conceptions morales : moins guidées, cependant, par la justification de ces intérêts que par la conséquence des sympathies et des antipathies qui en résultaient. Ce furent ces sympathies et antipathies, qui pourtant n'avaient que peu ou rien à voir avec les intérêts de la société, qui contribuèrent fortement à l'établissement des différentes morales.

Ce furent donc les préférences et les aversions de la société - ou celles de sa classe la plus puissante - qui, grâce à la sanction de la loi et de l'opinion, déterminèrent dans la pratique les règles à observer par tous. Et en général, les avant-gardes intellectuelles ne remirent pas en question cet état de choses, même s'il leur arrivait parfois de faire office d'opposition pour certains points de détail. Elles s'employèrent à réfléchir sur la nature des aversions et des préférences de la société, sans se demander s'il était bon que les individus les considérassent comme des lois. Elles préférèrent s'efforcer de modifier les conceptions sur ces points de détails auxquels elles s'opposaient plutôt que de faire cause commune pour la défense de la liberté avec l'ensemble des opposants. Seule la question religieuse connut une plus grande envergure en devenant l'objet d'un débat entretenu avec cohérence par l'ensemble de la société, exception faite de quelques individus disséminés. C'est un débat instructif à maints égards, d'autant plus qu'il constitue un exemple des plus frappants de la faillibilité de ce qu'on appelle le sens moral - car l'odium theologicum est, pour le bigot sincère, le fondement le moins équivoque de sa conception morale. Pourtant ceux qui, les pre- 
miers, secouèrent le joug de ce qui se prétendait Église universelle étaient en général aussi peu disposés que cette dernière à autoriser la liberté de culte. Mais lorsque la fièvre de la lutte fut retombée, sans donner victoire complète à aucun parti, et que chaque Église ou chaque secte dut se borner à rester en possession du terrain qu'elle occupait déjà, les minorités, constatant qu'elles n'avaient aucune chance de devenir la majorité, se virent contraintes de prier ceux qu'elles ne pouvaient convertir de leur accorder la permission de différer. C'est donc presque exclusivement sur ce terrain-là que les droits de l'individu contre la société ont été établis sur de larges principes, et que la prétention de la société à exercer son autorité sur les dissidents fut ouvertement contestée. Les grands écrivains, auxquels le monde doit ce qu'il possède de liberté religieuse, ont défini la liberté de conscience comme un droit inaliénable; il était inconcevable pour eux qu'un être humain eût à rendre compte aux autres de sa croyance religieuse. Cependant l'intolérance est si naturelle à l'espèce humaine pour tout ce qui lui tient réellement à cœur, que la liberté religieuse n'a été mise en application presque nulle part - excepté là où l'indifférence religieuse, qui n'aime guère voir sa paix troublée par des querelles théologiques, venait peser dans la balance. Dans l'esprit de la plupart des croyants - et cela même dans les pays les plus tolérants - la tolérance est un devoir qui n'est admis qu'avec des réserves tacites. L'un souffrira le désaccord en matière de gouvernement ecclésiastique, mais non de dogme; l'autre tolérera tout le monde, hormis les papistes et les unitariens ; un autre encore, tous ceux qui croient en la religion révélée ; et une minorité poussera la charité un peu plus loin, mais jamais au point de revenir sur la croyance en un dieu unique et en une vie future. Partout où le sentiment de la majorité est encore authentique et intense, on s'aperçoit que ses prétentions à se faire obéir n'ont guère diminué. Si, en Angleterre étant donné les circonstances particulières de notre histoire politique - le joug de l'opinion demeure pesant, celui de la loi est plus léger que dans la plupart des pays, d'Europe; on est très jaloux de préserver la vie privée face à l'interférence directe du pouvoir législatif ou exécutif, et cela non pas tant par souci de l'indépendance de l'individu que par habitude : l'habitude toujours persistante de considérer le gouvernement comme un intérêt opposé à celui du public. La majorité n'a pas encore compris que le pouvoir du gouvernement est son propre pouvoir, ni que les opinions du gouvernement sont les siennes propres : lorsqu'elle y parviendra, la liberté individuelle sera probablement exposée à l'invasion du gouvernement, autant qu'elle l'est déjà à celle de l'opinion publique. Mais pour l'instant, il existe une somme considérable de sentiments prêts à se soulever contre toute tentative de la loi pour contrôler les individus dans des domaines qui jusque-là n'étaient pas de son ressort, mais cela sans guère s'interroger sur ce qui fait partie ou non de la sphère légitime du contrôle officiel. Si bien que ces sentiments, hautement salutaires en soi, sont peut-être tout aussi souvent appliqués à tort qu'à raison. De fait, il n'existe aucun principe reconnu qui détermine dans la pratique les cas où l'intervention de l'État est justifiée ou non. On en décide selon ses préférences personnelles. Certains - partout où ils voient du bien à faire ou un mal à réparer - voudraient inciter le gouvernement à entreprendre cette tâche, tandis que d'autres préfèrent subir toute espèce de préjudices sociaux plutôt que de risquer d'élargir les attributions du gouvernement dans le domaine des intérêts humains. Dès que surgit un problème particulier, les hommes se rangent d'un 
côté ou de l'autre suivant l'orientation générale de leurs sentiments, suivant le degré d'intérêt qu'ils accordent à la chose en question qu'on propose d'ajouter à la compétence du gouvernement, ou encore suivant leur certitude que le gouvernement agit toujours, ou jamais, comme ils le souhaitent. Mais c'est très rarement une opinion mûrement réfléchie sur la nature des attributions du gouvernement qui les pousse à agir. Le résultat de cette absence de règle ou de principe, me semble-t-il, est qu'aujourd'hui un parti a aussi souvent tort que l'autre ; l'intervention du gouvernement est aussi souvent invoquée à tort que condamnée à tort.

L'objet de cet essai est de poser un principe très simple, fondé à régler absolument les rapports de la société et de l'individu dans tout ce qui est contrainte ou contrôle, que les moyens utilisés soient la force physique par le biais de sanctions pénales ou la contrainte morale exercée par l'opinion publique. Ce principe veut que les hommes ne soient autorisés, individuellement ou collectivement, à entraver la liberté d'action de quiconque que pour assurer leur propre protection. La seule raison légitime que puisse avoir une communauté pour user de la force contre un de ses membres est de l'empêcher de nuire aux autres. Contraindre quiconque pour son propre bien, physique ou moral, ne constitue pas une justification suffisante. Un homme ne peut pas être légitimement contraint d'agir ou de s'abstenir sous prétexte que ce serait meilleur pour lui, que cela le rendrait plus heureux ou que, dans l'opinion des autres, agir ainsi serait sage ou même juste. Ce sont certes de bonnes raisons pour lui faire des remontrances, le raisonner, le persuader ou le supplier, mais non pour le contraindre ou lui causer du tort s'il agit autrement. La contrainte ne se justifie que lorsque la conduite dont on désire détourner cet homme risque de nuire à quelqu'un d'autre. Le seul aspect de la conduite d'un individu qui soit du ressort de la société est celui qui concerne les autres. Mais pour ce qui ne concerne que lui, son indépendance est, de droit, absolue. Sur lui-même, sur son corps et son esprit, l'individu est souverain.

Il n'est peut-être guère nécessaire de préciser que cette doctrine n'entend s'appliquer qu'aux êtres humains dans la maturité de leurs facultés. Nous ne parlerons pas ici des enfants, ni des adolescents des deux sexes en dessous de l'âge de la majorité fixé par la loi. Ceux qui sont encore dépendants des soins d'autrui doivent être protégés contre leurs propres actions aussi bien que contre les risques extérieurs. C'est pour cette même raison que nous laisserons de côté ces âges arriérés de la société où l'espèce elle-même pouvait sembler dans son enfance. Les toutes premières difficultés qui se dressent sur le chemin du progrès spontané sont si considérables, qu'on a rarement le choix des moyens pour les surmonter; aussi un souverain progressiste peut-il se permettre d'utiliser n'importe quel expédient pour atteindre un but, autrement inaccessible. Le despotisme est un mode de gouvernement légitime quand on a affaire à des barbares, pourvu que le but vise à leur avancement et que les moyens se justifient par la réalisation effective de ce but. La liberté, comme principe, ne peut s'appliquer à un état de chose antérieur à l'époque où l'humanité devient capable de s'améliorer par la libre discussion entre individus égaux. Avant ce stade, il n'existe pour les hommes que l'obéissance aveugle à un Akbar ou à un Charlemagne, s'ils ont la bonne fortune d'en trouver un. Mais dès que l'humanité devient capable de 
se guider sur la voie du progrès grâce à la conviction ou la persuasion (c'est depuis longtemps le cas des nations qui nous intéressent ici), la contrainte - exercée directement ou en répression par le biais de sanctions pénales - ne peut plus être admise comme un moyen de guider les hommes vers leur propre bien : elle se justifie uniquement dès lors qu'il s'agit de la sécurité des autres.

Il convient de remarquer que je renonce à tout avantage que je pourrais tirer au cours de mon argumentation de l'idée d'un droit abstrait, indépendant de l'utilité. Je considère l'utilité comme le critère absolu dans toutes les questions éthiques ; mais ici l'utilité doit être prise dans son sens le plus large : se fonder sur les intérêts permanents de l'homme en tant qu'être susceptible de progrès. Je soutiens que ces intérêts autorisent la sujétion de la spontanéité individuelle à un contrôle extérieur uniquement pour les actions de chacun qui touchent l'intérêt d'autrui. Si un homme commet un acte nuisible pour les autres, c'est là la raison première de le punir, soit par la loi, soit par la réprobation générale, dans les cas où des sanctions pénales s'avéreraient risquées. Il existe également bon nombre d'actes positifs pour le bien des autres qu'un homme peut être légitimement contraint d'accomplir - comme de témoigner devant un tribunal, de participer pleinement à la défense commune ou à toute oeuvre collective nécessaire aux intérêts de la société dont il reçoit protection, et enfin d'accomplir des actes de bienfaisance individuelle (sauver la vie de son semblable ou s'interposer pour protéger les faibles des mauvais traitements par exemple). Un homme peut en effet être rendu responsable devant la société s'il a manqué d'accomplir de tels actes lorsque tel était son devoir. Une personne peut nuire aux autres non seulement par ses actions, mais aussi par son inaction, et dans les deux cas, elle est responsable envers eux du dommage causé. Il est vrai que dans le second cas, la contrainte doit être exercée avec beaucoup plus de prudence que dans le premier. Rendre quelqu'un responsable du mal qu'il fait aux autres, c'est la règle; le rendre responsable de n'avoir pas empêché un mal, c'est, comparativement, l'exception. Cependant, nombreux sont les cas suffisamment clairs et graves qui justifient cette exception. En tout ce qui concerne ses relations avec autrui, l'individu est de jure responsable envers ceux dont les intérêts sont engagés, et si nécessaire, envers la société en tant que leur protectrice. Il y a souvent de bonnes raisons pour ne pas lui infliger cette responsabilité, mais ces raisons restent à déterminer selon les cas: soit qu'il s'agisse d'un cas où l'individu a des chances de mieux se comporter livré à sa propre discrétion que contrôlé d'aucune façon par la société, soit qu'une tentative de contrôle causerait davantage de mal que celui qu'elle entend prévenir. Lorsque de telles raisons empêchent de sanctionner la responsabilité, la conscience de l'agent lui-même devrait prendre la place du juge absent afin de protéger les intérêts d'autrui qui ne jouissent d'aucune protection extérieure ; l'agent en question devrait se juger d'autant plus sévèrement que le cas ne le soumet pas au jugement de ses semblables.

Mais il y a une sphère d'action dans laquelle la société, en tant que distincte de l'individu, n'a tout au plus qu'un intérêt indirect, à savoir cette partie de la conduite d'une personne qui n'affecte qu'elle-même ou qui, si elle en affecte d'autres, c'est alors qu'ils y ont consenti et participé librement, volontairement et en toute connaissance 
de cause. Quand je dis « elle-même », j'entends ce qui la touche directement et prioritairement ; car tout ce qui affecte une personne peut en affecter d'autres par son intermédiaire ; et l'objection qui se fonde sur cette éventualité fera l'objet de nos réflexions ultérieures. Voilà donc la région propre de la liberté humaine. Elle comprend d'abord le domaine intime de la conscience qui nécessité la liberté de conscience au sens le plus large : liberté de penser et de sentir, liberté absolue d'opinions et de sentiments sur tous les sujets, pratiques ou spéculatifs, scientifiques, moraux ou théologiques. La liberté d'exprimer et de publier des opinions peut sembler soumise à un principe différent, puisqu'elle appartient à cette partie de conduite de l'individu qui concerne autrui ; mais comme elle est presque aussi importante que la liberté de penser elle-même, et qu'elle repose dans une large mesure sur les mêmes raisons, ces deux libertés sont pratiquement indissociables, C'est par ailleurs un principe qui requiert la liberté des goûts et des occupations, la liberté de tracer le plan de notre vie suivant notre caractère, d'agir à notre guise et risquer toutes les conséquences qui en résulteront, et cela sans en être empêché par nos semblables tant que nous ne leur nuisons pas, même s'ils trouvaient notre conduite insensée, perverse ou mauvaise. En dernier lieu, c'est de cette liberté propre à chaque individu que résulte, dans les mêmes limites, la liberté d'association entre individus : la liberté de s'unir dans n'importe quel but, à condition qu'il soit inoffensif pour autrui, que les associés soient majeurs et qu'il n'y ait eu dans leur enrôlement ni contrainte ni tromperie.

Une société quelle que soit la forme de son gouvernement n'est pas libre, à moins de respecter globalement ces libertés ; et aucune n'est complètement libre si elles n'y sont pas absolues et sans réserves. La seule liberté digne de ce nom est de travailler à notre propre avancement à notre gré, aussi longtemps que nous ne cherchons pas à priver les autres du leur ou à entraver leurs efforts pour l'obtenir. Chacun est le gardien naturel de sa propre santé aussi bien physique que mentale et spirituelle. L'humanité gagnera davantage à laisser chaque homme vivre comme bon lui semble qu'à le contraindre à vivre comme bon semble aux autres.

Quoique cette doctrine soit loin d'être neuve et que pour certains elle puisse avoir l'air d'un truisme, il n'y en a pas de plus directement opposée à l'opinion et à la pratique existantes. La société s'est tout autant appliquée (selon ses lumières) à forcer ses membres à se conformer à ses notions de perfection personnelle qu'à ses notions de perfection sociale. Les anciennes républiques s'arrogeaient le droit - et les philosophes de l'Antiquité les y encourageaient - de soumettre tous les aspects de la vie privée aux règles de l'autorité publique, sous prétexte que l'État prenait grand intérêt à la discipline physique et morale de ses citoyens. Cette manière de penser pouvait être envisagée dans de petites républiques entourées d'ennemis puissants et constamment à la merci d'une attaque extérieure ou de troubles intérieurs ; le moindre relâchement de leur vigilance et de leur maîtrise de soi leur eût été facilement fatal, de sorte qu'elles ne pouvaient se permettre d'attendre les effets salutaires et permanents de la liberté. Dans le monde moderne, la dimension des communautés politiques, et surtout la séparation des autorités spirituelle et temporelle (qui a placé la direction des consciences dans d'autres mains que celles qui contrôlaient ses affaires temporelles) 
empêcha une telle interférence de la loi dans les détails de la vie privée. Du même coup, c'est avec davantage de rigueur qu'on a utilisé les armes de la répression contre toute divergence par rapport à la morale régnante dans la vie privée ; car la religion le constituant le plus puissant du sentiment moral - a presque de tous temps été gouvernée, soit par l'ambition d'une hiérarchie aspirant à contrôler tous les aspects de la conduite humaine, soit par l'esprit du puritanisme. Et certains de ces réformateurs modernes qui se sont le plus violemment opposés aux religions du passé n'ont en aucune façon contesté aux Églises et aux sectes le droit de domination spirituelle qu'elles affirmaient : $M$. Comte, en particulier, dont le système social, tel qu'il l'expose dans son Système de politique positive, vise à établir (plutôt, il est vrai, par des moyens moraux que légaux) un despotisme de la société sur l'individu qui dépasse tout ce qu'ont pu imaginer les plus rigides partisans de la discipline parmi les philosophes de l'Antiquité.

Hormis ce type de doctrines propres à un penseur particulier, il y a aussi dans le monde une forte et croissante tendance à étendre indûment le pouvoir de la société sur l'individu, et cela autant par la force de l'opinion que par celle de la législation. Or, comme tous les changements qui surviennent dans le monde ont généralement pour effet de renforcer la société au détriment de l'individu, cet empiétement n'est pas de ces maux qui tendent à disparaître, mais de ceux qui au contraire vont en s'amplifiant. La disposition des hommes, tant dirigeants que concitoyens, à imposer aux autres leurs propres opinions et préférences comme règles de conduite est fortement soutenue par des sentiments - les meilleurs comme les pires -,inhérents à la nature humaine; au point que seul un affaiblissement de son pouvoir pourrait la contenir. Mais puisque ce pouvoir ne va pas déclinant mais croissant, il faut donc, dans la situation actuelle du monde - à moins qu'un mur de convictions morales ne vienne se dresser contre le mal - se résigner à le voir augmenter,

Pour les besoins de l'argument, au lieu d'aborder sur-le-champ la thèse générale, nous nous limiterons en premier lieu à une seule de ses branches, sur laquelle les opinions courantes s'accordent à reconnaître - sinon entièrement, du moins jusqu'à un certain point - le principe exposé ici. Cette branche a trait à la liberté de pensée, laquelle est indissociablement liée à la liberté de parler et d'écrire. Bien que ces libertés constituent dans une large mesure la morale politique de tous les pays qui professent la tolérance religieuse et les libres institutions, leurs fondements tant philosophiques que pratiques ne sont peut-être pas - contrairement à ce qu'on pourrait croire - aussi familiers au publie, voire parfaitement évalués par les chefs de file de l'opinion. Compris dans leur ensemble, ces fondements deviennent plus largement applicables que lorsqu'ils sont morcelés, et un examen approfondi de cet aspect du problème sera la meilleure introduction au reste. C'est pourquoi ceux qui ne trouveront rien de nouveau dans ce que je vais dire voudront bien, je l'espère, m'excuser si je m'aventure à discuter une fois de plus un sujet si souvent débattu depuis maintenant trois siècles. 


\section{Chapitre II}

\section{De la liberté de pensée et de discussion}

Il est à espérer que le temps où il aurait fallu défendre la « liberté de presse , comme l'une des sécurités contre un gouvernement corrompu ou tyrannique est révolu. On peut supposer qu'il est aujourd'hui inutile de défendre l'idée selon laquelle un législatif ou un exécutif dont les intérêts ne seraient pas identifiés à ceux du peuple n'est pas autorisé à lui prescrire des opinions ni à déterminer pour lui les doctrines et les arguments à entendre. D'ailleurs, les philosophes qui m'ont précédé ont déjà si souvent et triomphalement mis en évidence cet aspect du problème que point n'est besoin d'y insister ici. Quoique la loi anglaise sur la presse soit aussi servile de nos jours qu'au temps des Tudor, il n'y a guère de risque qu'elle fasse office d'outil de répression contre la discussion politique, sinon dans un moment de panique passagère 
où la crainte fait perdre la tête aux ministres et aux juges ${ }^{1}$. Et généralement, il n'est pas à craindre dans un pays constitutionnel que le gouvernement, qu'il soit ou non entièrement responsable envers le peuple, cherche souvent à contrôler l'expression de l'opinion, excepté lorsque, en agissant ainsi, il se fait l'organe de l'intolérance générale du public. Supposons donc que le gouvernement ne fasse qu'un avec le peuple et ne songe jamais à exercer aucun pouvoir de coercition, à moins d'être en accord avec ce qu'il estime être la voix du peuple. Mais je refuse au peuple le droit d'exercer une telle coercition, que ce soit de lui-même ou par l'intermédiaire de son gouvernement, car ce pouvoir est illégitime. Le meilleur gouvernement n'y a pas davantage de droit que le pire : un tel pouvoir est aussi nuisible, si ce n'est plus, lorsqu'il s'exerce en accord avec l'opinion publique qu'en opposition avec elle. Si tous les hommes moins un partageaient la même opinion, ils n'en auraient pas pour autant le droit d'imposer silence à cette personne, pas plus que celle-ci, d'imposer silence aux hommes si elle en avait le pouvoir. Si une opinion n'était qu'une possession personnelle, sans valeur pour d'autres que son possesseur; si d'être gêné dans la jouissance de cette possession n'était qu'un dommage privé, il y aurait une différence à ce que ce dommage fût infligé à peu ou à beaucoup de personnes. Mais ce qu'il y a de particulièrement néfaste à imposer silence à l'expression d'une opinion, c'est que cela revient à voler l'humanité : tant la postérité que la génération présente, les détracteurs de cette opinion davantage encore que ses détenteurs. Si l'opinion est juste, on les prive de l'occasion d'échanger l'erreur pour la vérité ; si elle est fausse, ils perdent un bénéfice presque aussi considérable: une perception plus claire et une impression plus vive de la vérité que produit sa confrontation avec l'erreur.

Il est nécessaire de considérer séparément ces deux hypothèses, à chacune desquelles correspond une branche distincte de l'argument. On ne peut jamais être sûr

\footnotetext{
Ces mots étaient à peine écrits lorsque, comme pour leur donner un démenti solennel, survinrent en 1858 les poursuites du gouvernement contre la presse. Cette intervention malavisée dans la discussion publique ne m'a pas entraîné à changer un seul mot au texte; elle n'a pas davantage affaibli ma conviction que, les moments de panique exceptés, l'ère des sanctions à l'encontre de la discussion politique était révolue dans notre pays. Car d'abord on ne persista pas dans les poursuites et secondement, ce ne furent jamais à proprement parler des poursuites politiques. L'offense reprochée n'était pas d'avoir critiqué les instructions, les actes ou les personnes des gouvernants, mais d'avoir propagé une doctrine estimée immorale : la légitimité du tyrannicide.

Si les arguments du présent chapitre ont quelque validité, c'est qu'il devrait y avoir la pleine liberté de professer et de discuter, en tant que conviction éthique, n'importe quelle doctrine, aussi immorale puisse-t-elle sembler. Il serait donc inapproprié et déplacé d'examiner ici si la doctrine du tyrannicide mérite bien ce qualificatif. Je me contenterai de dire que cette question fait depuis toujours partie des débats moraux et qu'un citoyen qui abat un criminel s'élève ce faisant au-dessus de la loi et se place hors de portée des châtiments et des contrôles légaux. Cette action est reconnue par des nations entières et par certains hommes, les meilleurs et les plus sages, non comme un crime, mais comme un acte d'extrême vertu. En tout cas, bon ou mauvais, le tyrannicide n'est pas de l'ordre de l'assassinat, mais de la guerre civile. En tant que tel, je considère que l'instigation au tyrannicide, dans un cas précis, peut donner lieu à un châtiment approprié, mais cela seulement s'il est suivi de l'acte proprement dit ou si un lien vraisemblable entre l'acte et l'instigation peut être établi. Mais dans ce cas, seul le gouvernement attaqué lui-même - et non un gouvernement étranger - peut légitimement, pour se défendre, punir les attaques contre sa propre existence.
} 
que l'opinion qu'on s'efforce d'étouffer est fausse ; et si nous l'étions, ce serait encore un mal.

Premièrement, il se peut que l'opinion qu'on cherche à supprimer soit vraie: ceux qui désirent la supprimer en contestent naturellement la vérité, mais ils ne sont pas infaillibles. Il n'est pas en leur pouvoir de trancher la question pour l'humanité entière, ni de retirer à d'autres qu'eux les moyens de juger. Refuser d'entendre une opinion sous prétexte qu'ils sont sûrs de sa fausseté, c'est présumer que leur certitude est la certitude absolue. Étouffer une discussion, c'est s'arroger l'infaillibilité. Cet argument commun suffira à la condamnation de ce procédé, car tout commun qu'il soit, il n'en est pas plus mauvais.

Malheureusement pour le bon sens des hommes, le fait de leur faillibilité est loin de garder dans leur jugement pratique le poids qu'ils lui accordent en théorie. En effet, bien que chacun se sache faillible, peu sont ceux qui jugent nécessaire de se prémunir contre cette faillibilité, ou d'admettre qu'une opinion dont ils se sentent très sûrs puisse être un exemple de cette erreur. Les princes absolus, ou quiconque accoutumé à une déférence illimitée, éprouvent ordinairement cette entière confiance en leurs propres opinions sur presque tous les sujets. Les hommes les plus heureusement placés qui voient parfois leurs opinions disputées, et qui ne sont pas complètement inaccoutumés à être corrigés lorsqu'ils ont tort, n'accordent cette même confiance illimitée qu'aux opinions qu'ils partagent avec leur entourage, ou avec ceux envers qui ils défèrent habituellement ; car moins un homme fait confiance à son jugement solitaire, plus il s'en remet implicitement à l'infaillibilité « du monde » en général. Et le monde, pour chaque individu, signifie la partie du monde avec laquelle il est en contact : son parti, sa secte, son Église, sa classe sociale. En comparaison, on trouvera à un homme l'esprit large et libéral s'il étend le terme de " monde » à son pays ou son époque. Et sa foi dans cette autorité collective ne sera nullement ébranlée quoiqu'il sache que d'autres siècles, d'autres pays, d'autres sectes, d'autres Églises, d'autres partis ont pensé et pensent encore exactement le contraire. il délègue a son propre monde la responsabilité d'avoir raison face aux mondes dissidents des autres hommes, et jamais il ne s'inquiète de ce que c'est un pur hasard qui a décidé lequel de ces nombreux mondes serait l'objet de sa confiance, et de ce que les causes qui font de lui un anglican à Londres sont les mêmes qui en auraient fait un bouddhiste ou confucianiste à Pékin. Cependant il est évident, comme pourraient le prouver une infinité d'exemples, que les époques ne sont pas plus infaillibles que les individus, chaque époque ayant professé nombre d'opinions que les époques suivantes ont estimées non seulement fausses, mais absurdes. De même il est certain que nombre d'opinions aujourd'hui répandues seront rejetées par les époques futures, comme l'époque actuelle rejette nombre d'opinions autrefois répandues.

Cet argument suscitera probablement une objection de la forme suivante: interdire la propagation de l'erreur n'est effectivement pas davantage une garantie d'infaillibilité que n'importe quel acte accompli par l'autorité publique selon son propre jugement et sous sa propre responsabilité, mais le jugement est donné aux hommes pour 
qu'ils s'en servent. Pour autant faut-il défendre purement et simplement aux hommes de s'en servir sous prétexte qu'ils risquent d'en faire mauvais usage ? En interdisant ce qu'ils estiment pernicieux, ils ne prétendent pas être exempts d'erreurs : ils ne font que remplir leur devoir d'agir selon leur conscience et leur conviction, malgré leur faillibilité. Si nous ne devions jamais agir selon nos opinions de peur qu'elles ne soient fausses, ce serait négliger à la fois tous nos intérêts et nos devoirs. Une opinion qui s'applique à toute conduite en général ne saurait être une objection valable à aucune conduite en particulier. C'est le devoir du gouvernement, et des individus, de se former les opinions les plus justes qu'ils peuvent, de se les former avec soin, sans jamais les imposer aux autres à moins d'être tout à fait sûrs d'avoir raison. Mais quand ils en sont sûrs (diront les raisonneurs), ce n'est point la conscience, mais la couardise qui les retient de laisser se diffuser certaines doctrines qu'honnêtement ils estiment dangereuses pour le bien-être de l'humanité, soit dans cette vie, soit dans l'autre ; et cela, parce que d'autres peuples en des temps moins éclairés ont réprimé des opinions qu'on croit justes aujourd'hui. Gardons-nous, dira-t-on, de refaire la même erreur. Mais gouvernements et nations ont commis des erreurs dans d'autres domaines dont on ne nie pas qu'ils soient du ressort de l'autorité publique: ils ont levé de mauvais impôts, mené des guerres injustes. Est-ce une raison pour ne plus lever d'impôts ou pour ne plus faire de guerres, en dépit des provocations ? Les hommes et les gouvernements doivent agir du mieux qu'ils peuvent. Il n'existe pas de certitude absolue, mais il y en a assez pour les besoins de la vie. Nous pouvons et devons présumer juste notre opinion, suffisamment pour diriger notre conduite ; et ce n'est présumer rien de plus que d'empêcher les mauvaises gens de pervertir la société en propageant des opinions que nous jugeons fausses et pernicieuses.

Je réponds que c'est présumer bien davantage. Il existe une différence extrême entre présumer vraie une opinion qui a survécu à toutes les réfutations et présumer sa vérité afin de ne pas en permettre la réfutation. La liberté complète de contredire et de réfuter notre opinion est la condition même qui nous permet de présumer sa vérité en vue d'agir: c'est là la seule façon rationnelle donnée à un être doué de facultés humaines de s'assurer qu'il est dans le vrai.

Quand nous considérons soit l'histoire de l'opinion, soit le cours ordinaire de la vie humaine, à quoi attribuer que l'une et l'autre ne soient pas pires ? Certes pas à la force propre de l'intelligence humaine; car, pour toute question délicate, une personne sur cent sera capable de trancher ; et encore, la capacité de cette unique personne n'est que relative. Car la majorité des grands hommes des générations passées a soutenu maintes opinions aujourd'hui tenues pour erronées et fait et approuvé nombre de choses que nul ne justifie plus aujourd'hui. Comment se fait-il alors qu'il y ait globalement prépondérance d'opinions et de conduites rationnelles dans l'humanité ? Si prépondérance il y a - et sans elle, les affaires humaines seraient et eussent toujours été dans un état presque désespéré - elle le doit à une qualité de l'esprit humain, à la source de tout ce qu'il y a de respectable en l'homme en tant qu'être intellectuel et moral, à savoir que se erreurs. Par la discussion et l'expérience - mais non par la seule expérience - il est capable de corriger ses erreurs : la discussion est nécessaire pour 
montrer comment interpréter l'expérience. Fausses opinions et fausses pratiques cèdent graduellement devant le fait et l'argument, mais pour produire quelque effet sur l'esprit, ces faits et arguments doivent lui être présentés. Rares sont les faits qui parlent d'eux-mêmes, sans commentaire qui fasse ressortir leur signification. Il s'ensuit que toute la force et la valeur de l'esprit humain - puisqu'il dépend de cette faculté d'être rectifié quand il s'égare - n'est vraiment fiable que si tous les moyens pour le rectifier sont à portée de main. Le jugement d'un homme s'avère-t-il digne de confiance, c'est qu'il a su demeurer ouvert aux critiques sur ses opinions et sa conduite; c'est qu'il a pris l'habitude d'écouter tout ce qu'on disait contre lui, d'en profiter autant qu'il était nécessaire et de s'exposer à lui-même - et parfois aux autres - la fausseté de ce qui était faux: c'est qu'il a senti que la seule façon pour un homme d'accéder à la connaissance exhaustive d'un sujet est d'écouter ce qu'en disent des personnes d'opinions variées et comment l'envisagent différentes formes d'esprit, Jamais homme sage n'acquit sa sagesse autrement; et la nature de l'intelligence humaine est telle qu'elle ne peut l'acquérir autrement. Loin de susciter doute et hésitation lors de la mise en pratique, s'habituer à corriger et compléter systématiquement son opinion en la comparant à celle des autres est la seule garantie qui la rende digne de confiance. En effet l'homme sage - pour connaître manifestement tout ce qui se peut dire contre lui, pour défendre sa position contre tous les contradicteurs, pour savoir que loin d'éviter les objections et les difficultés, il les a recherchées et n'a négligé aucune lumière susceptible d'éclairer tous les aspects du sujet - l'homme sage a le droit de penser que son jugement vaut mieux que celui d'un autre ou d'une multitude qui n'ont pas suivi le même processus.

Ce n'est pas trop exiger que d'imposer à ce qu'on appelle le public - ce mélange hétéroclite d'une minorité de sages et d'une majorité de sots - de se soumettre à ce que les hommes les plus sages - ceux qui peuvent le plus prétendre à la fiabilité de leur jugement - estiment nécessaire pour garantir leur jugement. La plus intolérante des Églises, l'Église catholique romaine, admet et écoute patiemment, même lors de la canonisation d'un saint, un " avocat du diable ». Les plus saints des hommes ne sauraient être admis aux honneurs posthumes avant que tout ce que le diable peut dire contre eux ne soit connu et pesé. S'il était interdit de remettre en question la philosophie newtonienne, l'humanité ne pourrait aujourd'hui la tenir pour vraie en toute certitude. Les croyances pour lesquelles nous avons le plus de garantie n'ont pas d'autre sauvegarde qu'une invitation constante au monde entier de les prouver non fondées. Si le défi n'est pas relevé - ou s'il est relevé et que la tentative échoue - nous demeurerons assez éloignés de la certitude, mais nous aurons fait de notre mieux dans l'état actuel de la raison humaine : nous n'aurons rien négligé pour donner à la vérité une chance de nous atteindre. Les lices restant ouvertes, nous pouvons espérer que s'il existe une meilleure vérité, elle sera découverte lorsque l'esprit humain sera capable de la recevoir. Entre-temps, nous pouvons être sûrs que notre époque a approché la vérité d'aussi près que possible. Voilà toute la certitude à laquelle peut prétendre un être faillible, et la seule manière d'y parvenir. 
Il est étonnant que les hommes admettent la validité des arguments en faveur de la libre discussion, mais qu'ils objectent dès qu'il s'agit de les « pousser jusqu'au bout », et cela sans voir que si ces raisons ne sont pas bonnes pour un cas extrême, c'est qu'elles ne valent rien. Il est étonnant qu'ils s'imaginent s'attribuer l'infaillibilité en reconnaissant la nécessité de la libre discussion sur tous les sujets ouverts au doute, mais pensent également que certaines doctrines ou principes particuliers devraient échapper à la remise en question sous prétexte que leur certitude est prouvée, ou plutôt qu'ils sont certains, eux, de leur certitude. Qualifier une proposition de certaine tant qu'il existe un être qui nierait cette certitude s'il en avait la permission alors qu'il est prive de celle-ci, c'est nous présumer - nous et ceux qui sont d'accord avec nous les garants de la certitude, garants qui de surcroît pourraient se dispenser d'entendre la partie adverse.

Dans notre époque - qu'on a décrite comme « privée de foi, mais terrifiée devant le scepticisme » - où les gens se sentent sûrs non pas tant de la vérité de leurs opinions que de leur nécessité, les droits d'une opinion à demeurer protégée contre l'attaque publique se fondent moins sur sa vérité que sur son importance pour la société. Il y a, dit-on, certaines croyances si utiles, voire si indispensables au bien-être qu'il est du devoir des gouvernements de les défendre, au même titre que d'autres intérêts de la société. Devant une telle situation de nécessité, devant un cas s'inscrivant aussi évidemment dans leur devoir, assure-t-on, un peu moins d'infaillibilité suffirait pour justifier, voire obliger, les gouvernements à agir selon leur propre opinion, confirmée par l'opinion générale de l'humanité. On avance aussi souvent - et on le pense plus souvent encore -que seuls les méchants désireraient affaiblir ces croyances salutaires ; aussi n'y a-t-il rien de mal à interdire ce qu'eux seuls voudraient faire. Cette manière de penser, en justifiant les restrictions sur la discussion, fait de ce problème non plus une question de vérité, mais d'utilité des doctrines ; et on se flatte ce faisant d'échapper à l'accusation de garant infaillible des opinions. Mais ceux qui se satisfont à si bon compte ne s'aperçoivent pas que la prétention à l'infaillibilité est simplement déplacée. L'utilité même d'une opinion est affaire d'opinion : elle est un objet de dispute ouvert à la discussion, et qui l'exige autant que l'opinion elle-même. Il faudra un garant infaillible des opinions tant pour décider qu'une opinion est nuisible que pour décider qu'elle est fausse, à moins que l'opinion ainsi condamnée n'ait toute latitude pour se défendre. Il ne convient donc pas de dire qu'on permet à un hérétique de soutenir l'utilité ou le caractère inoffensif de son opinion si on lui défend d'en soutenir la vérité. La vérité d'une opinion fait partie de son utilité. Lorsque nous voulons savoir s'il est souhaitable qu'une proposition soit partagée, est-il possible d'exclure la question de savoir si oui ou non elle est vraie ? Dans l'opinion, non des méchants mais des meilleurs des hommes, nulle croyance contraire à la vérité ne peut être réellement utile: pouvez-vous empêcher de tels hommes d'avancer cet argument quand on les accuse de s'opposer à l'utilité prétendue d'une doctrine qu'ils estiment fausse par ailleurs ? Ceux qui défendent les opinions reçues ne manquent jamais de tirer tous les avantages possibles de cette excuse : jamais on ne les voit, eux, traiter de la question de l'utilité comme si on pouvait l'abstraire complètement de celle de la vérité. Au contraire, c'est avant tout parce que leur doctrine est " la vérité » qu'ils 
estiment si indispensable de la connaître ou d'y croire. Il ne peut y avoir de discussion loyale sur la question de l'utilité quand un seul des deux partis peut se permettre d'avancer un argument aussi vital. Et en fait, lorsque la loi ou le sentiment public ne permettent pas de remettre en question la vérité d'une opinion, ils tolèrent tout aussi peu un déni de son utilité. Ce qu'ils permettent, tout au plus, c'est une atténuation de sa nécessité absolue ou de la faute indéniable qu'il y aurait à la rejeter.

Afin de mieux illustrer tout le mal qu'il y a à refuser d'écouter des opinions parce que nous les avons condamnées d'avance dans notre propre jugement, il convient d'ancrer la discussion sur un cas concret. Je choisirai de préférence les cas qui me sont le moins favorables, ceux dans lesquels les arguments contre la liberté d'opinion - tant du côté de la vérité que de l'utilité - sont estimés les plus forts. Supposons que les opinions contestées soient la croyance en un Dieu et en une vie future, ou n'importe laquelle des doctrines morales communément reçues. Livrer bataille sur un tel terrain, c'est donner grand avantage à un adversaire de mauvaise foi, car il dira sûrement (et bien d'autres qui ne voudraient pas faire montre de mauvaise foi se le diront intérieurement avec lui): sont-ce là les doctrines que vous n'estimez pas suffisamment certaines pour être protégées par la loi ? La croyance en un Dieu estelle, selon vous, de ces opinions dont on ne peut se sentir sûr sans prétendre à l'infaillibilité ? Qu'on me permette de remarquer que le fait de se sentir sûr d'une doctrine (quelle qu'elle soit) n'est pas ce que j'appelle prétendre à l'infaillibilité. J'entends par là le fait de vouloir décider cette question pour les autres sans leur permettre d'entendre ce qu'on peut dire de l'autre côté. Et je dénonce et ne réprouve pas moins cette prétention quand on l'avance en faveur de mes convictions les plus solennelles. Quelque persuadé que soit un homme non seulement de la fausseté, mais des conséquences pernicieuses d'une opinion - non seulement de ses conséquences pernicieuses, mais (pour employer des expressions que je condamne absolument) de son immoralité et de son impiété - c'est présumer de son infaillibilité, et cela en dépit du soutien que lui accorderait le jugement public de son pays ou de ses contemporains, que d'empêcher cette opinion de plaider pour sa défense. Et cette présomption, loin d'être moins dangereuse ou répréhensible, serait d'autant plus fatale que l'opinion en question serait appelée immorale ou impie. Telles sont justement les occasions où les hommes commettent ces terribles erreurs qui inspirent à la postérité stupeur et horreur. Nous en trouvons des exemples mémorables dans l'histoire lorsque nous voyons le bras de la justice utilisé pour décimer les meilleurs hommes et les meilleurs doctrines, et cela avec un succès déplorable quant aux hommes ; quant aux doctrines, certaines ont survécu pour être (comme par dérision) invoquées en défense d'une conduite semblable envers ceux-là mêmes qui divergeaient de celles-ci ou de leur interprétation couramment admise.

On ne saurait rappeler trop souvent à l'humanité qu'il a existé autrefois un homme du nom de Socrate, et qu'il y eut, entre celui-ci et les autorités et l'opinion publique de son temps, un affrontement mémorable. Né dans un siècle et dans un pays riche en grandeur individuelle, l'image qui nous a été transmise par ceux qui connaissaient le mieux à la fois le personnage et son époque, est celle de l'homme le plus vertueux de 
son temps; mais nous le connaissons également comme le chef et le modèle de tous ces grands maîtres de vertu qui lui furent postérieurs, tout à la fois la source et la noble inspiration de Platon et de l'utilitarisme judicieux d'Aristote, " i maëstri di color que sanno », eux-mêmes à l'origine de l'éthique et de toute philosophie. Ce maître avoué de tous les éminents penseurs qui vécurent après lui - cet homme dont la gloire ne cesse de croître depuis plus de deux mille ans et éclipse celle de tous les autres noms qui illustrèrent sa ville natale - fut mis à mort par ses concitoyens après une condamnation juridique pour impiété et immoralité. Impiété, pour avoir nié les dieux reconnus par l'État ; en effet, ses accusateurs affirmaient (voir l'Apologie) qu'il ne croyait en aucun dieu. Immoralité, pour avoir été par ses doctrines et son enseignement le " corrupteur de la jeunesse ». Il y a tout lieu de croire que le tribunal le trouva en conscience coupable de ces crimes; et il condamna à mort comme un criminel l'homme probablement le plus digne de mérite de ses contemporains et de l'humanité.

Passons à présent au seul autre exemple d'iniquité judiciaire dont la mention, après la condamnation de Socrate, ne nous fasse pas tomber dans la trivialité. L'événement eut lieu sur le Calvaire il y a un peu plus de mille huit cents ans. L'homme qui laissa sur tous les témoins de sa vie et de ses paroles une telle impression de grandeur morale que les dix-huit siècles suivants lui ont rendu hommage comme au Tout-Puissant en personne - cet homme fut ignominieusement mis à mort. A quel titre ? Blasphémateur. Non seulement les hommes méconnurent leur bienfaiteur, mais ils le prirent pour exactement le contraire de ce qu'il était et le traitèrent comme un prodige d'impiété, accusation aujourd'hui retournée contre eux pour le traitement qu'ils lui infligèrent. Aujourd'hui, les sentiments qui animent les hommes en considérant ces événements lamentables, spécialement le second, les rendent extrêmement injustes dans leur jugement envers les malheureux acteurs de ces drames. Ceux-ci, selon toute espérance, n'étaient point des méchants - ils n'étaient pas pires que le commun des hommes -, mais au contraire des hommes qui possédaient au plus haut point les sentiments religieux, moraux et patriotiques de leur temps et de leur peuple : la sorte même d'homme qui, à toutes les époques y compris la nôtre, ont toutes les chances de traverser la vie irréprochables et respectés. Le grand prêtre qui déchira ses vêtements en entendant prononcer les paroles qui, selon toutes les conceptions de son pays, constituaient le plus noir des crimes, éprouva sans doute une horreur sincère, à la mesure des sentiments moraux et religieux professés par le commun des hommes pieux et respectables. Pourtant la plupart de ceux qui frémissent aujourd'hui devant sa conduite auraient agi exactement de même s'ils avaient vécu à cette époque et étaient nés juifs. Les chrétiens orthodoxes qui sont tentés de croire que ceux qui lapidèrent les premiers martyrs furent plus méchants qu'eux mêmes devraient se souvenir que saint Paul fut au nombre des persécuteurs.

Ajoutons encore un exemple, le plus frappant de tous si tant est que le caractère impressionnant d'une erreur se mesure à la sagesse et à la vertu de celui qui la commet. Si jamais monarque eut sujet de se croire le meilleur et le plus éclairé de ses contemporains, ce fut l'empereur Marc Aurèle. Maître absolu du monde civilisé tout 
entier, il se conduisit toute sa vie avec la plus pure justice et conserva, en dépit de son éducation stoïcienne, le plus tendre des cœurs. Le peu de fautes qu'on lui attribue viennent toutes de son indulgence, tandis que ses écrits, l'œuvre éthique la plus noble de l'Antiquité, ne diffère qu'à peine, sinon pas du tout, des enseignements les plus caractéristiques du Christ. Ce fut cet homme - meilleur chrétien dans tous les sens du terme (le dogmatique excepté) que la plupart des souverains officiellement chrétiens qui ont régné depuis - ce fut cet homme qui persécuta le christianisme. A la pointe de tous les progrès antérieurs de l'humanité, doué d'une intelligence ouverte et libre et d'un caractère qui le portait à incarner dans ses écrits moraux l'idéal chrétien, il ne sut pas voir - tout pénétré qu'il était de son devoir - que le christianisme était un bien et non un mal pour le monde. Il savait que la société de son temps était dans un état déplorable. Mais telle qu'elle était, il vit ou s'imagina voir que ce qui l'empêchait d'empirer était la foi et la vénération qu'elle vouait aux anciennes divinités. En tant que souverain, il estima de son devoir de ne pas laisser la société se dissoudre, et ne vit pas comment, si on ôtait les liens existants, on en pourrait reformer d'autres pour la ressouder. La nouvelle religion visait ouvertement à défaire ces liens ; et comme son devoir ne lui dictait pas d'adopter cette religion, c'est qu'il lui fallait la détruire. C'est ainsi que le plus doux et le plus aimable des philosophes et des souverains parce qu'il ne pouvait ni croire que la théologie du christianisme fût vraie ou d'origine divine, ni accréditer cette étrange histoire d'un dieu crucifié, ni prévoir qu'un système censé reposer entièrement sur de telles bases s'avérerait par la suite, en dépit des revers, l'agent du renouvellement - fut conduit par un sens profond du devoir à autoriser la persécution du christianisme. À mon sens, c'est l'un des événements les plus tragiques de l'histoire. On n'imagine pas sans amertume combien le christianisme du monde aurait été différent si la foi chrétienne était devenue la religion de l'empire sous les auspices de Marc Aurèle et non ceux de Constantin. Mais ce serait être à la fois injuste envers Marc Aurèle et infidèle à la vérité de nier que, s'il réprima comme il le fit la propagation du christianisme, il invoqua tous les arguments pour réprimer les enseignements antichrétiens. Tout chrétien croit fermement que l'athéisme mène à la dissolution de la société: Marc Aurèle le pensait tout aussi fermement du christianisme, lui qui, de tous ses contemporains, paraissait le plus capable d'en juger. A moins de rivaliser en sagesse et en bonté avec Marc Aurèle, à moins d'être plus profondément versé dans la sagesse de son temps, de se compter parmi les esprits supérieurs, de montrer plus de sérieux dans la quête de la vérité et lui être plus dévoué après l'avoir trouvée - mieux vaut donc que le partisan des sanctions à l'encontre de ceux qui Propagent certaines opinions cesse d'affirmer sa propre infaillibilité et celle de la multitude, comme le fit le grand Antonin avec un si fâcheux résultat.

Conscients de l'impossibilité de défendre des sanctions à l'encontre des opinions irréligieuses sans justifier Marc Aurèle, les ennemis de la liberté de culte acceptent parfois cette conséquence, quand on les pousse dans leurs derniers retranchements; et ils disent, avec le Dr Johnson, que les persécuteurs du christianisme étaient dans le vrai, que la persécution est une épreuve que la vérité doit subir, et qu'elle subit toujours avec succès, puisque les sanctions - bien qu'efficaces contre les erreurs perni- 
cieuses - s'avèrent toujours impuissantes contre la vérité. Voilà une forme remarquable de l'argument en faveur de l'intolérance religieuse qui mérite qu'on s'y arrête.

Une théorie qui soutient qu'il est légitime de persécuter la vérité sous prétexte que la persécution ne peut pas lui faire de tort, ne saurait être accusée d'être hostile par avance à l'accueil de vérités nouvelles. Mais elle ne se recommande pas par la générosité du traitement qu'elle réserve à ceux envers qui l'humanité est redevable de ces vérités. Révéler au monde quelque chose qui lui importe au premier chef et qu'il ignorait jusque-là, lui montrer son erreur sur quelque point vital de ses intérêts spirituels et temporels, c'est le service le plus important qu'un être humain puisse rendre à ses semblables; et dans certains cas, comme celui des premiers chrétiens et des réformateurs, les partisans de l'opinion du Dr Johnson croient qu'il s'agit là des dons les plus précieux qu'on puisse faire à l'humanité. En revanche, qu'on récompense les auteurs de ces magnifiques bienfaits par le martyr ou le traitement qu'on réserve aux plus vils criminels, voilà qui n'est pas, selon cette théorie, une erreur et un malheur déplorables dont l'humanité devrait se repentir dans le sac et la cendre, mais le cours normal et légitime des choses. Toujours selon cette théorie, l'auteur d'une vérité nouvelle devrait, comme chez les Locriens celui qui proposait une loi nouvelle, se présenter la corde au cou qu'on serrait aussitôt si l'assemblée publique, après avoir entendu ses raisons, n'adoptait pas sur-le-champ sa proposition. Il est impossible de supposer que ceux qui défendent cette façon de traiter les bienfaiteurs attachent beaucoup de prix aux bienfaits. Et je crois que ce point de vue n'existe que chez les gens persuadés que les vérités nouvelles étaient peut-être souhaitables autrefois, mais que nous en avons assez aujourd'hui.

Mais assurément, cette affirmation selon laquelle la vérité triomphe toujours de la persécution est un de ces mensonges que les hommes se plaisent à se transmettre mais que réfute toute expérience - jusqu'à ce qu'ils deviennent des lieux communs. L'histoire regorge d'exemples de vérités étouffées par la persécution; et si elle n'est pas supprimée, elle se perpétuera encore des siècles durant. Pour ne parler que des opinions religieuses, la Réforme éclata au moins vingt fois avant Luther, et elle fut réduite au silence. Arnaud de Brescia, Fra Dolcino, Savonarole : réduits au silence. Les Albigeois, les Vaudois, les Lollards, les Hussites : réduits au silence. Même après Luther, partout où la persécution se perpétua, elle fut victorieuse. En Espagne, en Italie, en Flandres, en Autriche, le protestantisme fut extirpé ; et il en aurait été très probablement de même en Angleterre, si la reine Marie avait vécu, ou si la reine Elizabeth était morte. La persécution a triomphé partout, excepté là où les hérétiques formaient un parti trop puissant pour être efficacement persécutés. Le christianisme aurait pu être extirpé de l'empire romain: aucun homme raisonnable n'en peut douter. Il ne se répandit et ne s'imposa que parce que les persécutions demeurèrent sporadiques, de courte durée et séparées par de longs intervalles de propagande presque libre. C'est pure sensiblerie de croire que la vérité, la vérité la plus pure - et non l'erreur - porte en elle ce pouvoir de passer outre le cachot et le bûcher. Souvent les hommes ne sont pas plus zélés pour la vérité que pour l'erreur; et une application suffisante de peines légales ou même sociales réussit le plus souvent à arrêter la 
propagation de l'une et l'autre. Le principal avantage de la vérité consiste en ce que lorsqu'une opinion est vraie, on a beau l'étouffer une fois, deux fois et plus encore, elle finit toujours par réapparaître dans le corps de l'histoire pour s'implanter définitivement à une époque où, par suite de circonstances favorables, elle échappe à la persécution assez longtemps pour être en mesure de faire front devant les tentatives de répression ultérieures.

On nous dira qu'aujourd'hui, nous ne mettons plus à mort ceux qui introduisent des opinions nouvelles. Contrairement à nos pères, nous ne massacrons pas les prophètes : nous leur élevons des sépulcres. Il est vrai, nous ne mettons plus à mort les hérétiques, et les sanctions pénales que nous tolérons aujourd'hui, même contre les opinions les plus odieuses, ne suffiraient pas à les extirper. Mais ne nous flattons pas encore d'avoir échappé à la honte de la persécution légale. Le délit d'opinion - ou tout du moins de son expression - existe encore, et les exemples en sont encore assez nombreux pour ne pas exclure qu'ils reviennent un jour en force. En 1857, aux assises d'été du comté de Cornouailles, un malheureux ${ }^{1}$, connu pour sa conduite irréprochable à tous égards, fut condamné à vingt et un mois d'emprisonnement pour avoir dit et écrit sur une porte quelques mots offensants à l'égard du christianisme. À peine un mois plus tard, à l'Old Bailey, deux personnes, à deux occasions distinctes, furent refusées comme jurés ${ }^{2}$, et l'une d'elles fut grossièrement insultée par le juge et l'un des avocats, parce qu'elles avaient déclaré honnêtement n'avoir aucune croyance religieuse. Pour la même raison, une troisième personne, un étranger victime d'un vol ${ }^{3}$ se vit refuser justice. Ce refus de réparation fut établi en vertu de la doctrine légale selon laquelle une personne qui ne croit pas en Dieu (peu importe le dieu) et en une vie future ne peut être admise à témoigner au tribunal ; ce qui équivaut à déclarer ces personnes hors-la-loi, exclues de la protection des tribunaux; non seulement elles peuvent être impunément l'objet de vols ou de voies de fait si elles n'ont d'autres témoins qu'elles-mêmes ou des gens de leur opinion, mais encore n'importe qui peut subir ces attentats impunément si la preuve du fait dépend de leur témoignage. Le présupposé à l'origine de cette loi est que le serment d'une personne qui ne croit pas en une vie future est sans valeur, proposition qui révèle chez ceux qui l'admettent une grande ignorance de l'histoire (puisqu'il est historiquement vrai que la plupart des infidèles de toutes les époques étaient des gens dotés d'un sens de l'honneur et d'une intégrité remarquables); et pour soutenir une telle opinion, il faudrait ne pas soupçonner combien de personnes réputées dans le monde tant pour leurs vertus que leurs talents sont bien connues, de leurs amis intimes du moins, pour être des incroyants. D'ailleurs cette règle se détruit d'elle-même en se coupant de ce qui la fonde. Sous prétexte que les athées sont des menteurs, elle incite tous les athées à mentir et ne rejette que ceux qui bravent la honte de confesser publiquement une opinion détestée plutôt que de soutenir un mensonge. Une règle qui se condamne ainsi à l'absurdité eu égard à son but avoué ne peut être maintenue en vigueur que comme une marque de

1 Thomas Pooley, assises de Bodmin, 31 juillet 1857: au mois de décembre suivant, il reçut un libre pardon de la Couronne.

2 Georges-Jacob Holyake, 17 août 1857; Edward Truelove, juillet 1857.

3 Baron de Gleichen, cour de police de Marlborough Street, 4 août 1857. 
haine, comme un vestige de persécution - persécution dont la particularité est de n'être infligée ici qu'à ceux qui ont prouvé ne pas la mériter. Cette règle et la théorie qu'elle implique ne sont guère moins insultantes pour les croyants que pour les infidèles. Car si celui qui ne croit pas en une vie future est nécessairement un menteur, il s'ensuit que seule la crainte de l'enfer empêche, si tant est qu'elle empêche quoi que ce soit, ceux qui y croient de mentir. Nous ne ferons pas aux auteurs et aux complices de cette règle l'injure de supposer que l'idée qu'ils se sont formée de la vertu chrétienne est le fruit de leur propre conscience.

À la vérité, ce ne sont là que des lambeaux et des restes de persécution que l'on peut considérer non pas tant comme l'indication de la volonté de persécuter, mais comme une manifestation de cette infirmité très fréquente chez les esprits anglais de prendre un plaisir absurde à affirmer un mauvais principe alors qu'ils ne sont plus eux-mêmes assez mauvais pour désirer réellement le mettre en pratique. Avec cette mentalité, il n'y a malheureusement aucune assurance que la suspension des plus odieuses formes de persécution légale, qui s'est affirmée l'espace d'une génération, continuera. A notre époque, la surface paisible de la routine est fréquemment troublée à la fois par des tentatives de ressusciter des maux passés que d'introduire de nouveaux biens. Ce qu'on vante à présent comme la renaissance de la religion correspond toujours dans les esprits étroits et incultes à la renaissance de la bigoterie; et lorsqu'il couve dans les sentiments d'un peuple ce puissant levain d'intolérance, qui subsiste dans les classes moyennes de ce pays, il faut bien peu de choses pour les pousser à persécuter activement ceux qu'il n'a jamais cessé de juger dignes de persécution ${ }^{1}$. C'est bien cela - les opinions que cultivent les hommes et les sentiments qu'ils nourrissent à l'égard de ceux qui s'opposent aux croyances qu'ils estiment importantes - qui empêche ce pays de devenir un lieu de liberté pour l'esprit. Depuis longtemps déjà, le principal méfait des sanctions légales est de renforcer le stigmate social. Et ce stigmate est particulièrement virulent en Angleterre où l'on professe bien moins

1 Il faut voir un avertissement sérieux dans le déchaînement de passions persécutrices qui s'est mêlé, lors de la révolte des Cipayes, à l'expression générale des pires aspects de notre caractère national. Les délires furieux que des fanatiques ou des charlatans proféraient du haut de leurs chaires ne sont peut-être pas dignes d'être relevés ; mais les chefs du parti évangélique ont posé pour principe de gouvernement des Hindous et des Musulmans de ne financer par les deniers publics que les écoles dans lesquelles on enseigne la Bible, et de n'attribuer par conséquent les postes de fonctionnaire qu'à des chrétiens réels ou prétendus tels. Un sous-secrétaire d'État, dans un discours à ses électeurs le 12 novembre 1857, aurait déclaré : « Le gouvernement britannique, en tolérant leur foi » (la foi de cent millions de sujets britanniques), « n'a obtenu d'autres résultats que freiner la suprématie du nom anglais et d'empêcher le développement salutaire christianisme. (...) La tolérance est la grande pierre angulaire de ce pays ; mais ne les laissez pas abuser de ce mot précieux de tolérance. » Comme l'entendait le sous-secrétaire d'État, elle signifiait liberté complète, la liberté de culte pour tous parmi les chrétiens qui célébraient leur culte sur de mêmes bases. Elle signifiait la tolérance de toutes les sectes et confessions de chrétiens croyant en la seule et unique médiation. Je souhaite attirer l'attention sur le fait qu'un homme qui a été jugé apte à remplir une haute fonction dans le gouvernement de ce pays, sous un ministère libéral, défend là la doctrine selon laquelle tous ceux qui ne croient pas en la divinité du Christ sont hors des bornes de la tolérance. Qui, après cette démonstration imbécile, peut s'abandonner à l'illusion que les persécutions religieuses sont révolues? 
fréquemment des opinions mises au ban de la société que dans d'autres pays où l'on avoue des opinions entraînant des punitions judiciaires. Pour tout le monde, excepté ceux que leur fortune ne rend pas dépendants de la bonne volonté des autres, l'opinion est sur ce point aussi efficace que la loi : il revient au même que les hommes soient emprisonnés qu'empêchés de gagner leur pain. Ceux dont le pain est déjà assuré et qui n'attendent la faveur ni des hommes au pouvoir, ni d'aucun corps, ni du public, ceux-là n'ont rien à craindre en avouant franchement n'importe quelle opinion si ce n'est le mépris ou la calomnie, et, pour supporter cela, point n'est besoin d'un grand héroïsme. Il n'y a pas lieu d'en appeler ad misericordiam en faveur de telles personnes. Mais, bien que nous n'infligions plus tant de maux qu'autrefois à ceux qui pensent différemment de nous, nous nous faisons peut-être toujours autant de mal. Socrate fut mis à mort, mais sa philosophie s'éleva comme le soleil dans le ciel et répandit sa lumière sur tout le firmament intellectuel. Les chrétiens furent jetés aux lions, mais l'Église chrétienne devint un arbre imposant et large, dépassant les plus vieux et les moins vigoureux et les étouffant de son ombre. Notre intolérance, purement sociale, ne tue personne, n'extirpe aucune opinion, mais elle incite les hommes à déguiser les leurs et à ne rien entreprendre pour les diffuser. Aujourd'hui, les opinions hérétiques ne gagnent ni même ne perdent grand terrain d'une décade ou d'une génération à l'autre; mais jamais elles ne brillent d'un vif éclat et perdurent dans le cercle étroit de penseurs et de savants où elles ont pris naissance, et cela sans jamais jeter sur les affaires générales de l'humanité une lumière qui s'avérerait plus tard vraie ou trompeuse. C'est ainsi que se perpétue un état de choses très satisfaisant pour certains esprits, parce qu'il maintient toutes les opinions dominantes dans un calme apparent, sans avoir le souci de mettre quiconque à l'amende ou au cachot et sans interdire absolument l'exercice de la raison aux dissidents affligés de la maladie de penser. C'est là un plan fort commode pour maintenir la paix dans le monde intellectuel et pour laisser les choses suivre leur cours habituel. Mais le prix de cette sorte de pacification intellectuelle est le sacrifice de tout le courage moral de l'esprit humain. Un état de chose, où les plus actifs et les plus curieux des esprits jugent prudent de garder pour eux les principes généraux de leurs convictions, et où ils s'efforcent en public d'adapter autant que faire se peut leurs propres conclusions à des prémisses qu'ils nient intérieurement, un tel système cesse de produire ces caractères francs et hardis, ces intelligences logiques et cohérentes qui ornaient autrefois le monde de la pensée. Le genre d'hommes qu'engendre un tel système sont soit de purs esclaves du lieu commun, soit des opportunistes de la vérité dont les arguments sur tous les grands sujets s'adaptent en fonction de leurs auditeurs et ne sont pas ceux qui les ont convaincus eux-mêmes. Ceux qui évitent cette alternative y parviennent en limitant leur champ de pensée et d'intérêt aux choses dont on peut parler sans s'aventurer sur le terrain des principes ; c'est-à-dire un petit nombre de problèmes pratiques qui se résoudraient d'eux-mêmes si seulement les esprits se raffermissaient et s'élargissaient, mais qui resteront sans solution tant qu'est laissé à l'abandon ce qui renforce et ouvre l'esprit humain aux spéculations libres et audacieuses sur les sujets les plus élevés.

Les hommes qui ne jugent pas mauvaise cette réserve des hérétiques devraient d'abord considérer qu'un tel silence revient à ce que les opinions hérétiques ne fassent 
jamais l'objet d'une réflexion franche et approfondie, de sorte que celles d'entre elles qui ne résisteraient pas à une pareille discussion ne disparaissent pas, même si par ailleurs on les empêche de se répandre. Mais ce n'est pas à l'esprit hérétique que nuit le plus la mise au ban de toutes les recherches dont les conclusions ne seraient pas conformes à l'orthodoxie. Ceux qui en souffrent davantage sont les bien-pensants, dont tout le développement intellectuel est entravé et dont la raison est soumise à la crainte de l'hérésie. Qui peut calculer ce que perd le monde dans cette multitude d'intelligences prometteuses doublées d'un caractère timide qui n'osent pas mener à terme un enchaînement d'idées hardi, vigoureux et indépendant de peur d'aboutir à une conclusion jugée irréligieuse ou immorale ? Parmi eux, il est parfois des hommes d'une grande droiture, à l'esprit subtil et raffiné, qui passent leur vie à ruser avec une intelligence qu'ils ne peuvent réduire au silence, épuisant ainsi leurs ressources d'ingéniosité à s'efforcer de réconcilier les exigences de leur conscience et de leur raison avec l'orthodoxie, sans forcément toujours y parvenir. Il est impossible d'être un grand penseur sans reconnaître que son premier devoir est de suivre son intelligence, quelle que soit la conclusion à laquelle elle peut mener. La vérité bénéficie encore plus des erreurs d'un homme qui, après les études et la préparation nécessaire, pense par lui-même, que des opinions vraies de ceux qui les détiennent uniquement parce qu'ils s'interdisent de penser. Non pas que la liberté de penser soit exclusivement nécessaire aux grands penseurs. Au contraire, elle est aussi indispensable sinon plus indispensable - à l'homme du commun pour lui permettre d'atteindre la stature intellectuelle dont il est capable. il y a eu, et il y aura encore peut-être, de grands penseurs individuels dans une atmosphère générale d'esclavage intellectuel. Mais il n'y a jamais eu et il n'y aura jamais dans une telle atmosphère de peuple intellectuellement actif. Quand un peuple accédait temporairement à cette activité ,c'est que la crainte des spéculations hétérodoxes était pour un temps suspendue. Là où il existe une entente tacite de ne pas remettre en question les principes, là où la discussion des questions fondamentales qui préoccupent l'humanité est estimée close, on ne peut espérer trouver cette activité intellectuelle de grande envergure qui a rendu si remarquables certaines périodes de l'histoire. Lorsque la controverse évite les sujets assez fondamentaux pour enflammer l'enthousiasme, jamais on ne voit l'esprit d'un peuple se dégager de ses principes fondamentaux, jamais il ne reçoit l'impulsion qui élève même les gens d'une intelligence moyenne à la dignité d'êtres pensants. L'Europe a connu de telles périodes d'émulation intellectuelle: la première, immédiatement après la Réforme; une autre, quoique limitée au Continent et à la classe la plus cultivée, lors du mouvement spéculatif de la dernière moitié du XVIIIe siècle ; et une troisième plus brève encore, lors de la fermentation intellectuelle de l'Allemagne au temps de Goethe et de Fichte. Ces trois périodes diffèrent grandement quant aux opinions particulières qu'elles développèrent, mais elles se ressemblent en ce que tout le temps de leur durée le joug de l'autorité fut brisé. Dans les trois cas, un ancien despotisme intellectuel fut détrôné, sans qu'un autre ne soit venu le remplacer. L'impulsion donnée par chacune de ces trois périodes a fait de l'Europe ce qu'elle est aujourd'hui. Le moindre progrès qui s'est produit, dans l'esprit ou dans les institutions humaines, remonte manifestement à l'une ou l'autre de ces périodes. Tout indique 
depuis quelque temps que ces trois impulsions sont pour ainsi dire épuisées ; et nous ne prendrons pas de nouveau départ avant d'avoir réaffirmé la liberté de nos esprits.

Passons maintenant à la deuxième branche de notre argument et, abandonnant l'hypothèse que les opinions reçues puissent être fausses, admettons qu'elles soient vraies et examinons ce que vaut la manière dont on pourra les soutenir là où leur vérité n'est pas librement et ouvertement débattue. Quelque peu disposé qu'on soit à admettre la possibilité qu'une opinion à laquelle on est fortement attaché puisse être fausse, on devrait être touché par l'idée que, si vraie que soit cette opinion, on la considérera comme un dogme mort et non comme une vérité vivante, si on ne la remet pas entièrement, fréquemment, et hardiment en question.

Il y a une classe de gens (heureusement moins nombreuse qu'autrefois) qui estiment suffisant que quelqu'un adhère aveuglément à une opinion qu'ils croient vraie sans même connaître ses fondements et sans même pouvoir la défendre contre les objections les plus superficielles. Quand de telles personnes parviennent à faire enseigner leur croyance par l'autorité, elles pensent naturellement que si l'on en permettait la discussion, il n'en résulterait que du mal. Là où domine leur influence, elles rendent presque impossible de repousser l'opinion reçue avec sagesse et réflexion, bien qu'on puisse toujours la rejeter inconsidérément et par ignorance ; car il est rarement possible d'exclure complètement la discussion, et aussitôt qu'elle reprend, les croyances qui ne sont pas fondées sur une conviction réelle cèdent facilement dès que surgit le moindre semblant d'argument. Maintenant, écartons cette possibilité et admettons que l'opinion vraie reste présente dans l'esprit, mais à l'état de préjugé, de croyance indépendante de l'argument et de preuve contre ce dernier: ce n'est pas encore là la façon dont un être raisonnable devrait détenir la vérité. Ce n'est pas encore connaître la vérité. Cette conception de la vérité n'est qu'une superstition de plus qui s'accroche par hasard aux mots qui énoncent une vérité.

Si l'intelligence et le jugement des hommes doivent être cultivés - ce que les protestants au moins ne contestent pas -, sur quoi ces facultés pourront-elles le mieux s'exercer si ce n'est sur les choses qui concernent chacun au point qu'on juge nécessaire pour lui d'avoir des opinions à leur sujet ? Si l'entretien de l'intelligence a bien une priorité, c'est bien de prendre conscience des fondements de nos opinions personnelles. Quoi que l'on pense sur les sujets où il est primordial de penser juste, on devrait au moins être capable de défendre ses idées contre les objections ordinaires. Mais, nous rétorquera-t-on: «Qu'on enseigne donc aux hommes les fondements de leurs opinions ! Ce n'est pas parce qu'on n'a jamais entendu contester des opinions qu'on doit se contenter de les répéter comme un perroquet. Ceux qui étudient la géométrie ne se contentent pas de mémoriser les théorèmes, mais ils les comprennent et en apprennent également les démonstrations : aussi serait-il absurde de prétendre qu'ils demeurent ignorants des fondements des vérités géométriques sous prétexte qu'ils n'entendent jamais qui que ce soit les rejeter et s'efforcer de les réfuter. » Sans doute. Mais un tel enseignement suffit pour une matière comme les mathématiques, où la contestation est impossible. L'évidence des vérités mathématiques a ceci de 
singulier que tous les arguments sont du même côté. Il n'y a ni objection ni réponses aux objections. Mais sur tous sujets où la différence d'opinion est possible, la vérité dépend d'un équilibre à établir entre deux groupes d'arguments contradictoires. Même en philosophie naturelle, il y a toujours une autre explication possible des mêmes faits : une théorie géocentrique au lieu de l'héliocentrique, le phlogistique au lieu de l'oxygène; et il faut montrer pourquoi cette autre théorie ne peut pas être la vraie; et avant de savoir le démontrer, nous ne comprenons pas les fondements de notre opinion. Mais si nous nous tournons vers des sujets infiniment plus compliqués, vers la morale, la religion, la politique, les relations sociales et les affaires de la vie, les trois quarts des arguments pour chaque opinion contestée consistent à dissiper les aspects favorables de l'opinion opposée. L'un des plus grands orateurs de l'Antiquité rapporte qu'il étudiait toujours la cause de son adversaire avec autant, sinon davantage, d'attention que la sienne propre. Ce que Cicéron faisait en vue du succès au barreau doit être imité par tous ceux qui se penchent sur un sujet afin d'arriver à la vérité. Celui qui ne connaît que ses propres arguments connaît mal sa cause. Il se peut que ses raisons soient bonnes et que personne n'ait été capable de les réfuter. Mais s'il est tout aussi incapable de réfuter les raisons du parti adverse, s'il ne les connaît même pas, rien ne le fonde à préférer une opinion à l'autre. Le seul choix raisonnable pour lui serait de suspendre son jugement, et faute de savoir se contenter de cette position, soit il se laisse conduire par l'autorité, soit il adopte, comme on le fait en général, le parti pour lequel il se sent le plus d'inclination. Mais il ne suffit pas non plus d'entendre les arguments des adversaires tels que les exposent ses propres maîtres, c'est-à-dire à leur façon et accompagnés de leurs réfutations. Telle n'est pas la façon de rendre justice à ces arguments ou d'y mesurer véritablement son esprit. Il faut pouvoir les entendre de la bouche même de ceux qui y croient, qui les défendent de bonne foi et de leur mieux. Il faut les connaître sous leur forme la plus plausible et la plus persuasive : il faut sentir toute la force de la difficulté que la bonne approche du sujet doit affronter et résoudre. Autrement, jamais on ne possédera cette partie de vérité qui est seule capable de rencontrer et de supprimer la difficulté. C'est pourtant le cas de quatre-vingt-dix-neuf pour cent des hommes dits cultivés, même de ceux qui sont capables d'exposer leurs opinions avec aisance. Leur conclusion peut être vraie, mais elle pourrait être fausse sans qu'ils s'en doutassent: jamais ils ne se sont mis à la place de ceux qui pensent différemment, jamais ils n'ont prêté attention à ce que ces personnes avaient à dire. Par conséquent, ils ne connaissent pas, à proprement parler, la doctrine qu'ils professent. Ils ne connaissent pas ces points fondamentaux de leur doctrine qui en expliquent et justifient le reste, ces considérations qui montrent que deux faits, en apparence contradictoires, sont réconciliables, ou que de deux raisons apparemment fortes, l'une doit être préférée à l'autre. De tels hommes demeurent étrangers à tout ce pan de la vérité qui décide du jugement d'un esprit parfaitement éclairé. Du reste, seuls le connaissent ceux qui ont également et impartialement fréquentés les deux partis et qui se sont attachés respectivement à envisager leurs raisons sous leur forme la plus convaincante. Cette discipline est si essentielle à une véritable compréhension des sujets moraux ou humains que, s'il n'y a pas d'adversaires pour toutes les vérités importantes, il est indispensable d'en imaginer et de leur fournir les arguments les plus forts que puisse invoquer le plus habile avocat du diable. 
Pour diminuer la force de ces considérations, supposons qu'un ennemi de la libre discussion rétorque qu'il n'est pas nécessaire que l'humanité tout entière connaisse et comprenne tout ce qui peut être avancé pour ou contre ses opinions par des philosophes ou des théologiens ; qu'il n'est pas indispensable pour le commun des hommes de pouvoir exposer toutes les erreurs et les sophismes d'un habile adversaire; qu'il suffit qu'il y ait toujours quelqu'un capable d'y répondre, afin qu'aucun sophisme propre à tromper les personnes sans instruction ne reste pas sans réfutation et que les esprits simples, une fois qu'ils connaissent les principes évidents des vérités qu'on leur a inculquées, puissent s'en remettre à l'autorité pour le reste ; que, bien conscients qu'ils n'ont pas la science et le talent nécessaires pour résoudre toutes les difficultés susceptibles d'être soulevées, ils peuvent avoir l'assurance que toutes celles qu'on a soulevées ont reçu une réponse ou peuvent en recevoir une de ceux qui sont spécialement entraînés à cette tâche.

Même en concédant à ce point de vue tout ce que peuvent réclamer en sa faveur ceux qui se satisfont le plus facilement d'une compréhension imparfaite de la vérité, les arguments les plus convaincants en faveur de la libre discussion n'en sont nullement affaiblis ; car même cette doctrine reconnaît que l'humanité devrait avoir l'assurance que toutes les objections ont reçu une réponse satisfaisante. Or, comment peut-on y répondre si ce qui demande réponse n'est pas exprimé ? Comment savoir si la réponse est satisfaisante si les objecteurs n'ont pas la possibilité de montrer qu'elle ne l'est pas ? Si le public en est empêché, il faut au moins que les philosophes et les théologiens puissent résoudre ces difficultés, se familiariser avec celles-ci sous leur forme la plus déconcertante; pour cela, ils ne peuvent y parvenir que si elles sont présentées sous leur jour le plus avantageux. L'Église catholique traite à sa façon ce problème embarrassant. Elle sépare nettement entre ceux qui ont le droit de se convaincre des doctrines et ceux qui doivent les accepter sans examen. A la vérité, elle ne permet à aucun des deux groupes de choisir ce qu'ils veulent ou non accepter; mais pour le clergé - ou du moins ceux de ses membres en qui on peut avoir confiance -, il est non seulement permis, mais méritoire de se familiariser avec les arguments des adversaires afin d'y répondre; il peut par conséquent lire les livres hérétiques ; tandis que les laïques ne le peuvent pas sans une permission spéciale difficile à obtenir. Cette discipline juge bénéfique que les professeurs connaissent la cause adverse, mais trouve les moyens appropriés de la refuser aux autres, accordant ainsi à l'élite une plus grande culture, sinon une plus grande liberté d'esprit, qu'à la masse. C'est par ce procédé qu'elle réussit à obtenir la sorte de liberté intellectuelle qu'exige son but ; car bien qu'une culture sans liberté n'ait jamais engendré d'esprit vaste et libéral, elle peut néanmoins produire un habile avocat d'une cause. Mais ce recours est exclu dans les pays professant le protestantisme, puisque les protestants soutiennent, du moins en théorie, que la responsabilité de choisir sa propre religion incombe à chacun et qu'on ne peut s'en décharger sur ses maîtres. D'ailleurs, dans l'état actuel du monde, il est pratiquement impossible que les ouvrages lus par les gens instruits demeurent hors d'atteinte des incultes. S'il faut que les maîtres de 
l'humanité aient connaissance de tout ce qu'ils devraient savoir, il faut avoir l'entière liberté d'écrire et de publier.

Cependant, si l'absence de libre discussion ne causait d'autre mal - lorsque les opinions reçues sont vraies - que de laisser les hommes dans l'ignorance des principes de ces opinions, on pourrait penser qu'il s'agit là non d'un préjudice moral, mais d'un préjudice simplement intellectuel, n'affectant nullement la valeur des opinions quant à leur influence sur le caractère. Le fait est pourtant que l'absence de discussion fait oublier non seulement les principes, mais trop souvent aussi le sens même de l'opinion. Les mots qui l'expriment cessent de suggérer des idées ou ne suggèrent plus qu'une mince partie de celles qu'ils servaient à rendre originairement. Au lieu d'une conception forte et d'une foi vivante, il ne reste plus que quelques phrases apprises par cœur ; ou si l'on garde quelque chose du sens, ce n'en est plus que l'enveloppe: l'essence la plus subtile est perdue. Ce fait, qui occupe et remplit un grand chapitre de l'histoire, ne saurait être trop étudié et médité.

Il est présent dans l'expérience de presque toutes les doctrines morales et croyances religieuses. Elles sont pleines de sens et de vitalité pour leurs initiateurs et leurs premiers disciples. Leur sens demeure aussi fort - peut-être même devient-il plus pleinement conscient - tant qu'on lutte pour donner à la doctrine ou la croyance un ascendant sur toutes les autres. A la fin, soit elle s'impose et devient l'opinion générale, soit son progrès s'arrête ; elle conserve le terrain conquis, mais cesse de s'étendre. Quand l'un ou l'autre de ces résultats devient manifeste, la controverse sur le sujet faiblit et s'éteint graduellement. La doctrine a trouvé sa place, sinon comme l'opinion reçue, du moins comme l'une des sectes ou divisions admises de l'opinion ; ses détenteurs l'ont généralement héritée, ils ne l'ont pas adoptée ; c'est ainsi que les conversions de l'une à l'autre de ces doctrines deviennent un fait exceptionnel et que leurs partisans finissent par ne plus se préoccuper de convertir. Au lieu de se tenir comme au début constamment sur le qui-vive, soit pour se défendre contre le monde, soit pour le conquérir, ils tombent dans l'inertie, n'écoutent plus que rarement les arguments avancés contre leur credo et cessent d'ennuyer leurs adversaires (s'il y en a) avec des arguments en sa faveur. C'est à ce point qu'on date habituellement le déclin de la vitalité d'une doctrine. On entend souvent les catéchistes de toutes croyances se plaindre de la difficulté d'entretenir dans l'esprit des croyants une perception vive de la vérité qu'ils reconnaissent nominalement afin qu'elle imprègne leurs sentiments et acquière une influence réelle sur leur conduite. On ne rencontre pas une telle difficulté tant que la croyance lutte encore pour s'établir; alors, même les combattants les plus faibles savent et sentent pourquoi ils luttent et connaissent la différence entre leur doctrine et les autres. C'est à ce moment de l'existence de toute croyance qu'on rencontre nombre de personnes qui ont assimilé ses principes fondamentaux sous toutes les formes de la pensée, qui les ont pesés et considérés sous tous leurs aspects importants, et qui ont pleinement ressenti sur leur caractère l'effet que cette croyance devrait produire sur un esprit qui en est totalement pénétré. Mais une fois la croyance devenue héréditaire - une fois qu'elle est admise passivement et non plus activement, une fois que l'esprit ne se sent plus autant contraint de concentrer toutes ses facultés 
sur les questions qu'elle lui pose - on tend à tout oublier de cette croyance pour ne plus en retenir que des formules ou ne plus lui accorder qu'un mol et torpide assentiment, comme si le fait d'y croire dispensait de la nécessité d'en prendre clairement conscience ou de l'appliquer dans sa vie: c'est ainsi qu'une croyance finit par ne plus se rattacher du tout à la vie intérieure de l'être humain. Alors apparaissent ces cas - si fréquents aujourd'hui qu'ils sont presque la majorité - où la croyance semble demeurer hors de l'esprit, désormais encroûte et pétrifié contre toutes les autres influences destinées aux parties les plus nobles de notre nature, figement qui se manifeste par une allergie à toute conviction nouvelle et vivante et qui joue le rôle de sentinelle afin de maintenir vides l'esprit et le cœur.

On voit à quel point les doctrines susceptibles en elles-mêmes de produire la plus profonde impression sur l'esprit peuvent y résider à l'état de croyances mortes, et cela sans jamais nourrir ni l'imagination, ni les sentiments, ni l'intelligence, lorsqu'on voit comment la majorité des croyants professent le christianisme. Par christianisme, j'entends ici ce que tiennent pour tel toutes les Églises et sectes : les maximes et les préceptes contenus dans le Nouveau Testament. Tous ceux qui se prétendent chrétiens les tiennent pour sacrés et les acceptent comme lois. Et pourtant on peut dire que moins d'un chrétien sur mille guide ou juge sa conduite individuelle d'après ces lois. Le modèle auquel on se réfère est la coutume de son pays, de sa classe ou de sa secte religieuse. Le chrétien croit donc qu'il existe d'un côté une collection de maximes éthiques que la sagesse infaillible, selon lui, a daigné lui transmettre comme règle de conduite, et de l'autre un ensemble de jugements et de pratiques habituels qui s'accordent assez bien avec certaines de ces maximes, moins bien avec d'autres, ou qui s'opposent directement à d'autres encore - lesquels constituent en somme un compromis entre la foi chrétienne et les intérêts et les suggestions de la vie matérielle. $\mathrm{Au}$ premier de ces modèles le chrétien donne son hommage ; au deuxième, son obéissance effective. Tous les chrétiens croient que bienheureux sont les pauvres, les humbles et tous ceux que le monde maltraite; qu'il est plus facile à un chameau de passer par le chas d'une aiguille qu'à un riche d'entrer au royaume des cieux; qu'ils ne doivent pas juger de peur d'être jugés eux-mêmes; qu'ils ne doivent pas jurer; qu'ils doivent aimer leur prochain comme eux-mêmes; que si quelqu'un prend leur manteau, ils doivent lui donner aussi leur tunique; qu'ils ne doivent pas penser au lendemain; que pour être parfaits, ils doivent vendre tout ce qu'ils ont et le donner aux pauvres. Ils ne mentent pas quand ils disent qu'ils croient ces choses-là, ils les croient comme les gens croient ce qu'ils ont toujours entendu louer, mais jamais discuter. Mais, dans le sens de cette croyance vivante qui règle la conduite, ils croient en ces doctrines uniquement dans la mesure où l'on a coutume d'agir d'après elles. Dans leur intégrité, les doctrines servent à accabler les adversaires; et il est entendu qu'on doit les mettre en avant (si possible) pour justifier tout ce qu'on estime louable. Mais s'il y avait quelqu'un pour leur rappeler que ces maximes exigent une foule de choses qu'ils n'ont jamais l'intention de faire, il n'y gagnerait que d'être classé parmi ces personnages impopulaires qui affectent d'être meilleurs que les autres. Les doctrines n'ont aucune prise sur les croyants ordinaires, aucun pouvoir sur leurs esprits. Par habitude, ils en respectent les formules, mais pour eux, les mots sont dépourvus de sens et ne 
suscitent aucun sentiment qui force l'esprit à les assimiler et à les rendre conformes à la formule. Pour savoir quelle conduite adopter, les hommes prennent comme modèle leurs voisins pour apprendre jusqu'où il faut aller dans l'obéissance du Christ.

Nous pouvons être certains qu'il en allait tout autrement chez les premiers chrétiens. Autrement, jamais le christianisme ne serait passé de l'état de secte obscure d'Hébreux méprisés à la religion officielle de l'Empire romain. Quand leurs ennemis disaient: «Voyez comme ces chrétiens s'aiment les uns les autres » (une remarque que personne ne ferait aujourd'hui), ils avaient assurément un sentiment autrement plus vif qu'aujourd'hui de la signification de leur croyance. Voilà sans doute la raison principale pour laquelle le christianisme fait aussi peu de progrès maintenant et se trouve, après dix-huit siècles, à peu près circonscrit aux Européens et à leurs descendants. Même chez les personnes strictement religieuses, qui prennent leurs doctrines au sérieux et qui y attachent plus de signification qu'on ne le fait en général, il arrive fréquemment que la partie la plus active de leur esprit soit fermée par Calvin ou Knox, ou toute autre personnalité d'un caractère apparenté au leur. Les paroles du Christ coexistent passivement dans leur esprit, ne produisant guère d'autre effet que l'audition machinale de paroles si aimables et si douces. Nombre de raisons pourraient sans doute expliquer pourquoi les doctrines servant d'attribut distinctif à une secte conservent mieux leur vitalité que les doctrines communes à toutes les sectes reconnues ; l'une d'elle est que ceux qui les enseignent prennent plus de soin à maintenir vive leur signification. Mais la principale raison, c'est que ces doctrines sont davantage mises en question et doivent plus souvent se défendre contre des adversaires déclarés. Dès qu'il n'y a plus d'ennemi en vue, maîtres et disciples s'endorment à leur poste.

La même chose vaut en général pour toutes les doctrines traditionnelles - dans les domaines de la prudence et de la connaissance de la vie, aussi bien que de la morale et de la religion. Toutes les langues et toutes les littératures abondent en observations générales sur la vie et sur la manière de s'y comporter - observations que chacun connaît, répète ou écoute docilement, qu'on reçoit comme des truismes et dont pourtant on n'apprend en général le vrai sens que lorsque l'expérience souvent pénible les transforme en réalité. Que de fois une personne accablée par un malheur ou une déception ne se rappelle-t-elle pas quelque proverbe ou dicton populaire qu'elle connaît depuis toujours et qui, si elle en avait plus tôt compris la signification, lui aurait épargné cette calamité. En fait, il y a d'autres raisons à cela que l'absence de discussion ; nombreuses sont les vérités dont on ne peut pas comprendre tout le sens tant qu'on ne les a pas vécues personnellement. Mais on aurait bien mieux compris la signification de ces vérités, et ce qui en aurait été compris aurait fait sur l'esprit une impression bien plus profonde, si l'on avait eu l'habitude d'entendre des gens qui la comprenaient effectivement discuter le pour et le contre. La tendance fatale de l'espèce humaine à laisser de côté une chose dès qu'il n'y a plus de raison d'en douter est la cause de la moitié de ses erreurs. Un auteur contemporain a bien décrit « le profond sommeil d'une opinion arrêtée ». 
« Mais quoi! » demandera-t-on, « l'absence d'unanimité est-elle une condition indispensable au vrai savoir ? Est-il nécessaire qu'une partie de l'humanité persiste dans l'erreur pour permettre à l'autre de comprendre la vérité ? Une croyance cesse-telle d'être vraie et vivante dès qu'elle est généralement acceptée ? Une proposition n'est-elle jamais complètement comprise et éprouvée si l'on ne conserve quelque doute sur son compte ? La vérité périt-elle aussitôt que l'humanité l'a unanimement acceptée ? N'a-t-on pas pensé jusqu'à présent que le but suprême et le résultat le plus parfait du progrès de l'intelligence étaient d'unir les hommes dans la reconnaissance de toutes les vérités fondamentales ? L'intelligence ne dure-t-elle que tant qu'elle n'a pas atteint son but ? Les fruits de la conquête meurent-ils avec la plénitude, la victoire? »

Je n'affirme rien de tel. À mesure que l'humanité progressera, le nombre des doctrines qui ne sont plus objet ni de discussion ni de doute ira croissant; et le bien-être de l'humanité pourra presque se mesurer au nombre et à l'importance des vérités arrivées au point de n'être plus contestées. L'abandon progressif des différents points d'une controverse sérieuse est l'un des aléas nécessaires de la consolidation de l'opinion, consolidation aussi salutaire dans le cas d'une opinion juste que dangereuse et nuisible quand les opinions sont erronées. Mais, quoique ce rétrécissement progressif des limites de la diversité d'opinions soit nécessaire dans les deux sens du terme - à la fois inévitable et indispensable -, rien ne nous oblige pour autant à conclure que toutes ses conséquences doivent être bénéfiques. Bien que la perte d'une aide aussi importante que la nécessité d'expliquer ou de défendre une vérité contre des opposants ne puisse se mesurer au bénéfice de sa reconnaissance universelle, elle n'en est pas moins un inconvénient non négligeable. Là où n'existe plus cet avantage, j'avoue que j'aimerais voir les maîtres de l'humanité s'attacher à lui trouver un substitut - un moyen de mettre les difficultés de la question en évidence dans l'esprit de l'élève, tel un fougueux adversaire s'acharnant à le convertir.

Mais au lieu de chercher de tels moyens, ils perdent ceux qu'ils avaient autrefois. La dialectique socratique, si magnifiquement illustrée dans les dialogues de Platon, en était un. Elle était essentiellement une discussion négative des grandes questions de la philosophie et de la vie visant à convaincre avec un art consommé quiconque s'était contenté d'adopter les lieux communs de l'opinion reçue, qu'il ne comprenait pas le sujet - qu'il n'avait attaché aucun sens défini aux doctrines qu'il professait jusque-là - de sorte qu'en prenant conscience de son ignorance, il fût en mesure de se constituer une croyance stable, reposant sur une perception claire à la fois du sens et de l'évidence des doctrines. Au moyen âge, les disputes scolastiques avaient un but à peu près similaire. Elles servaient à vérifier que l'élève comprenait sa propre opinion et (par une corrélation nécessaire) l'opinion opposée, et qu'il pouvait aussi bien défendre les principes de l'une que réfuter ceux de l'autre. Ces joutes avaient pourtant un défaut irrémédiable: celui de tirer leurs prémisses non de la raison, mais de l'autorité; c'est pourquoi en tant que discipline de l'esprit, elles étaient en tout point inférieure à la puissante dialectique qui modèle les intelligences des « Socratici viri » ; mais l'esprit moderne doit beaucoup plus à toutes deux qu'il ne veut généralement le 
reconnaître, et les modes d'éducation actuels n'ont pour ainsi dire rien pour prétendre remplacer l'une ou l'autre. Celui qui tient toute son instruction des professeurs ou des livres n'est nullement contraint d'entendre les deux côtés d'une question, et cela même s'il échappe à la tentation habituelle de se satisfaire de connaître les choses par cœur. C'est pourquoi il est fort rare de bien connaître les deux versants d'un même problème; c'est ce qu'il y a de plus faible dans ce que l'on dit pour défendre ses opinions qui fait office de réplique à ses adversaires. C'est aujourd'hui la mode de déprécier la logique négative, celle qui révèle les faiblesses théoriques et les erreurs pratiques, sans établir de vérités positives. Il est vrai qu'une telle critique négative ferait un assez pauvre résultat final; mais en tant que moyen d'acquérir une connaissance positive ou une conviction digne de ce nom, on ne saurait trop insister sur sa valeur. Et tant que les hommes n'y seront pas de nouveau systématiquement entraînés, il y aura fort peu de grands penseurs, et le niveau moyen d'intelligence dans les domaines de la spéculation autres que les mathématiques et les sciences physiques demeurera très bas. Sur tout autre sujet, aucune opinion ne mérite le nom de connaissance à moins d'avoir suivi, de gré ou de force, la démarche intellectuelle qu'eût exigé de son tenant une controverse active avec des adversaires. On voit donc à quel point il est aussi absurde de renoncer à un avantage indispensable qui s'offre spontanément, alors qu'il est si difficile à créer quand il manque. S'il y a des gens pour contester une opinion reçue ou pour désirer le faire si la loi ou l'opinion publique le leur permet, il faut les en remercier, ouvrir nos esprits à leurs paroles et nous réjouir qu'il y en ait qui fassent pour nous ce que nous devrions prendre davantage la peine de faire, si tant est que la certitude ou la vitalité de nos convictions nous importe.

Il nous reste encore à parler d'une des principales causes qui rendent la diversité d'opinions avantageuse et qui le demeurera tant que l'humanité n'aura pas atteint un niveau de développement intellectuel dont elle semble aujourd'hui encore à mille lieues. Nous n'avons jusqu'à présent examiné que deux possibilités: la première, que l'opinion reçue peut être fausse, et une autre, du même coup, vraie; la deuxième, que si l'opinion reçue est vraie, c'est que la lutte entre celle-ci et l'erreur opposée est essentielle à une perception claire et à un profond sentiment de sa vérité. Mais il arrive plus souvent encore que les doctrines en conflit, au lieu d'être l'une vraie et l'autre fausse, se départagent la vérité; c'est ainsi que l'opinion non conforme est nécessaire pour fournir le reste de la vérité dont la doctrine reçue n'incarne qu'une partie. Les opinions populaires sur les sujets qui ne sont pas à la portée des sens sont souvent vraies, mais elles ne sont que rarement ou jamais toute la vérité. Elles sont une partie de la vérité, tantôt plus grande, tantôt moindre, mais exagérée, déformée et coupée des vérités qui devraient l'accompagner et la limiter. De l'autre côté, les opinions hérétiques sont généralement de ces vérités exclues, négligées qui, brisant leurs chaînes, cherchent soit à se réconcilier avec la vérité contenue dans l'opinion commune, soit à l'affronter comme ennemie et s'affirment aussi exclusivement comme l'entière vérité. Ce dernier cas a été jusqu'à présent le plus fréquent, car l'esprit humain est plus généralement partial qu'ouvert. De là vient qu'ordinairement, même dans les révolutions de l'opinion, une partie de la vérité sombre tandis qu'une autre monte à la surface. Le progrès lui-même, qui devrait être un gain, se contente le plus 
souvent de substituer une vérité partielle et incomplète à une autre. L'amélioration consiste surtout en ceci que le nouveau fragment de vérité est plus nécessaire, mieux adapté au besoin du moment que celui qu'il supplante. La partialité des opinions dominantes est telle que même lorsqu'elle se fonde sur la vérité, toute opinion qui renferme une once de la portion de vérité omise par l'opinion commune, devrait être considérée comme précieuse, quelle que soit la somme d'erreur et de confusion mêlée à cette vérité. Aucun juge sensé des affaires humaines ne se sentira forcé de s'indigner parce que ceux qui mettent le doigt sur des vérités que, sans eux, nous eussions contournées, ne négligent à leur tour certaines que nous apercevons. Il pensera plutôt que tant que la vérité populaire sera partiale, il sera encore préférable qu'une vérité impopulaire ait aussi des détenteurs partiaux, parce qu'au moins ils sont plus énergiques et plus aptes à forcer une attention rétive à considérer le fragment de sagesse qu'ils exaltent comme la sagesse tout entière.

C'est ainsi qu'au XVIIIe siècle les paradoxes de Rousseau produisirent un choc salutaire lorsqu'ils explosèrent au milieu de cette société de gens instruits et d'incultes sous leur coupe, éperdus d'admiration devant ce qu'on appelle la civilisation, devant les merveilles de la science, de la littérature, de la philosophie modernes, n'exagérant la différence entre les Anciens et les Modernes que pour y voir leur propre supériorité. Rousseau rendit le service de disloquer la masse de l'opinion partiale et de forcer ses éléments à se reconstituer sous une meilleure forme et avec des ingrédients supplémentaires. Non pas que les opinions admises fussent dans l'ensemble plus éloignées de la vérité que celles de Rousseau; au contraire, elles en étaient plus proches ; elles contenaient davantage de vérité positive et bien moins d'erreur. Néanmoins, il y avait dans la doctrine de Rousseau un grand nombre de ces vérités qui manquaient précisément à l'opinion populaire, et qui depuis se sont mêlées à son flux: aussi continuèrent-elles à subsister. Le mérite supérieur de la vie simple, l'effet débilitant et démoralisant des entraves et des hypocrisies d'une société artificielle, sont des idées qui depuis Rousseau n'ont jamais complètement quitté les esprits cultivés ; et elles produiront un jour leur effet, quoique, pour le moment, elles aient encore besoin d'être proclamées haut et fort et d'être traduites ; car sur ce sujet, les mots ont à peuprès épuisé toutes leurs forces. Parallèlement, il est reconnu en politique qu'un parti d'ordre ou de stabilité et un parti de progrès ou de réforme sont les deux éléments nécessaires d'une vie politique florissante, jusqu'à ce que l'un ou l'autre ait à ce point élargi son horizon intellectuel qu'il devienne à la fois un parti d'ordre et de progrès, connaissant et distinguant ce qu'il est bon de conserver et ce qu'il faut éliminer. Chacune de ces manières de penser tire son utilité des défauts de l'autre ; mais c'est dans une large mesure leur opposition mutuelle qui les maintient dans les limites de la raison et du bon sens. Si l'on ne peut exprimer avec une égale liberté, soutenir et défendre avec autant de talent que d'énergie toutes les grandes questions de la vie pratique - qu'elles soient favorables à la démocratie ou à l'aristocratie, à la propriété ou à l'égalité, à la coopération ou à la compétition, au luxe ou à l'abstinence, à la sociabilité ou à l'individualisme, à la liberté ou à la discipline -, il n'y a aucune raison que les deux éléments obtiennent leur dû: il est inévitable que l'un des plateaux ne monte au détriment de l'autre. Dans les grandes questions pratiques de la vie, la vérité 
est surtout affaire de conciliation et de combinaison des extrêmes ; aussi très peu d'esprits sont-ils assez vastes et impartiaux pour réaliser cet accommodement le plus correctement possible, c'est-à-dire brutalement, par une lutte entre des combattants enrôlés sous des bannières opposées. Pour toutes les grandes questions énumérées cidessus, si une opinion a davantage de droit que l'autre à être, non seulement tolérée, mais encore encouragée et soutenue, c'est celle qui, a un moment ou dans un lieu donné, se trouve minoritaire. C'est l'opinion qui, pour l'instant, représente les intérêts négligés, l'aspect du bien-être humain qui court le risque d'obtenir moins que sa part. Je suis conscient qu'il n'y a dans ce pays aucune intolérance en matière de différences d'opinions sur la plupart de ces sujets. Je les ai cités pour montrer, à l'aide d'exemples nombreux et significatifs, l'universalité du fait que, dans l'état actuel de l'esprit humain, seule la diversité donne une chance équitable à toutes les facettes de la vérité. Lorsqu'on trouve des gens qui ne partagent point l'apparente unanimité du monde sur un sujet, il est toujours probable - même si le monde est dans le vrai - que ces dissidents ont quelque chose de personnel à dire qui mérite d'être entendu, et que la vérité perdrait quelque chose à leur silence.

« Mais », objectera-t-on, «certains des principes généralement admis, spécialement sur les sujets les plus nobles et les plus vitaux, sont davantage que des demivérités. La morale chrétienne, par exemple, contient toute la vérité sur ce sujet, et si quelqu'un enseigne une morale différente, il est complètement dans l'erreur. » Comme il s'agit là d'un des cas pratiques les plus importants, aucun n'est mieux approprié pour mettre à l'épreuve la maxime générale. Mais avant de décider ce que la morale chrétienne est ou n'est pas, il serait souhaitable de décider ce qu'on entend par morale chrétienne. Si cela signifie la morale du Nouveau Testament, je m'étonne que quelqu'un qui tire son savoir du livre lui-même puisse supposer que cette morale ait été présentée ou voulue comme une doctrine morale complète. L'Évangile se réfère toujours à une morale préexistante et limite ses préceptes aux points particuliers sur lesquels cette morale devait être corrigée ou remplacée par une autre morale plus tolérante et plus élevée; en outre elle s'exprime toujours en termes généraux, souvent impossibles à interpréter littéralement, sans compter que ces textes possèdent davantage l'onction de la poésie ou de l'éloquence que la précision de la législation. Jamais on n'a pu en extraire un corps de doctrine éthique sans le compléter par des éléments de l'Ancien Testament - système certes élaboré, mais barbare à bien des égards et destiné uniquement à un peuple barbare. Saint Paul - ennemi déclaré de l'interprétation judaïque de la doctrine et de cette façon de compléter l'esquisse de son maître admet également une morale préexistante, à savoir celle des Grecs et des Romains; et ce qu'il conseille aux chrétiens dans une large mesure, c'est d'en faire un système d'accommodement, au point de n'accorder qu'un semblant de condamnation à l'esclavage. Ce qu'on appelle la morale chrétienne -mais qu'on devrait plutôt qualifier de théologique - n'est l'œuvre ni du Christ ni des apôtres ; elle est d'une origine plus tardive, puisqu'elle a été élaborée graduellement par l'Église chrétienne des cinq premiers siècles; et, même si les modernes et les protestants ne l'ont pas adoptée sans réserve, ils l'ont beaucoup moins modifiée qu'on aurait pu s'y attendre. À vrai dire, ils 
se sont contentés, pour la plupart, de retrancher les additions faites au moyen âge, chaque secte remplissant le vide laissé par de nouvelles additions plus conformes à son caractère et à ses tendances. Je ne prétends nullement nier que l'humanité soit extrêmement redevable envers cette morale et ses premiers maîtres ; mais je me permets de dire qu'elle est, sur nombre de points importants, incomplète et partiale, et que si des idées et des sentiments qu'elle ne sanctionne pas n'avaient pas contribué à la formation du mode de vie et du caractère européens, les affaires humaines seraient actuellement bien pires qu'elles ne le sont. La morale chrétienne, comme on l'appelle, possède toutes les caractéristiques d'une réaction : c'est en grande partie une protestation contre le paganisme. Son idéal est négatif plus que positif, passif plus qu'actif ; c'est l'innocence plus que la noblesse, l'abstinence du mal plus que la quête énergique du bien; dans ses commandements (comme on l'a justement fait remarquer) le « tu ne dois pas » prédomine indûment sur le «tu dois ». Dans son horreur de la sensualité, elle a fait de l'ascétisme une idole, laquelle est devenue à son tour, à force de compromis, celle de la légalité. Elle tient l'espoir du ciel et la crainte de l'enfer pour les motifs convenus et appropries d'une vie vertueuse - ce en quoi elle reste loin derrière certains des plus grands sages de l'Antiquité -, et elle fait tout ce qui est en son pouvoir pour imprimer sur la morale humaine un caractère essentiellement égoïste, " déconnectant » pour ainsi dire le sens du devoir présent en chaque homme des intérêts de ses semblables, excepté lorsqu'on lui suggère un motif intéressé pour les consulter. C'est essentiellement une doctrine d'obéissance passive; elle inculque la soumission à toutes les autorités établies - lesquelles ne sont d'ailleurs pas activement obéies lorsqu'elles commandent ce que la religion interdit, mais cela sans qu'il soit pour autant possible de leur résister ou de se révolter contre elles, quel que soit le tort qu'elles nous fassent. Et, alors que dans la morale des grandes nations païennes, le devoir du citoyen envers l'État tient une place disproportionnée et empiète sur la liberté individuelle, cette grande part de notre devoir est à peine mentionnée ou reconnue dans la morale chrétienne. C'est dans le Coran, non dans le Nouveau Testament, que nous trouvons cette maxime : «Tout gouvernant qui désigne un homme à un poste quand il existe dans ses territoires un autre homme mieux qualifié pour celui-ci pèche contre Dieu et contre l'État. » Le peu de reconnaissance que reçoit l'idée d'obligation envers le public dans la morale moderne ne nous vient même pas des chrétiens, mais des Grecs et des Romains. De même, ce qu'il y a dans la morale privée de magnanimité, de grandeur d'âme, de dignité personnelle, voire de sens de l'honneur, ne nous vient pas du versant religieux, mais du versant purement humain de notre éducation ; et jamais ces qualités n'auraient pu être le fruit d'une doctrine morale qui n'accorde de valeur qu'à l'obéissance.

Je suis bien loin de prétendre que ces défauts sont nécessairement inhérents à la morale chrétienne de quelque manière qu'on la conçoive, ou bien que tout ce qui lui manque pour devenir une doctrine morale complète ne saurait se concilier avec elle; et je l'insinue encore bien moins des doctrines et des préceptes du Christ lui-même. Je crois que les paroles du Christ sont devenues, à l'évidence, tout ce qu'elles ont voulu être, qu'elles ne sont inconciliables avec rien de ce qu'exige une morale complète, qu'on peut y faire entrer tout ce qu'il y a d'excellent en morale, et cela sans faire 
davantage de violence à leur lettre que tous ceux qui ont tenté d'en déduire un quelconque système pratique de conduite. Mais je crois par ailleurs que cela n'entre nullement en contradiction avec le fait de croire qu'elles ne contiennent et ne voulaient contenir qu'une partie de la vérité. Je crois que dans ses instructions, le fondateur du christianisme a négligé à dessein beaucoup d'éléments essentiels de haute morale, que l'Église chrétienne, elle, a complètement rejetés dans le système moral qu'elle a érigé sur la base de cet enseignement. Cela étant, je considère comme une grande erreur le fait de vouloir à toute force trouver dans la doctrine chrétienne cette règle complète de conduite que son auteur n'entendait pas détailler tout entière, mais seulement sanctionner et mettre en vigueur. Je crois aussi que cette théorie est en train de causer grand tort dans la pratique, en diminuant beaucoup la valeur de l'éducation et de l'instruction morales que tant de personnes bien intentionnées s'efforcent enfin d'encourager. Je crains fort qu'en essayant de former l'esprit et les sentiments sur un modèle exclusivement religieux, et en évacuant ces normes séculières (comme on les appelle faute d'un meilleur terme) qui coexistaient jusqu'ici avec la morale chrétienne et la complétaient, mêlant leur esprit au sien, il n'en résulte - comme c'est le cas de plus en plus - un type de caractère bas, abject, servile, qui se soumet comme il peut à ce qu'il prend pour la Volonté suprême, mais qui est incapable de s'élever à la conception de la Bonté suprême ou de s'y ouvrir. Je crois que des morales différentes d'une morale exclusivement issue de sources chrétiennes doivent exister parallèlement à elle pour produire la régénération morale de l'humanité; et, selon moi, le système chrétien ne fait pas exception à cette règle selon laquelle, dans un état imparfait de l'esprit humain, les intérêts de la vérité exigent la diversité d'opinions. Il n'est pas dit qu'en cessant d'ignorer les vérités morales qui ne sont pas contenues dans le christianisme, les hommes doivent se mettre à ignorer aucune de celles qu'il contient. Un tel préjugé, une telle erreur, quand elle se produit, est un mal absolu; mais c'est aussi un mal dont on ne peut espérer être toujours exempts, et qui doit être considéré comme le prix à payer pour un bien inestimable. Il faut s'élever contre la prétention exclusive d'une partie de la vérité d'être la vérité tout entière ; et si un mouvement de réaction devait rendre ces rebelles injustes à leur tour, cette partialité serait déplorable au même titre que l'autre, mais devrait pourtant être tolérée. Si les chrétiens voulaient apprendre aux infidèles à être justes envers le christianisme, il leur faudrait être justes eux-mêmes envers leurs croyances. C'est mal servir la vérité que de passer sous silence ce fait - bien connu de tous ceux qui ont la moindre notion d'histoire littéraire -qu'une grande part des enseignements moraux les plus nobles et les plus estimables sont l'œuvre d'hommes qui non seulement ne connaissaient pas la foi chrétienne, mais encore la rejetaient en toute connaissance de cause.

Je ne prétends pas que l'usage le plus illimité de la liberté d'énoncer toutes les opinions possibles mettrait fin au sectarisme religieux ou philosophique. Toutes les fois que des hommes de faible stature intellectuelle prennent une vérité au sérieux, ils se mettent aussitôt à la proclamer, la transmettre, et même à agir d'après elle, comme s'il n'y avait pas au monde d'autre vérité, ou du moins aucune autre susceptible de la limiter ou de la modifier. Je reconnais que la plus libre discussion ne saurait empêcher le sectarisme en matière d'opinions, et que souvent, au contraire, c'est elle qui 
l'accroît et l'exaspère ; car on repousse la vérité d'autant plus violemment qu'on a manqué à l'apercevoir jusque-là et qu'elle est proclamée par des gens en qui l'on voit des adversaires. Ce n'est pas sur le partisan passionné, mais sur le spectateur calme et désintéressé que cette confrontation d'opinions produit un effet salutaire. Ce n'est pas la lutte violente entre les parties de la vérité qu'il faut redouter, mais la suppression silencieuse d'une partie de la vérité; il y a toujours de l'espoir tant que les hommes sont contraints à écouter les deux côtés ; c'est lorsqu'ils ne se préoccupent que d'un seul que leurs erreurs s'enracinent pour devenir des préjugés, et que la vérité, caricaturée, cesse d'avoir les effets de la vérité. Et puisque rien chez un juge n'est plus rare que la faculté de rendre un jugement sensé sur une cause où il n'a entendu plaider qu'un seul avocat, la vérité n'a de chance de se faire jour que dans la mesure où chacune de ses facettes, chacune des opinions incarnant une fraction de vérité, trouve des avocats et les moyens de se faire entendre.

Nous avons maintenant affirmé la nécessité - pour le bien-être intellectuel de l'humanité (dont dépend son bien-être général) - de la liberté de pensée et d'expression à l'aide de quatre raisons distinctes que nous allons récapituler ici.

Premièrement, une opinion qu'on réduirait au silence peut très bien être vraie : le nier, c'est affirmer sa propre infaillibilité.

Deuxièmement, même si l'opinion réduite au silence est fausse, elle peut contenir - ce qui arrive très souvent - une part de vérité; et puisque l'opinion générale ou dominante sur n'importe quel sujet n'est que rarement ou jamais toute la vérité, ce n'est que par la confrontation des opinions adverses qu'on a une chance de découvrir le reste de la vérité.

Troisièmement, si l'opinion reçue est non seulement vraie, mais toute la vérité, on la professera comme une sorte de préjugé, sans comprendre ou sentir ses principes rationnels, si elle ne peut être discutée vigoureusement et loyalement.

Et cela n'est pas tout Car, quatrièmement, le sens de la doctrine elle-même sera en danger d'être perdu, affaibli ou privé de son effet vital sur le caractère et la conduite: le dogme deviendra une simple profession formelle, inefficace au bien, mais encombrant le terrain et empêchant la naissance de toute conviction authentique et sincère fondée sur la raison ou l'expérience personnelle.

Avant de clore ce sujet de la liberté d'opinion, il convient de se tourner un instant vers ceux qui disent qu'on peut permettre d'exprimer librement toute opinion, pourvu qu'on le fasse avec mesure, et qu'on ne dépasse pas les bornes de la discussion loyale. On pourrait en dire long sur l'impossibilité de fixer avec certitude ces bornes supposées; car si le critère est le degré d'offense éprouvé par ceux dont les opinions sont attaquées, l'expérience me paraît démontrer que l'offense existe dès que l'attaque est éloquente et puissante: ils accuseront donc de manquer de modération tout adversaire qui les mettra dans l'embarras. Mais bien que cette considération soit importante sur 
le plan pratique, elle disparaît devant une objection plus fondamentale. Certes, la manière de défendre une opinion, même vraie, peut être blâmable et encourir une censure sévère et légitime. Mais la plupart des offenses de ce genre sont telles qu'elles sont le plus souvent impossibles à prouver, sauf si le responsable en vient à l'avouer accidentellement. La plus grave de ces offenses est le sophisme, la suppression de certains faits ou arguments, la déformation des éléments du cas en question ou la dénaturation de l'opinion adverse. Pourtant tout cela est fait continuellement - même à outrance - en toute bonne foi par des personnes qui ne méritent par ailleurs pas d'être considérées comme ignorantes ou incompétentes, au point qu'on trouve rarement les raisons adéquates d'accuser un exposé fallacieux d'immoralité ; la loi elle-même peut encore moins prétendre à interférer dans ce genre d'inconduite controversée. Quant à ce que l'on entend communément par le manque de retenue en discussion, à savoir les invectives, les sarcasmes, les attaques personnelles, etc., la dénonciation de ces armes mériterait plus de sympathie si l'on proposait un jour de les interdire également des deux côtés ; mais ce qu'on souhaite, c'est uniquement en restreindre l'emploi au profit de l'opinion dominante. Qu'un homme les emploie contre les opinions minoritaires, et il est sûr non seulement de n'être pas blâmé, mais d'être loué pour son zèle honnête et sa juste indignation. Cependant, le tort que peuvent causer ces procédés n'est jamais si grand que lorsqu'on les emploie contre les plus faibles, et les avantages déloyaux qu'une opinion peut tirer de ce type d'argumentation échoient presque exclusivement aux opinions reçues. La pire offense de cette espèce qu'on puisse commettre dans une polémique est de stigmatiser comme des hommes dangereux et immoraux les partisans de l'opinion adverse. Ceux qui professent des opinions impopulaires sont particulièrement exposés à de telles calomnies, et cela parce qu'ils sont en général peu nombreux et sans influence, et que personne ne s'intéresse à leur voir rendre justice. Mais étant donné la situation, cette arme est refusée à ceux qui attaquent l'opinion dominante ; ils courraient un danger personnel à s'en servir, et s'ils s'en servaient malgré tout, ils ne réussiraient qu'à exposer par contrecoup leur propre cause. En général, les opinions contraires à celles communément reçues ne parviennent à se faire entendre qu'en modérant scrupuleusement leur langage et en mettant le plus grand soin à éviter toute offense inutile: elles ne sauraient dévier d'un pouce de cette ligne de conduite sans perdre de terrain. En revanche, de la part de l'opinion dominante, les injures les plus outrées finissent toujours par dissuader les gens de professer une opinion contraire, voire même d'écouter ceux qui la professent. C'est pourquoi dans l'intérêt de la vérité et de la justice, il est bien plus important de réfréner l'usage du langage injurieux dans ce cas précis que dans le premier; et par exemple, s'il fallait choisir, il serait bien plus nécessaire de décourager les attaques injurieuses contre l'incroyance que contre la religion. Il est évident toutefois que ni la loi ni l'autorité n'ont à se mêler de réprimer l'une ou l'autre, et que le jugement de l'opinion devrait être déterminé, dans chaque occasion, par les circonstances du cas particulier. D'un côté ou de l'autre, on doit condamner tout homme dans la plaidoirie duquel percerait la mauvaise foi, la malveillance, la bigoterie ou encore l'intolérance, mais cela sans inférer ses vices du parti qu'il prend, même s'il s'agit du parti adverse. Il faut rendre à chacun l'honneur qu'il mérite, quelle que soit son opinion, s'il possède assez de calme et d'honnêteté 
pour voir et exposer - sans rien exagérer pour les discréditer, sans rien dissimuler de ce qui peut leur être favorable - ce que sont ses adversaires et leurs opinions. Telle est la vraie moralité de la discussion publique ; et, si elle est souvent violée, je suis heureux de penser qu'il y a de nombreux polémistes qui en étudient de très près les raisons, et un plus grand nombre encore qui s'efforce de la respecter. 


\section{Chapitre III}

\section{De l'individualité comme l'un des éléments du bien-être}

On vient de voir les raisons pour lesquelles il est impératif de laisser les hommes libres de former leurs opinions et de les exprimer sans réserve ; on a vu également que si cette liberté n'est pas accordée, ou du moins revendiquée, en dépit de l'interdiction, les conséquences en sont funestes pour l'intelligence et la nature morale de l'homme. Examinons à présent si ce ne sont pas les mêmes raisons qui exigent que les hommes soient libres d'agir selon leurs opinions - c'est-à-dire libres de les appliquer à leur vie sans que leurs semblables les en empêchent physiquement ou moralement, tant que leur liberté ne s'exerce qu'à leurs seuls risques et périls. Cette dernière condition est naturellement indispensable. Personne ne soutient que les actions doivent être aussi libres que les opinions. Au contraire, même les opinons perdent leur immunité lorsqu'on les exprime dans des circonstances telles que leur expression devient une instigation manifeste à quelque méfait. L'idée que ce sont les marchands de blé qui affament les pauvres ou que la propriété privée est un vol ne devrait pas être inquiétée tant qu'elle ne fait que circuler dans la presse ; mais elle peut encourir une juste 
punition si on l'exprime oralement, au milieu d'un rassemblement de furieux attroupés devant la porte d'un marchand de blé, ou si on la répand dans ce même rassemblement sous forme de placard. Les actes de toute nature qui sans cause justifiable nuisent à autrui peuvent être contrôlés - et dans les cas les plus graves, ils le doivent par la réprobation et, si nécessaire, par une intervention active des gens. La liberté de l'individu doit être contenue dans cette limite: il ne doit pas nuire à autrui. Et dès lors qu'il s'abstient d'importuner les autres et qu'il se contente d'agir suivant son inclination et son jugement dans ce qui ne concerne que lui, les mêmes raisons qui montrent que l'opinion doit être libre prouvent également qu'on devrait pouvoir, sans vexations, mettre son opinion en pratique à ses propres dépens. Que les hommes ne soient pas infaillibles, que ses vérités ne soient, pour la plupart, que des demi-vérités, que l'unité d'opinions ne soit pas souhaitable si elle ne résulte pas de la comparaison la plus libre et la plus totale des opinions contraires, et enfin que la diversité d'opinions ne soit pas un mal mais un bien tant que l'humanité n'est pas mieux à même de reconnaître toutes les facettes de la vérité : voilà des principes applicables tant à la manière d'agir des hommes qu'à leurs opinions. De même qu'il est utile, tant que l'humanité est imparfaite, qu'il y ait des opinions différentes, il est bon qu'il y ait différentes façons de vivre et que toute latitude soit donnée aux divers caractères, tant qu'ils ne nuisent pas aux autres, et qu'il est donné à chacun d'éprouver la valeur des différents genres de vie. Bref, il est souhaitable que l'individualité puisse s'affirmer dans tout ce qui ne touche pas directement les autres. Si ce n'est pas le caractère propre de la personne, mais les traditions et les mœurs des autres qui dictent les règles de conduite, c'est qu'il manque l'un des principaux ingrédients du bonheur humain, et en tout cas l'ingrédient le plus essentiel du progrès individuel ou social.

Lorsqu'on soutient ce principe, Ia plus grande difficulté ne réside pas tant dans l'appréciation des moyens qui conduisent à un but reconnu que dans l'indifférence générale des gens envers le but lui-même. Si l'on considérait le libre développement de l'individualité comme l'un des principes essentiels du bien-être, si on le voyait non pas comme accessoire coordonné à tout ce qu'on désigne par civilisation, instruction, éducation, culture, mais comme un élément et une condition nécessaires de toutes ces choses, il n'y aurait pas de danger que la liberté fût sous-estimée, et il n'y aurait pas de difficulté extraordinaire à tracer la frontière entre elle et le contrôle social. Mais malheureusement, les modes de pensée habituels ne reconnaissent que rarement une valeur intrinsèque ou un mérite spécifique à la spontanéité individuelle. La majorité, satisfaite des coutumes habituelles de l'humanité (parce que c'est elle qui les a faites ce qu'elles sont), ne voit pas pourquoi ces coutumes ne satisferaient pas tout le monde. Plus encore, la spontanéité n'entre pas dans l'idéal de la plupart des réformateurs moraux et sociaux: on la considère avec jalousie, comme un obstacle gênant, voire rebelle à l'acceptation générale de ce qu'ils jugent être le mieux pour l'humanité. Rares sont ceux qui, en dehors de l'Allemagne, comprennent cette doctrine à l'origine du traité de l'éminent savant et politicien Wilhelm von Humboldt: « La fin de l'homme, non pas telle que la suggèrent de vagues et fugitifs désirs, mais telle que la prescrivent les décrets éternels ou immuables de la raison, est le développement le plus large et le plus harmonieux de toutes ses facultés en un tout complet et cohérent »; de 
sorte que l'objet « vers lequel doit tendre constamment tout être humain, et en particulier ceux qui ont l'ambition d'influencer leurs semblables, est l'individualité de la puissance et du développement. » Il y a pour cela deux conditions à remplir: « la liberté et la variété des situations », de l'union desquelles naissent " la vigueur individuelle et la diversité », lesquelles fusionnent enfin dans « l'originalité » ${ }^{1}$.

Cependant, si neuve et si surprenante que puisse paraître une doctrine telle que celle de Humboldt qui attache tant de prix à l'individualité, il faut néanmoins pouvoir l'évaluer. Personne n'estime que la perfection en matière de conduite humaine consiste à se copier tout simplement les uns les autres. Personne n'estime non plus que le jugement ou le caractère particulier d'un homme ne doit compter pour rien dans sa manière de vivre et de soigner ses intérêts. D'un autre côté, il serait absurde de prétendre que les hommes doivent vivre comme si on ne connaissait rien dans le monde avant leur naissance, comme si jamais encore l'expérience n'avait montré que certaines façons de vivre étaient préférables à d'autres. Nul ne conteste qu'on doive élever et instruire la jeunesse de façon à lui faire profiter des acquis de l'expérience humaine. Mais c'est là le privilège et la condition propre d'un être humain dans la maturité de ses facultés que de se servir de l'expérience et de l'interpréter à sa façon. C'est à lui de découvrir ce qui, dans l'expérience transmise, est applicable à sa situation et à son caractère. Les traditions et les coutumes des autres sont, jusqu'à un certain point, des témoignages de ce que leur expérience leur a appris, et elles justifient une présomption qui, comme telle, est digne de respect. Mais il se peut en premier lieu que l'expérience des autres soit trop étroite, ou qu'il l'ait mal interprétée; il se peut deuxièmement que leur interprétation soit juste sans toutefois convenir à un individu particulier. Les coutumes sont faites pour les vies et les caractères ordinaires ; mais un individu peut avoir une vie et un caractère extraordinaires. Troisièmement, même si les coutumes sont à la fois bonnes en soi et adaptées à l'individu, il se peut que se conformer à la coutume uniquement en tant que telle n'entretienne ni ne développe en lui aucune des qualités qui sont l'attribut distinctif d'un être humain. Les facultés humaines de la perception, du jugement, du discernement, de l'activité intellectuelle, et même la préférence morale, ne s'exercent qu'en faisant un choix. Celui qui n'agit jamais que suivant la coutume ne fait pas de choix. Il n'apprend nullement à discerner ou à désirer ce qui vaut mieux. La force intellectuelle et la force morale, tout comme la force physique, ne s'améliorent qu'avec l'exercice. On n'exerce pas ses facultés en faisant ou en croyant une chose simplement parce que d'autres la font ou qu'ils y croient. Si une personne adopte une opinion sans que les principes de celle-ci lui paraissent concluants, sa raison n'en sortira pas renforcée, mais probablement affaiblie ; et si elle fait une action (qui n'affecte ni les affections ni les droits d'autrui) dont les motifs ne sont pas conformes à ses opinions et à son caractère, ceux-ci tomberont dans l'inertie et la torpeur au lieu d'être stimulés.

Celui qui laisse le monde, ou du moins son entourage, tracer pour lui le plan de sa vie, n'a besoin que de la faculté d'imitation des singes. Celui qui choisit lui-même sa

1 De la sphère et des devoirs du Gouvernement, par le baron Wilhelm von Humboldt. 
façon de vivre utilise toutes ses facultés : l'observation pour voir, le raisonnement et le jugement pour prévoir, l'activité pour recueillir les matériaux en vue d'une décision, le discernement pour décider et, quand il a décidé, la fermeté et la maîtrise de soi pour s'en tenir à sa décision délibérée. Il lui faut avoir et exercer ces qualités dans l'exacte mesure où il détermine sa conduite par son jugement et ses sentiments personnels. Il est possible qu'il soit sur une bonne voie et préservé de toute influence nuisible sans aucune de ces choses. Mais quelle sera sa valeur relative en tant qu'être humain ? Ce qui importe réellement, ce n'est pas seulement ce que font les hommes, mais le genre d'homme qu'ils sont en le faisant. Parmi les œuvres de l'homme que la vie s'ingénie à perfectionner et à embellir, la plus importante est sûrement l'homme lui-même. A supposer que ce soit des machines - des automates d'apparence humaine - qui construisent les maisons, cultivent le blé, se battent à la guerre, jugent les causes, élèvent des églises et disent les prières, ce serait encore une perte considérable d'échanger ces automates contre les hommes et les femmes qui peuplent aujourd'hui les parties les plus civilisées du monde, car ils ne sont que de tristes échantillons de ce que la nature peut et veut produire. La nature humaine n'est pas une machine qui se construit d'après un modèle et qui se programme pour faire exactement le travail qu'on lui prescrit, c'est un arbre qui doit croître et se développer de tous côtés, selon la tendance des forces intérieures qui en font un être vivant.

On concèdera probablement qu'il est préférable que les hommes cultivent leur intelligence et qu'il vaut mieux suivre intelligemment la coutume - quitte à dévier à l'occasion - que de s'y conformer aveuglément et mécaniquement. Jusqu'à un certain point, il est admis que notre intelligence doit nous appartenir; mais on n'admet pas aussi volontiers qu'il doit en être de même pour nos désirs et nos impulsions, et qu'en posséder de forts puisse être autre chose qu'un péril et un piège. Et pourtant, désirs et impulsions font partie de la perfection de l'être humain, au même titre que les croyances et les contraintes ; et de fortes impulsions ne sont dangereuses que lorsqu'elles sont mal équilibrées: lorsqu'un ensemble de buts et d'inclinations s'est fortement développé au détriment d'autres avec qui il aurait dû coexister. Ce n'est pas parce que les désirs des hommes sont forts qu'ils agissent mal, mais parce que leurs consciences sont faibles. Il n'y a pas de lien naturel entre des impulsions fortes et une conscience faible : le lien naturel s'établit en sens inverse. Dire que les désirs et les sentiments d'une personne sont plus forts et plus variés que ceux d'une autre, c'est dire simplement qu'il y a en elle davantage de matière brute de la nature humaine; ce qui signifie que si elle est capable de plus de mal, elle est aussi capable de plus de bien. De fortes impulsions, c'est simplement une autre façon de nommer l'énergie. L'énergie a beau pouvoir être employée à de mauvaises fins, on tirera toujours davantage d'une nature énergique que d'une nature indolente et apathique. Ceux qui ont le plus de sensibilité naturelle sont aussi ceux qui peuvent développer les sentiments les plus cultivés. Cette ardente sensibilité qui rend les impulsions personnelles vives et puissantes peut aussi bien engendrer l'amour le plus passionné de la vertu que la maîtrise de soi la plus sévère. C'est en cultivant ces deux tendances que la société fait son devoir et protège ses intérêts, et non en rejetant l'étoffe qui fait les héros, parce qu'elle n'en fabrique justement pas. On dit d'une personne qu'elle a du caractère lorsqu'elle a des 
désirs et des impulsions personnels qui sont l'expression de sa propre nature telle que l'a développée et modifiée sa propre culture. Celui qui n'a ni désirs ni impulsions personnels n'a pas davantage de caractère qu'une machine à vapeur. Si un individu a des impulsions non seulement personnelles, mais fortes et dominées par une volonté puissante, il a ce qu'on appelle un caractère énergique. Penser qu'il ne faut pas encourager le développement de l'individualité en matière de désirs et d'impulsions, c'est soutenir que la société n'a nul besoin de natures fortes - qu'elle ne s'en trouve pas mieux pour contenir un grand nombre de personnes de caractère - et qu'il n'est pas souhaitable de voir la moyenne des hommes posséder trop d'énergie.

Dans les sociétés naissantes, ces énergies étaient peut-être trop développées, et la société n'avait pas le pouvoir de les discipliner et de les contrôler. C'était un temps où l'élément de spontanéité et d'individualité dominait à l'excès, et où le principe social avait à lui livrer de rudes combats. La difficulté était alors d'amener les hommes puissants de corps ou d'esprit à obéir à des règles qui prétendaient contrôler leurs impulsions. Pour vaincre cette difficulté, la loi et la discipline, à l'instar des papes dans leur lutte contre les empereurs, proclamèrent leur pouvoir sur l'homme tout entier, revendiquant le droit de contrôler sa vie tout entière afin de pouvoir contrôler aussi son caractère, que la société n'était pas parvenue à contenir jusque-là. Mais, aujourd'hui, alors que la société a largement raison de l'individu, le danger qui guette la nature humaine n'est plus l'excès, mais la déficience des impulsions et des inclinations. Les choses ont bien changé depuis que les passions des puissants, forts de leur position ou de leurs talents personnels, étaient en rébellion constante contre les lois et les règlements et devaient être étroitement bridées pour que leur voisinage pût jouir de quelque sécurité. A notre époque, de la classe la plus haute à la plus basse, tout le monde vit sous le regard d'une censure hostile et redoutée. Non seulement en ce qui concerne les autres, mais en ce que ne concerne qu'eux-mêmes, jamais les individus et les familles ne se demandent : "Qu'est-ce que je préfère ? Qu'est-ce qui conviendrait à mon caractère et à mes dispositions ? Qu'est-ce qui permettrait à ce qu'il y a de plus élevé et de meilleur en moi d'avoir libre jeu, de se développer et de prospérer ? » Mais au contraire, ils se demandent: « Qu'est-ce qui convient à ma situation ? » ou " Que font ordinairement les personnes de ma position et de ma fortune ? » ou pire encore "Que font ordinairement les personnes d'une position et d'une fortune supérieures à la mienne ? » Je ne veux pas dire qu'ils préfèrent l'usage à leurs inclinations, car jamais il ne leur vient à l'idée qu'ils puissent avoir d'aspirations autres que la coutume. Ainsi l'esprit lui-même plie sous le joug, et même dans ce que les gens font pour leur plaisir, leur première pensée va à la conformité: ils aiment en masse; ils ne portent leur choix que sur les choses qu'on fait en général ; ils évitent comme un crime toute singularité de goût, toute excentricité de conduite, si bien qu'à force de ne pas suivre leur naturel, ils n'ont plus de naturel à suivre. Leurs capacités humaines sont atrophiées et inertes ; ils deviennent incapables du moindre désir vif, du moindre plaisir spontané; ils n'ont généralement ni opinions ni sentiments de leur cru, ou vraiment leurs. Maintenant, est-ce là la condition idéale de la. nature humaine ? 
Oui, si l'on en croit la théorie calviniste. Selon elle, le plus grand péché de l'homme, c'est d'avoir une volonté propre. Tout le bien dont l'humanité est capable tient dans l'obéissance. Vous n'avez pas le choix; vous devez agir ainsi et non autrement: « Tout ce qui n'est pas un devoir est péché. » La nature humaine étant complètement corrompue, il n'y a de rachat pour quiconque n'a pas tué en lui la nature humaine. Pour celui qui accepte semblable théorie, ce n'est pas un mal que de réprimer toutes les facultés, toutes les capacités et tous les sentiments humains: l'homme n'a besoin d'aucune aptitude si ce n'est celle de s'abandonner à la volonté de Dieu; et s'il se sert de ses facultés dans un but autre que d'accomplir cette volonté plus efficacement, il vaudrait mieux pour lui qu'il ne les possède pas. Voilà la théorie du calvinisme, et nombre de ceux qui ne se considèrent pas calvinistes la professent sous une autre forme plus modérée; l'adoucissement consiste à donner une interprétation moins ascétique de la volonté supposée de Dieu, en affirmant qu'il veut que les hommes satisfassent certaines de leurs inclinations, non pas à leur manière, mais par l'obéissance, c'est-à-dire d'une certaine manière prescrite par l'autorité, et qui doit être la même pour tous.

Sous l'une ou l'autre de ces formes, on tend maintenant fortement vers cette théorie étroite de la vie, et vers ce type de caractère humain étriqué et borné qu'elle favorise. Sans aucun doute, nombreux sont ceux qui croient sincèrement que les hommes ainsi torturés et rabougris sont tels que les a voulus leur créateur, tout comme beaucoup croient que les arbres sont bien plus beaux taillés en boule ou en formes d'animaux que laissés dans leur état naturel. Mais si cela fait partie de la religion de croire que l'homme a été créé par un Être bon, il est alors plus logique de croire que cet Être a donné à l'homme ses facultés pour qu'il les cultive et les développe, et non pour qu'elles soient extirpées et réduites à néant, et qu'Il se réjouit chaque fois que ses créatures font un pas vers l'idéal qu'elles portent en elles, qu'elles accroissent une de leurs facultés, de compréhension, d'action ou de jouissance. Il existe un modèle d'excellence humaine bien différent du calvinisme, à savoir que l'humanité n'a pas reçu sa nature seulement pour en faire l'abnégation. « L'affirmation païenne de soi » est un des éléments de la valeur humaine, au même titre que " l'abnégation chrétienne de soi ${ }^{1}$. Il y a un idéal grec de développement personnel, auquel se mêle, sans s'y substituer, l'idéal platonicien et chrétien de maîtrise de soi. Peut-être vaut-il mieux être un John Knox qu'un Alcibiade, mais mieux vaut encore être un Périclès ; et s'il existait un Périclès aujourd'hui, aucune des bonnes qualités de John Knox ne lui ferait sans doute défaut.

Ce n'est pas en noyant dans l'uniformité tout ce qu'il y a d'individuel chez les hommes, mais en le cultivant et en le développant dans les limites imposées par les droits et les intérêts d'autrui, qu'ils deviennent un noble et bel objet de contemplation; et de même que l'œuvre prend le caractère de son auteur, de même la vie humaine devient riche, diversifiée, animée, apte à nourrir plus abondamment les nobles pensées et les sentiments élevés ; elle renforce le lien entre les individus et l'espèce, en

1 Sterling: Essais. 
accroissant infiniment la valeur de leur appartenance a celle-ci. À mesure que se développe son individualité, chacun acquiert plus de valeur à ses propres yeux et devient par conséquent mieux à même d'en acquérir davantage aux yeux des autres. On atteint alors à une plus grande plénitude dans son existence, et lorsqu'il y a davantage de vie dans les unités, il y en a également davantage dans la masse qu'elles composent. On ne peut pas se dispenser de comprimer les spécimens les plus vigoureux de la nature humaine autant que nécessaire pour les empêcher d'empiéter sur les droits des autres ; mais a cela, on trouve ample compensation, même du point de vue du développement humain. Les moyens de développement que l'individu perd par l'interdiction de satisfaire des penchants nuisibles aux autres s'obtiennent surtout aux dépens du développement d'autrui. Et lui-même y trouve une compensation, car la contrainte imposée à son égoïsme autorise du même coup le meilleur développement possible de l'aspect social de sa nature. Être astreint pour le bien des autres aux strictes règles de la justice développe les sentiments et les facultés qui ont pour objet le bien des autres. Mais d'être ainsi contraint par le seul déplaisir des autres à ne pas commettre d'actions susceptibles de leur nuire ne développe par ailleurs rien de bon, sinon une force de caractère qui se manifestera peut-être par une résistance à la contrainte. Si l'on se soumet, c'est une contrainte qui émousse et ternit le caractère. Pour donner une chance équitable à la nature de chacun, il faut que différentes personnes puissent mener différents genres de vie. Les époques où une telle latitude a été laissée sont celles qui se signalent le plus à l'attention de la postérité. Le despotisme lui-même ne produit pas ses pires effets tant qu'il laisse subsister l'individualité ; et tout ce qui opprime l'individualité est un despotisme, quel que soit le nom qu'on lui donne, qu'il prétende imposer la volonté de Dieu ou les injonctions des hommes.

Après avoir identifié individualité et développement et démontré que seul l'entretien de l'individualité produit et peut produire des êtres humains bien développés, je pourrais clore ici mon argumentation; en effet, que dire de plus ou de mieux en faveur d'un certain état des affaires humaines, si ce n'est qu'il rapproche de la perfection à laquelle les hommes peuvent aspirer. Ou alors, que dire de pire d'un obstacle au bien, si ce n'est qu'il empêche ce progrès ? Il se peut cependant que ces considérations ne suffisent point à convaincre ceux qui ont le plus besoin d'être convaincus; aussi est-il nécessaire de montrer en outre que ces êtres humains développés peuvent être de quelque utilité aux non-développés. Il faut montrer à ceux qui ne souhaitent pas la liberté et qui n'en auraient pas l'usage qu'ils peuvent être récompensés de permettre aux autres d'en user sans entrave.

Tout d'abord, j'aimerais suggérer qu'il est possible pour eux d'apprendre quelque chose des hommes qui goûtent cette liberté. Personne ne niera que l'originalité ne soit un élément précieux dans les affaires humaines. On a toujours besoin de gens non seulement pour découvrir des vérités nouvelles et signaler le moment où ce qui fut autrefois une vérité cesse de l'être, mais encore pour initier des pratiques nouvelles et donner l'exemple d'une conduite plus éclairée, montrant davantage de goût et de bon sens dans les affaires humaines. Ceci ne saurait être contredit par quiconque ne croit pas que le monde ait déjà atteint la perfection dans toutes ses coutumes et pratiques. 
Il est vrai que n'importe qui peut rendre ce service, mais rares sont ceux dans l'espèce humaine dont les expériences seraient un progrès sur l'usage établi si les autres les adoptaient. Mais ces rares personnes sont le sel de la terre ; sans elles, la vie humaine deviendrait une mare stagnante. Car non seulement ce sont elles qui introduisent les bonnes choses inconnues jusque-là, mais ce sont elles encore qui gardent en vie celles qui existent déjà. S'il n'y avait plus rien de nouveau à faire, l'intelligence humaine cesserait-elle pour autant d'être nécessaire ? Serait-ce une raison pour ceux qui pratiquent des coutumes anciennes d'oublier pourquoi ils les pratiquent ou de les pratiquer comme du bétail, et non comme des êtres humains ? Il y a dans les croyances et les pratiques les meilleures une trop grande tendance à dégénérer en action mécanique ; et, sans cette succession de personnes dont l'originalité perpétuellement renouvelée entretient la vie de ces croyances et de ces pratiques, une telle matière morte ne résisterait guère au choc causé par une matière réellement vivante; aussi n'y aurait-il alors aucune raison pour que la civilisation ne périsse pas, comme ce fut le cas de l'Empire byzantin. À la vérité, les hommes de génie sont et demeureront probablement toujours une faible minorité; mais pour qu'il y en ait, encore faut-il entretenir le terreau dans lequel ils croissent. Le génie ne peut respirer librement que dans une atmosphère de liberté. Les hommes de génie sont, ex vi termini, plus "individuels » que les autres, et donc moins capables de se couler, sans que cette compression ne leur soit dommageable, dans les quelques moules que la société fournit à ses membres pour leur éviter la peine de se former un caractère. Si, par timidité, les hommes de génie se résignent à entrer dans un de ces moules, et à laisser s'atrophier cette partie d'eux-mêmes qui ne peut s'épanouir sous une telle pression, la société ne profitera guère de leur génie. Si en revanche, ils sont doués d'une grand force de caractère et brisent leurs chaînes, ils deviennent une cible pour la société qui, parce qu'elle n'a pas réussi à les réduire au lieu commun, se met alors à les montrer du doigt et à les traiter de « sauvages », de " fous » ou autres qualificatifs de ce genre - un peu comme si on se plaignait que le Niagara n'ait pas le flot paisible d'un canal hollandais.

Si j'insiste avec autant de force sur l'importance du génie et sur la nécessité de le laisser se développer librement, tant en pensée que dans la vie, c'est que, bien que je sache que nul ne refuse cette position en théorie, je sais aussi que le monde y est en réalité totalement indifférent. Les gens pensent que le génie est une belle chose si elle permet à un homme d'écrire un poème émouvant ou de peindre un tableau. Mais bien que le génie, dans son sens vrai d'originalité de pensée et d'action, soit pour les hommes un objet d'admiration, ils n'en pensent pas moins dans leur for intérieur qu'on peut très bien s'en passer. Malheureusement, cette attitude est trop naturelle pour qu'on puisse s'en étonner. S'il y a une chose dont les esprits peu originaux ne ressentent aucun besoin, c'est bien de l'originalité. Ils sont incapables de voir à quoi elle pourrait leur servir; et d'ailleurs, comment le pourraient-ils ? S'ils le pouvaient, ils ne manqueraient pas d'originalité. Le premier service que l'originalité doive leur rendre, c'est de leur ouvrir les yeux; après quoi, seulement, ils auraient quelque chance de devenir eux-mêmes originaux. Mais en attendant, qu'ils se souviennent que rien n'a jamais été fait sans que quelqu'un le fasse en premier, et que toutes les bonnes choses qui existent sont le fruit de l'originalité ; et qu'ils soient alors assez modestes pour 
croire que l'originalité a encore bien des choses à accomplir et pour se persuader que moins ils en ressentent le besoin, plus elle leur est nécessaire.

En vérité, quels que soient les hommages qu'on veuille bien rendre à la supériorité d'esprit, réelle ou supposée, la tendance générale dans le monde est d'accorder la place dominante à la médiocrité. Dans l'histoire ancienne, au moyen âge - et à un degré moindre durant la longue transition entre la féodalité et l'époque actuelle -, l'individu représentait une puissance en soi ; et s'il avait de grands talents ou une position sociale élevée, cette puissance était considérable. À présent, les individus sont perdus dans la foule. En politique, c'est presque un lieu commun de dire que c'est l'opinion qui, aujourd'hui, dirige le monde. Le seul pouvoir digne de ce nom est celui des masses et celui des gouvernements en tant qu'ils se font les organes des tendances et des instincts des masses. Et cela vaut aussi bien pour les relations morales et sociales de la vie privée que pour les affaires publiques. Ceux dont les opinions passent pour l'opinion publique diffèrent selon les pays : en Amérique, c'est toute la population blanche; en Angleterre, c'est principalement la classe moyenne. Mais toujours ils forment une masse : une médiocrité collective. Et, nouveauté plus grande encore, les gens de la masse n'empruntent plus leurs opinions aux dignitaires de l'Église ou de l'État, mais à quelques chefs notoires et à des livres. Leurs avis sont formés par des hommes très semblables à eux qui, par l'intermédiaire des journaux, s'adressent à eux ou parlent en leur nom dans l'inspiration du moment. Je ne me plains pas de cet état de choses. Je n'affirme pas que rien de mieux soit compatible en règle générale avec la médiocrité actuelle de l'esprit humain. Mais cela n'empêche pas le gouvernement de la médiocrité d'être un gouvernement médiocre. Jamais gouvernement d'une démocratie ou d'une aristocratie nombreuse ne s'est élevé et n'aurait pu s'élever au-dessus de la médiocrité, que ce soit dans ses actes politiques, les opinions, les talents, la mentalité qu'il produit, si la multitude souveraine ne s'était pas laissée guidée (comme elle l'a toujours fait à ses meilleurs moments) par les conseils et l'influence d'un homme ou d'une minorité plus doué et plus instruit. L'initiation aux choses sages et nobles vient et doit venir des individus, et d'abord généralement d'un individu isolé. L'honneur et la gloire de l'homme du commun est de pouvoir suivre cette initiative, d'avoir le sens de ce qui est sage et noble et de s'y laisser conduire les yeux ouverts. Je n'encourage pas ici cette sorte de « culte du héros » qui applaudit l'homme fort et génial quand il s'empare du gouvernement du monde et le réduit à ses ordres contre son gré. Tout ce à quoi un tel homme peut prétendre, c'est la liberté de montrer la voie. Le pouvoir de forcer les autres à l'emprunter est non seulement contraire à la liberté et aux développement du reste de la population, mais corrupteur pour l'homme de génie lui-même. il semble bien cependant que partout où les masses composées d'hommes ordinaires deviennent le pouvoir dominant, le contre-poids et le correctif de cette tendance se traduise par l'individualité toujours plus marquée des penseurs les plus éminents. C'est surtout dans de telles circonstances qu'au lieu de réprimer les individus exceptionnels, il faudrait les encourager à agir différemment de la masse. Autrefois, il n'y avait aucun avantage à ce qu'ils agissent différemment, si ce n'était pas pour agir mieux. Aujourd'hui, le simple exemple de la non-conformité, le simple refus de plier le genou devant la coutume est en soi un véritable service. 
Justement parce que la tyrannie de l'opinion est telle qu'elle fait de l'excentricité une honte, il est souhaitable, pour ouvrir une brèche dans cette tyrannie, que les gens soient excentriques. L'excentricité et la force de caractère vont toujours de paire, et le niveau d'excentricité d'une société se mesure généralement à son niveau de génie, de vigueur intellectuelle et de courage moral. Que si peu de gens osent maintenant être excentriques, voilà qui révèle le principal danger de notre époque.

J'ai dit qu'il était important de laisser le plus de champ possible aux choses contraires à l'usage, afin qu'on puisse voir en temps voulu lesquelles méritent de passer dans l'usage. Mais l'indépendance d'action et le dédain de l'usage ne méritent pas seulement d'être encouragés pour la chance qu'ils donnent de découvrir de meilleures façons d'agir et des coutumes plus dignes d'être adoptées par tous. Il n'y a pas que les gens dotés d'un esprit supérieur qui puissent prétendre à mener la vie qui leur plaît. Il n'y a pas de raison pour que toute existence humaine doive se construire sur un modèle unique ou sur un petit nombre de modèles.

Il suffit d'avoir une dose suffisante de sens commun et d'expérience pour tracer le plan de vie le meilleur, non pas parce qu'il est le meilleur en soi, mais parce qu'il est personnel. Les êtres humains ne sont pas des moutons; et même les moutons ne se ressemblent pas au point qu'on ne puisse pas les distinguer. Un homme ne trouve un habit ou une paire de souliers qui lui vont que s'ils sont faits sur mesure ou s'il dispose d'un magasin entier pour faire son choix. Trouve-t-on plus facilement chaussure à son pied que vie à sa convenance ? Ou se peut-il qu'il y ait moins de diversité dans la conformation physique et intellectuelle des hommes que dans la forme de leurs pieds ? Ne serait-ce que parce que les hommes n'ont pas tous les mêmes goûts, il ne faut pas tenter de les fabriquer tous sur le même modèle. Il y a autant d'hommes que d'itinéraires intellectuels : de même que les plantes ne peuvent pas toutes vivre sous le même climat, les hommes ne peuvent pas tous prospérer dans la même atmosphère morale. Les mêmes choses qui aident une personne à cultiver sa nature supérieure peuvent être des obstacles pour une autre. Le même mode de vie est pour l'une une stimulation salutaire qui entretient au mieux ses facultés d'action et de jouissance, tandis que pour l'autre il est un fardeau gênant qui suspend ou détruit la vie intérieure. Il y a de telles différences entre les hommes, dans leurs sources de plaisir, dans leurs façons de souffrir et de ressentir l'effet des diverses influences physiques et morales que, sans différence correspondante dans leurs modes de vie, jamais ils ne pourront prétendre à leur part de bonheur ni s'élever à la stature intellectuelle dont leur nature est capable. Pourquoi donc la tolérance devrait-elle seulement se limiter, dans le sentiment du publie, aux goûts et aux modes de vie qui arrachent l'assentiment par le nombre de leurs adhérents ? il n'y a personne (si ce n'est dans les institutions monastiques) pour nier complètement la diversité des goûts. Une personne peut, sans encourir de blâme, aimer ou ne pas aimer le canotage, le cigare, la musique, la gymnastique, les échecs, les cartes ou l'étude, et cela parce que les partisans et les ennemis de toutes ces choses sont trop nombreux pour être réduits au silence. Mais les hommes - et plus encore les femmes - qui peuvent être accusés soit de faire « ce que personne ne fait », soit de ne pas faire « ce que tout le monde fait », 
peuvent se voir autant dénigrés que s'ils avaient commis quelque grave délit moral. Il faut que les gens aient un titre ou quelqu'autre insigne qui les élève dans l'opinion de leurs concitoyens au niveau de gens de qualité, pour qu'ils puissent se permettre tant soi peu le luxe de faire ce qui leur plaît, sans nuire à leur réputation. Se le permettre tant soi peu, je le répète, car quiconque se permet trop ce luxe risque bien pire que l'injure, à savoir d'être traduit devant une commission de lunatico et de se voir enlever ses biens au profit de sa famille ${ }^{1}$.

Il y a une caractéristique dans l'orientation actuelle de l'opinion publique qui est singulièrement de nature à la rendre intolérante envers toute démonstration marquée d'individualisme. En moyenne, les hommes ne sont pas seulement modérés dans leur intelligence, mais encore modérés dans leurs inclinations. Ils n'ont pas de goûts ou de désirs assez vifs qui les incitent à faire quoi que ce soit d'extraordinaire, si bien qu'ils ne comprennent pas ceux qui en ont et qu'ils les classent parmi les fous et les agités qu'ils ont coutume de mépriser. Maintenant, pour savoir à quoi nous attendre, supposons que, outre ce fait général, s'amorce un fort mouvement en faveur du progrès moral. De nos jours, un tel mouvement s'est amorcé : on a beaucoup fait pour promouvoir la régularité de la conduite et décourager les excès ; et il y a dans l'air un esprit philanthropique qui ne trouve pas pour S'exercer terrain plus propice que l'amélioration de ses semblables en fait de morale et de prudence. Ces tendances rendent le public plus disposé qu'autrefois à prescrire des règles de conduite générales et à s'efforcer de ramener tout le monde à la norme reçue. Et cette norme, expresse ou tacite, est de ne rien désirer vivement. Son idéal de caractère est de n'avoir pas de caractère marqué - d'estropier, à force de compression, comme le pied d'une dame chinoise, toute partie saillante de la nature humaine qui tend à rendre une personne franchement dissemblable du commun des hommes.

\footnotetext{
Il y a quelque chose de méprisable et de terrifiant à la fois dans le genre de témoignage sur lequel on peut, depuis quelques années, déclarer toute personne judiciairement incapable de diriger ses affaires et, après sa mort, tenir pour non-avenue la disposition qu'elle a faite de ses biens, si l'on trouve de quoi payer les frais qui sont prélevés sur les biens eux-mêmes. On fouille dans tous les menus détails de sa vie quotidienne, et tout ce qu'on trouve qui, vu a travers les facultés perceptives et descriptives des derniers des derniers, semble différer un peu de la banalité la plus stricte, est présenté au jury comme preuve de folie ; et cela réussit souvent, les jurés étant à peine moins vulgaires et ignorants que les témoins, tandis que les juges, avec cette extraordinaire ignorance de la nature humaine et de la vie qui ne laisse de nous étonner chez les juristes anglais, contribuent souvent à les induire en erreur. Ces procès en disent long sur l'état des sentiments et des opinions du vulgaire sur la liberté humaine. Loin de valoriser l'individualité, loin de respecter le droit de tout individu d'agir dans les choses indifférentes comme son jugement et ses inclinations l'y portent, les juges et les jurés ne peuvent même pas concevoir qu'une personne saine d'esprit puisse désirer une telle libéré. Jadis, quand on proposait de brûler des athées, des gens charitables suggéraient de les mettre plutôt dans une maison de fous. On ne s'étonnerait pas de voir faire la même chose aujourd'hui et de voir les acteurs s'applaudir d'avoir adopté une manière si humaine et si chrétienne de traiter ces infortunés au lieu de les persécuter pour raisons religieuses, non sans une satisfaction secrète de leur avoir fait un sort selon leur mérite.
} 
Comme il en va généralement des idéaux qui excluent la moitié de ce qui est désirable, la norme actuelle d'approbation ne produit qu'une imitation inférieure de l'autre moitié. Au lieu de grandes énergies guidées par une raison vigoureuse et de forts sentiments puissamment contrôlés par une volonté scrupuleuse, elle produit de faibles sentiments et de faible énergies qui, pour cette raison, peuvent se conformer à la règle, du moins extérieurement, sans grand effort de la part de la volonté ou de la raison. Déjà, les caractères énergiques et d'envergure appartiennent de plus en plus au passé. Aujourd'hui, dans notre pays, cette énergie ne s'exprime guère plus que dans les affaires. L'énergie qu'on y dépense peut encore être jugée considérable. Le peu qu'il en reste après cet emploi est utilisé à quelque passe-temps, peut-être utile, voire philanthropique, mais qui est toujours une chose unique, et généralement sans envergure. La grandeur de l'Angleterre est maintenant toute collective: petits individuellement, nous ne semblons capables de rien de grand que par notre habitude de nous associer; et cela suffit amplement à contenter nos philanthropes moraux et religieux. Mais ce sont des hommes d'une autre trempe qui ont fait de l'Angleterre ce qu'elle est; et des hommes d'une autre trempe seront nécessaires pour empêcher son déclin.

Le despotisme de la coutume est partout l'obstacle qui défie le progrès humain, parce qu'il livre une dispute incessante à cette disposition de viser mieux que l'ordinaire, et qu'on appelle, suivant les circonstances, esprit de liberté, esprit de progrès et d'amélioration. L'esprit de progrès n'est pas toujours un esprit de liberté, car il peut chercher à imposer le progrès à un peuple réticent ; et l'esprit de liberté, quand il résiste à de tels efforts, peut s'allier localement et temporairement aux adversaires du progrès ; mais la seule source d'amélioration intarissable et permanente du progrès est la liberté, puisque grâce à elle, il peut y avoir autant de foyers de progrès que d'individus. Quoi qu'il en soit, le principe progressif, sous ses deux formes d'amour de la liberté et d'amour de l'amélioration, s'oppose à l'empire de la Coutume, car il implique au moins l'affranchissement de ce joug; et la lutte entre ces deux forces constitue le principal intérêt de l'histoire de l'humanité. La plus grande partie du monde n'a, à proprement parler, pas d'histoire, parce que le despotisme de la Coutume y est total. C'est le cas de tout l'Orient. La coutume est là, souverain arbitre de toutes choses : justice et droit signifient conformité à la coutume ; et personne, si ce n'est quelques tyrans enivrés de pouvoir, ne songe à lui résister. Et nous en voyons le résultat. Ces nations doivent avoir eu autrefois de l'originalité ; elles ne sont pas sorties de terre peuplées, lettrées et profondément versées dans de nombreux arts de vivre; sous tous ces rapports, elles se sont faites elles-mêmes, et elles étaient alors les plus grandes et les plus puissantes nations du monde. Que sont-elles maintenant ? Elles sont asservies à des tribus dont les ancêtres erraient dans les forêts, tandis que les leurs avaient de magnifiques palais et des temples fastueux, à une époque où la coutume se départageait le pouvoir avec la liberté et le progrès. Un peuple, semble-t-il, peut progresser pendant un certain temps, puis s'arrêter: quand s'arrête-t-il ? Quand il perd l'Individualité. Si un tel changement devait affecter les nations de l'Europe, ce ne serait pas exactement sous la même forme: le despotisme de la coutume qui menace ces nations n'est pas précisément l'immobilisme. C'est un despotisme qui proscrit la singularité, mais qui n'exclut pas le changement, pourvu que tout change en même temps. Nous 
en avons fini avec les costumes traditionnels de nos aïeux. Chacun doit encore s'habiller comme les autres mais la mode peut changer une ou deux fois par an. Nous prenons alors soin de changer pour l'amour du changement, et non par une quelconque idée de beauté ou de commodité; car la même idée de beauté ou de commodité ne frapperait pas tout le monde au même moment, et ne serait pas abandonnée par tous simultanément. Mais nous sommes tous progressistes comme nous sommes tous versatiles; nous inventons continuellement de nouvelles choses en mécanique, et nous les conservons jusqu'à ce qu'elles soient remplacées par de meilleures; nous sommes avides d'amélioration en politique, en éducation et même en morale, quoiqu'ici notre idée d'amélioration consiste surtout à persuader ou à forcer les autres d'être aussi bons que nous-même. Ce n'est pas au progrès que nous nous opposons; au contraire, nous nous flattons d'être le peuple le plus progressiste qui vécût jamais. C'est contre l'individualité que nous sommes en guerre ; nous croirions avoir fait merveille si nous nous étions rendus tous semblables, oubliant que la dissemblance d'une personne à l'autre est la première chose qui attire l'attention, soit sur l'imperfection de l'un de ces types et la supériorité de l'autre, soit sur la possibilité de produire quelque chose de meilleur que chacun d'eux, en combinant les avantages des deux. L'exemple de la Chine peut nous servir d'avertissement : c'est une nation fort ingénieuse, et à certains égards, douée de beaucoup de sagesse, grâce à l'insigne bonne fortune d'avoir reçu de bonne heure un ensemble de coutumes particulièrement justes, oeuvre dans une certaine mesure d'hommes auxquels les européens les plus éclairés doivent accorder, dans certaines limites, le titre de sages et de philosophes. Ces coutumes sont remarquables aussi par l'excellence de leur méthode pour imprimer autant que possible leurs meilleurs préceptes dans tous les esprits de la communauté, et pour s'assurer que ceux qui en sont le mieux pénétrés occuperont le poste honorifique et les fonctions de commandement. Assurément le peuple qui avait créé cette méthode avait découvert le secret du progrès humain, et il devait se maintenir a la tête du progrès universel ! Or, au contraire, les Chinois se sont immobilisés; ils sont depuis des milliers d'années tels que nous les voyons, et, s'ils doivent s'améliorer encore, ce sera nécessairement grâce à des étrangers. Ils ont réussi au-delà de toute espérance l'entreprise à laquelle les philanthropes anglais s'adonnent avec zèle : uniformiser un peuple en faisant adopter par tous les mêmes maximes et les mêmes règles pour les mêmes pensées et les mêmes conduites. Voilà le fruit. Le régime moderne de l'opinion publique est, sous une forme non organisée, ce que sont les systèmes éducatif et politique chinois sous une forme organisée. Et, si l'individualité n'est pas capable de s'affirmer contre ce joug, l'Europe, malgré ses nobles antécédents et le christianisme qu'elle professe, tendra à devenir une autre Chine.

Et, jusqu'à présent, qu'est-ce qui a préservé l'Europe de ce sort ? Pourquoi la famille des nations européennes continue-t-elle de progresser ? Pourquoi n'est-elle pas une partie stationnaire de l'humanité ? Ce n'est certes pas grâce à leurs prétendues qualités supérieures, car là où elles existent, c'est à titre d'effet, et non de cause ; mais c'est plutôt grâce à leur remarquable diversité de caractère et de culture. En Europe, les individus, les classes, les nations sont extrêmement dissemblables : ils se sont frayé une grande variété de chemins, chacun conduisant à quelque chose de précieux; 
et bien qu'à chaque époque ceux qui empruntaient ces différents chemins aient été intolérants les uns envers les autres, et que chacun eût préféré obliger tous les autres à suivre sa route, leurs efforts mutuels pour freiner leur développement ont rarement eu un succès définitif. Et, peu à peu, chacun en est venu à accepter bon gré mal gré, le bien qu'apportaient les autres. Selon moi, c'est à cette pluralité de voies que l'Europe doit son développement varié. Mais déjà elle commence à perdre considérablement cet avantage. Elle avance décidément vers l'idéal chinois de l'uniformisation des personnes. Dans sa dernière oeuvre importante, $M$. de Tocqueville remarque combien les Français d'aujourd'hui se ressemblent plus que ceux de la génération précédente. La remarque vaudrait encore bien davantage pour les Anglais. Dans un passage déjà cité, Wilhelm von Humboldt désigne deux conditions nécessaires au développement humain - nécessaires pour rendre les hommes dissemblables - à savoir la liberté et la variété des situations. La seconde de ces deux conditions se perd chaque jour en Angleterre. Les circonstances qui entourent les différentes classes et les différents individus et qui forment leurs caractères, s'uniformisent chaque jour davantage. Autrefois, différents rangs sociaux, différents voisinages, différents métiers et professions vivaient pour ainsi dire dans des mondes différents ; à présent ils vivent tous largement dans le même monde. Aujourd'hui ils lisent plus ou moins les mêmes choses, écoutent les mêmes choses, regardent les mêmes choses ; ils vont aux mêmes endroits ; leurs espérances et leurs craintes ont les mêmes objets ; ils ont les mêmes droits, les mêmes libertés et les mêmes moyens de les revendiquer. Si grandes que soient les différences de positions qui subsistent, elles ne sont rien auprès de celles qui ont disparu. Et l'assimilation continue. Tous les changements politiques de l'époque la favorisent, puisqu'ils tendent tous à élever les classes inférieures et à abaisser les classes supérieures. Toute extension de l'éducation la favorise, parce que l'éducation réunit les hommes sous des influences communes et leur donne accès au stock général de faits et de sentiments. Le progrès des moyens de communication la favorise en mettant en contact personnel les habitants de contrées éloignées et en entretenant une succession rapide de changements de résidence d'un lieu à l'autre. Le développement du commerce et des manufactures favorise encore cette uniformisation en diffusant plus largement les avantages du confort et en offrant tous les plus hauts objets d'ambition à la compétition générale, d'où il s'ensuit que le désir de s'élever n'appartient plus exclusivement à une classe, mais à toutes. Un moyen d'uniformisation générale plus efficace encore que tous ceux-ci, c'est l'établissement complet, dans ce pays et dans d'autres, de l'ascendant de l'opinion publique dans l'État. A mesure que se nivellent les différents rangs hiérarchiques supérieurs de la société, qui permettaient aux personnes retranchées derrière elles de mépriser l'opinion de la multitude, à mesure que l'idée même de résister à la volonté du public, lorsque cette volonté est manifeste, disparaît de l'esprit des politiciens, il cesse d'y avoir aucun soutien social pour la non-conformité à savoir aucun pouvoir indépendant dans la société, lui même opposé à l'ascendant des masses, qui a intérêt à prendre sous sa protection les opinions et les tendances opposées à celles du public.

La réunion de toutes ces causes forme une si grande masse d'influences hostiles à l'Individualité qu'on ne voit guère comment elle conservera son terrain. Elle le 
gardera avec une difficulté croissante, à moins que les plus intelligents n'apprennent à en sentir la valeur - à tenir pour bénéfiques les différences, même si elles ne vont pas dans le sens d'une amélioration et même si certaines leur semblent apporter une dégradation. Si jamais les droits de l'individualité doivent être revendiqués, le temps est venu de le faire, car l'uniformisation n'est pas terminée. C'est seulement au début du processus qu'on peut réagir avec succès contre l'empiétement. L'uniformisation des caractères est une exigence qui croît par ce dont elle se nourrit. Si on attend pour y résister que la vie soit presque réduite à un type uniforme, alors tout ce qui s'écartera de ce type sera considéré comme impie, immoral, voire monstrueux, et contre nature. L'humanité devient rapidement incapable de concevoir la diversité lorsqu'elle s'en est déshabituée un temps. 


\section{Chapitre IV}

\section{Des limites de l'autorité de la société sur l'individu}

Quelle est donc la juste limite de la souveraineté de l'individu sur lui-même ? Où commence l'autorité de la société ? Quelle part de la vie humaine revient-elle à l'individualité, quelle part, à la Société ?

Chacune des deux recevra ce qui lui revient si chacune se préoccupe de ce qui la concerne plus particulièrement. À l'individualité devrait appartenir cette partie de la vie qui intéresse d'abord d'individu; à la société, celle qui intéresse d'abord la société.

Bien que la société ne soit pas fondée sur un contrat, et bien qu'il ne serve à rien de l'inventer pour en déduire les obligations sociales, tous ceux qui reçoivent protection de la société lui sont néanmoins redevables de ce bienfait. Le fait seul de vivre en société impose à chacun une certaine ligne de conduite envers autrui. Cette conduite consiste premièrement, à ne pas nuire aux intérêts d'autrui, ou plutôt à cer- 
tains de ces intérêts qui, soit par disposition expresse légale, soit par accord tacite, doivent être considérés comme des droits; deuxièmement, à assumer sa propre part (à fixer selon un principe équitable) de travail et de sacrifices nécessaires pour défendre la société ou ses membres contre les préjudices et les vexations. Mais ce n'est pas là tout ce que la société peut faire. Les actes d'un individu peuvent être nuisibles aux autres, ou ne pas suffisamment prendre en compte leur bien-être, sans pour autant violer aucun de leurs droits constitués. Le coupable peut alors être justement puni par l'opinion, mais non par la loi. Dès que la conduite d'une personne devient préjudiciable aux intérêts d'autrui, la société a le droit de la juger, et la question de savoir si cette intervention favorisera ou non le bien-être général est alors ouverte à la discussion. Mais cette question n'a pas lieu d'être tant que la conduite de quelqu'un n'affecte que ses propres intérêts, ou tant qu'elle n'affecte les autres que s'ils le veulent bien, si tant est que les personnes concernées sont adultes et en possession de toutes leurs facultés. Dans tous les cas, on devrait avoir liberté complète - légale et sociale d'entreprendre n'importe quelle action et d'en supporter les conséquences.

Ce serait grandement se méprendre sur cette doctrine que d'y voir une défense de l'indifférence égoïste, selon laquelle un homme ne s'intéresserait nullement à la conduite des autres, et qu'il ne devrait s'inquiéter de leur « bien-agir » et de leur bienêtre que lorsque que son propre intérêt est en jeu. Il ne faut pas moins, mais bien davantage d'efforts désintéressés pour promouvoir le bien d'autrui. Mais la bienveillance désintéressée peut trouver d'autres instruments de persuasion que le fouet et la cravache, au propre comme au figuré. Je suis le dernier à sous-estimer les vertus privées ; mais elles ne viennent qu'après les vertus sociales. C'est le rôle de l'éducation que de les cultiver également toutes deux. Mais l'éducation elle-même agit par la conviction et la persuasion, aussi bien que par la contrainte, et ce n'est que par le premier moyen qu'une fois l'éducation achevée, les vertus privées devraient être inculquées. Les hommes doivent s'aider les uns les autres à distinguer le meilleur du pire, et s'encourager à préférer l'un et à éviter l'autre. Ils ne devraient avoir de cesse que de se stimuler mutuellement à exercer leurs plus nobles facultés et à orienter davantage leurs sentiments et leurs desseins vers la sagesse, et non la folie, vers des objets de contemplation édifiants, et non dégradants. Mais personne n'est autorisé à dire à un homme d'âge mûr que, dans son intérêt, il ne doit pas faire de sa vie ce qu'il a choisi d'en faire. Il est celui que son bien-être préoccupe le plus: l'intérêt que peut y prendre un étranger est insignifiant - à moins d'un vif attachement personnel - comparé au sien même. L'intérêt que la société lui porte individuellement (sauf dans sa conduite envers les autres) est partiel et proprement indirect ; tandis qu'en matière de sentiments et de situation, l'homme et la femme les plus ordinaires savent infiniment mieux à quoi s'en tenir que n'importe qui d'autre. L'intervention de la société pour diriger le jugement et les desseins d'un homme dans ce qui ne regarde que lui, se fonde toujours sur des présomptions générales ; or, celles-ci peuvent être complètement erronées ; et si elles étaient justes, elles risqueraient encore d'être fort mal appliquées par des personnes peu familières des circonstances particulières, des observateurs extérieurs par exemple. C'est pourquoi cette partie des affaires humaines est le champ d'action privilégié de l'individualité. Pour ce qui est de la conduite des 
hommes les uns envers les autres, l'observance des règles générales est nécessaire afin que chacun puisse savoir à quoi s'attendre; mais dans les affaires personnelles, la spontanéité individuelle a le droit de s'exercer librement. On peut offrir à quelqu'un, voire le forcer à entendre, des conseils pour l'aider à juger, des exhortations pour raffermir sa volonté; mais il demeure le juge suprême. Il peut se tromper en dépit des conseils et des avertissements ; mais c'est là un moindre mal que de laisser les autres le contraindre à faire ce qu'ils estiment être son bien.

Je ne veux pas dire que les sentiments qu'on éprouve pour quelqu'un ne doivent nullement être affectés par ses qualités ou ses défauts individuels ; cela n'est ni possible ni souhaitable. S'il possède au plus haut point les qualités qui le mènent à son élévation, il est par là même digne d'admiration. Si en revanche, ces qualités lui font manifestement défaut, on éprouvera pour lui un sentiment contraire à l'admiration. Il y a un degré de bêtise et un degré de ce qu'on pourrait nommer (bien que le terme soit contestable) médiocrité ou dépravation du goût qui, s'il ne mérite pas qu'on maltraite celui qui en est affligé, en fait nécessairement et naturellement un objet de répulsion, voire dans les cas extrêmes, de mépris. Il serait impossible à quiconque possède pleinement les qualités opposées de ne pas éprouver ces sentiments. Sans nuire à personne, un homme peut faire en sorte de nous forcer à le tenir pour sot ou pour une nature inférieure ; et comme cette façon de le juger ne lui plairait pas, c'est lui rendre service que de l'en avertir d'avance, ainsi que des autres conséquences désagréables auxquelles il s'expose. Il vaudrait mieux en vérité que la politesse actuelle permît de rendre plus souvent ce service, et qu'une personne pût dire franchement à son voisin qu'il est en faute sans passer pour grossière ou prétentieuse. Nous avons également le droit d'agir de différentes façons, en fonction de notre opinion défavorable sur quelqu'un, et cela sans la moindre atteinte à son individualité, mais simplement dans l'exercice de la nôtre. Rien ne nous oblige, par exemple, à rechercher la compagnie d'une personne; nous sommes en droit de l'éviter (quoique sans ostentation), car nous sommes en droit de choisir la compagnie qui nous convient le mieux. Nous avons également le droit, et parfois le devoir, de mettre les autres en garde contre quelqu'un, si nous jugeons son exemple ou sa conversation nuisible à ceux qu'il fréquente. Nous pouvons lui préférer d'autres personnes quand il s'agit de rendre des services non obligatoires, excepté lorsqu'ils visent à son amélioration. C'est ainsi que quelqu'un peut recevoir de très sévères punitions de la part d'autrui pour des fautes qui, directement, le concernent seul ; mais il ne subit ces sanctions que dans la mesure où elles sont les conséquences naturelles, et pour ainsi dire spontanées, de ses défauts eux-mêmes ; on ne les lui inflige pas intentionnellement, dans le but de le punir. Une personne qui montre de la précipitation, de l'obstination, de la vanité, qui ne peut vivre dans des conditions modestes, renoncer aux divertissements nocifs, et qui recherche les plaisirs primaires, sacrifiant ainsi le sentiment et l'intelligence - une telle personne doit s'attendre à baisser dans l'opinion des autres et à mériter moins d'estime de leur part. Mais elle n'a aucun droit de s'en plaindre, à moins d'avoir gagné leurs faveurs par des relations sociales particulièrement excellentes qui lui aient acquis un droit à la reconnaissance à l'épreuve de ses démérites personnels. 
Ce que je soutiens, c'est que les inconvénients strictement liés au jugement défavorable d'autrui sont les seuls auxquels une personne devrait jamais être soumise pour les aspects de sa conduite et de son caractère qui ne concernent que son propre bien, sans qu'ils affectent par ailleurs les intérêts de ceux avec qui elle est liée. En revanche, les actes nuisibles aux autres requièrent un traitement totalement différent. Empiéter sur leurs droits, leur infliger une perte ou un préjudice que ne justifient pas ses propres droits, user de fausseté ou de duplicité à leur égard, profiter à leurs dépens d'avantages déloyaux ou simplement peu généreux, voire même s'abstenir par égoïsme de les préserver de quelque tort, c'est encourir à juste titre la réprobation morale et, dans les cas graves, les sanctions ou punitions morales. Mais ce ne sont pas seulement ces actes, mais les dispositions qui y conduisent, qui sont proprement immoraux et dignes d'une réprobation pouvant aller jusqu'à l'horreur. La disposition à la cruauté, la méchanceté, l'envie - passion antisociale et odieuse entre toutes -, la dissimulation et l'hypocrisie, l'irascibilité gratuite, le ressentiment disproportionné, l'amour de la domination, le désir d'accaparer plus que sa part d'avantages (la pleonexia des Grecs), l'orgueil qui se nourrit de l'abaissement des autres, l'égoïsme qui favorise sa personne et ses intérêts avant tout et tranche toute question douteuse en sa faveur - autant de vices moraux qui témoignent d'une moralité défaillante et odieuse, à la différence des défauts personnels mentionnés précédemment, qui ne sont pas à proprement parler de l'immoralité ou de la méchanceté, quel qu'en soit l'excès. Ces vices peuvent être une marque de bêtise, de manque de dignité personnelle et de respect de soi, mais ils ne deviennent des sujets de réprobation morale que lorsqu'ils entraînent le mépris des devoirs envers les autres, pour le bien desquels l'individu se doit de veiller sur lui-même. Ce qu'on appelle devoirs envers soi-même ne constituent pas une obligation sociale, à moins que les circonstances n'en fassent simultanément des devoirs envers autrui. Le terme devoir envers soi-même, lorsqu'il va au-delà de la prudence, signifie respect de soi ou développement personnel ; or, de ces qualités nul n'est responsable devant ses semblables, puisqu'on ne saurait être rendu responsable du bien qu'on fait à l'humanité.

La distinction entre le discrédit justifié que s'attire une personne par son manque de prudence ou de dignité personnelle, et la réprobation qui lui revient pour atteinte au droit d'autrui, n'est pas une distinction purement nominale. Il y a une grande différence tant dans nos sentiments que dans notre conduite envers une personne, selon qu'elle nous déplaît dans les choses où nous estimons être en droit de la contrôler, ou dans celles où nous savons ne pas avoir ce droit. Nous pouvons exprimer notre aversion et nous tenir à distance d'une personne ou d'une chose qui nous déplaît; mais que cela ne nous incite pas à lui rendre la vie difficile. Il faut penser qu'elle porte déjà ou portera l'entière responsabilité de son erreur. Si elle gâche sa vie en la dirigeant mal, ce n'est pas une raison de désirer la lui gâcher davantage : au lieu de vouloir la punir, il faut plutôt s'efforcer d'alléger sa punition en lui montrant comment éviter ou guérir les maux auxquels sa conduite l'expose. Cette personne sera pour nous un objet de pitié, voire d'aversion, mais non de courroux ou de ressentiment ; nous ne devons pas la traiter en ennemi de la société: le pire que 
nous puissions nous estimer en droit de faire, c'est de l'abandonner à elle-même si nous ne voulons pas intervenir avec bienveillance en montrant de l'intérêt pour sa personne. Il en va tout autrement si cette personne a enfreint les règles nécessaires à la protection de ses semblables, individuellement ou collectivement. Car dans ce cas, les conséquences funestes de ses actes ne retombent pas sur elle, mais sur d'autres ; et la société, en tant que protectrice de tous ses membres, doit user de représailles contre elle, lui infliger un châtiment suffisamment sévère, dans l'intention expresse de punir. Dans le premier cas, le coupable comparaît devant nous et nous sommes appelés non seulement à délibérer sur son cas, mais encore à exécuter d'une façon ou d'une autre notre propre sentence. Dans l'autre cas, il ne nous appartient pas de lui infliger des souffrances, sauf si elles proviennent incidemment du fait que nous usons, dans la direction de nos propres affaires, de la même liberté que nous lui reconnaissons dans les siennes.

Beaucoup refuseront d'admettre la distinction établie ici entre la partie de la vie qui ne concerne que l'individu et celle qui concerne les autres. Comment, demanderat-on, une partie quelconque de la conduite d'un membre de la société peut-elle rester indifférente aux autres ? Personne n'est entièrement isolé: il est impossible à un homme de se nuire considérablement et durablement sans que le dommage ne se répercute au moins sur ses proches, et souvent un cercle bien plus large. S'il compromet sa fortune, il nuit à ceux qui directement ou indirectement en tiraient leurs moyens d'existence, et d'ordinaire, il diminue plus ou moins les ressources générales de la communauté. S'il détériore ses facultés physiques ou morales, il fait non seulement du tort à tous ceux dont le bonheur dépendait de lui, mais il se rend incapable de rendre les services qu'il doit généralement à ses semblables; il tombe peut-être à la charge de leur affection et de leur bienveillance; et si une telle conduite était très fréquente, il n'y aurait guère de faute plus susceptible de porter atteinte au bien général. Enfin, dira-t-on encore, si une personne ne nuit pas directement aux autres par ses vices ou ses folies, elle n'en est pas moins pernicieuse par son exemple, et il faudrait la forcer à se contrôler par égard pour ceux que la vue ou la connaissance de sa conduite pourrait corrompre ou égarer.

Et même, ajoutera-t-on, si les conséquences de l'inconduite pouvaient se limiter à l'individu vicieux et irréfléchi, la société doit-elle pour autant abandonner des gens manifestement incapables de se conduire ? Si l'on reconnaît que les enfants et les mineurs doivent être protégés contre eux-mêmes, la société n'en doit-elle pas autant aux adultes aussi peu capables de se gouverner seuls ? Si le jeu, la boisson, l'incontinence l'oisiveté ou la saleté sont un obstacle au bonheur et au progrès au même titre que la plupart des actes interdits par la loi, pourquoi, demandera-ton, la loi ne s'efforcerait-elle, dans la mesure où cela est praticable et opportun socialement, de réprimer également ces abus ? Et pour remédier aux imperfections inévitables de la loi, l'opinion ne devrait-elle pas au moins organiser une police puissante contre ces vices, et infliger à ceux connus pour les pratiquer toute la rigueur des pénalités sociales ? Il n'est pas question ici, dira-t-on, de restreindre l'individualité ni d'empêcher quiconque de tenter des expériences de vie nouvelles et originales. Tout ce qu'on 
cherche à éviter, ce sont les expériences tentées et condamnées depuis le début des temps jusqu'à nos jours - les choses qui, avec l'expérience, ne se sont avérées ni utiles ni convenables pour l'individualité de personne. Il faut une somme considérable de temps et d'expérience pour qu'une vérité dictée par la morale ou la prudence soit tenue pour établie; et l'on souhaite simplement éviter que les générations ne se précipitent les unes après les autres dans ces mêmes abîmes qui ont été fatals à leurs prédécesseurs.

J'admets parfaitement que le tort qu'une personne se fait, puisse sérieusement affecter les sentiments et les intérêts de ses proches et, à un degré moindre, la société tout entière. Quand, par une telle conduite, un homme est amené à violer une obligation distincte et assignable envers une ou plusieurs personnes, le cas cesse d'être privé et tombe sous le coup de la désapprobation morale au sens propre du terme. Si, par exemple, de par son intempérance ou son extravagance, un homme se trouve incapable de payer ses dettes, ou si, s'étant chargé de la responsabilité morale d'une famille, les mêmes raisons le rendent incapable de la nourrir et de l'élever, il mérite la réprobation et peut être justement puni, non pas pour son extravagance, mais simplement pour avoir manqué à son devoir envers sa famille ou ses créanciers. Même si les ressources qui leur étaient destinées avaient été détournées en vue du placement le plus prudent, la culpabilité morale aurait été la même. George Barnwell assassina son oncle afin d'obtenir de l'argent pour sa maîtresse, mais s'il l'avait fait pour s'établir dans le commerce, on l'aurait pendu également. Mais dans le cas fréquent où un homme cause le malheur de sa famille en s'adonnant à de mauvaises habitudes, on peut à juste titre lui reprocher sa cruauté ou son ingratitude; mais le reproche serait le même s'il cultivait des habitudes non point vicieuses en elles-mêmes, mais pénibles pour ceux avec lesquels il passe sa vie ou qui, par des liens personnels, dépendent de lui pour leur bien-être. Quiconque n'accorde pas la considération généralement due aux intérêts et aux sentiments d'autrui, sans y être contraint par un devoir plus impérieux, ou sans pouvoir le justifier par quelque inclination permise, mérite la réprobation morale pour ce manquement, mais non pour la cause de celui-ci, ni pour les erreurs purement privées dont cette faute peut être la conséquence éloignée. De même, si une personne, par une conduite purement égoïste, se rend incapable d'accomplir un devoir précis envers le public, elle est coupable d'un crime contre la société. Personne ne devrait être puni uniquement pour ivresse; mais un soldat ou un policier doivent être punis s'ils sont ivres dans l'exercice de leurs fonctions. Bref, partout où il y a un dommage défini, ou un risque défini de dommage, soit pour un individu, soit pour la société, le cas sort du domaine de la liberté pour tomber sous le coup de la morale ou de la loi.

Mais quant au préjudice purement contingent ou, pour ainsi dire, constructif qu'une personne cause à la société par une conduite qui ne viole aucun devoir spécifique envers le public, ni n'occasionne de dommage perceptible à nul autre qu'ellemême, l'inconvénient est alors de ceux que la société peut supporter, pour l'amour de ce bien supérieur qu'est la liberté humaine. S'il fallait punir les adultes parce qu'ils ne prennent pas soin d'eux-mêmes, je voudrais que ce fût pour leur bien, et non pas sous 
prétexte de compromettre leur capacité de rendre à la société des services que celle-ci ne prétend par ailleurs pas avoir le droit de leur imposer. Mais je ne saurais débattre cette question comme si la société n'avait pas d'autres moyens de ramener ses membres les plus faibles à un niveau ordinaire de conduite raisonnable, que d'attendre qu'ils fassent une bêtise pour les punir, légalement ou moralement. La société a eu tout pouvoir sur eux pendant la première partie de leur existence ; elle a eu toute la période de l'enfance et de la minorité pour essayer de les rendre capables de se conduire raisonnablement dans la vie. La génération présente est maîtresse à la fois de l'éducation et du sort de la génération à venir. Il est vrai qu'elle ne peut la rendre parfaitement sage et bonne, parce qu'elle manque elle-même si lamentablement de sagesse et de bonté ; et ses plus grands efforts ne sont pas toujours, dans les cas individuels, les mieux récompensés; mais dans l'ensemble, elle est parfaitement capable de rendre la génération montante aussi bonne, voire meilleure, qu'elle-même. Si la société laisse un grand nombre de ses membres dans un état d'enfance prolongée, sourds à l'influence de la considération rationnelle des motifs généraux, c'est la société seule qui est à blâmer pour les conséquences. Forte non seulement de tous les pouvoirs de l'éducation, mais de l'ascendant constant de l'opinion reçue sur les esprits les moins autonomes en matière de jugement, aidée de surcroît par les sanctions naturelles qui tombent inévitablement sur ceux qui s'exposent au dégoût et au mépris de leur entourage - que la société n'aille pas réclamer en outre le pouvoir de légiférer et de punir dans le domaine des intérêts personnels des individus, dans lequel, selon tous les principes de justice et de politique, la décision devrait appartenir à ceux qui doivent en supporter les conséquences. Il n'y a rien qui tende davantage à discréditer ou à annuler les bons moyens d'influencer la conduite humaine que d'avoir recours aux pires. Si, parmi ceux qu'on essaie de contraindre à la prudence ou à la tempérance, certains ont l'étoffe d'un caractère vigoureux et indépendant, ils se révolteront immanquablement contre le joug. Aucun homme de cette trempe n'admettra jamais que les autres aient le droit de le contrôler dans ses affaires privées, comme ils ont le droit de l'empêcher de nuire aux leurs. Et on en vient vite à considérer comme une marque de caractère et de courage le fait de tenir tête à une autorité à ce point usurpée, et de faire ostensiblement exactement le contraire de ce qu'elle prescrit. C'est ainsi qu'on vit, au temps de Charles Il, la mode de l'indécence succéder à l'intolérance morale née du fanatisme puritain. Quant à ce qu'on dit de la nécessité de protéger la société contre le mauvais exemple que sont les hommes vicieux et intempérants, il est vrai que le mauvais exemple - surtout le fait de nuire aux autres impunément - peut avoir un effet pernicieux. Mais nous parlons maintenant de la conduite qui, sans nuire à autrui, est censée faire grand tort à l'agent lui-même; et dans ce cas, comment ne pas trouver l'exemple plus salutaire que nuisible, puisqu'en montrant l'inconduite au grand jour, il montre aussi les conséquences pénibles ou dégradantes qui résultent généralement d'une conduite justement censurée.

Mais l'argument le plus fort contre l'intervention du public dans la conduite purement personnelle, c'est que lorsqu'il intervient, il y a fort à parier que ce soit à tort et à travers. Dans les questions de morale sociale, de devoir envers autrui, l'opinion du public - c'est-à-dire d'une majorité dominante - peut être aussi souvent fausse 
que vraie ; car en effet, dans de telles questions, on ne demande aux gens que de juger de leurs propres intérêts, et de la façon dont certaines conduites les affecteraient si elles étaient autorisées. Mais l'opinion d'une telle majorité, imposée comme loi à une telle minorité, aura autant de chance d'être fausse que vraie; car, ici, l'opinion publique signifie tout au plus l'opinion de certaines gens sur ce qui est bon ou mauvais pour d'autres, et très souvent elle ne signifie même pas cela, puisque le public passe en toute indifférence au-dessus du plaisir ou du bien-être de ceux dont il censure la conduite pour ne tenir compte que de sa propre inclination. Beaucoup de gens considèrent comme un préjudice personnel les conduites qu'ils n'aiment pas, et les ressentent comme un outrage à leurs sentiments : comme ce bigot qui, accusé de mépriser les sentiments religieux des autres, répliqua que c'était eux qui méprisaient les siens en persistant dans leur culte ou leur croyance abominable. Mais il n'y a aucune commune mesure entre le sentiment d'un homme envers sa propre opinion et celui d'un autre qui s'offense de ce qu'on la détienne, pas plus qu'entre le désir qu'éprouve un voleur de prendre une bourse et celui qu'éprouve son propriétaire légitime de la garder. Et le goût d'une personne est son affaire, au même titre que son opinion ou sa bourse. On peut aisément imaginer un public idéal qui n'entrave pas la liberté de choix des individus dans les questions incertaines, et qui leur demanderait simplement de renoncer aux modes de conduite que l'expérience universelle a condamnés. Mais a-t-on jamais vu un public imposer de telles limites à sa censure ? Depuis quand le public se soucie-t-il de l'expérience universelle ? Lorsqu'il se mêle de la conduite personnelle, il pense rarement à autre chose qu'à l'énormité que représente pour lui le fait d'agir et de sentir différemment de lui. Et ce critère de jugement, à peine déguisé, est présenté à l'humanité comme le précepte de religion et de philosophie par les neuf dixièmes des moralistes et des auteurs spéculatifs. Ils nous enseignent que les choses sont justes parce qu'elles sont justes : parce que nous sentons qu'elles le sont. Ils nous disent de chercher dans notre esprit ou notre cœur les lois de conduite obligatoires pour nous mêmes et pour les autres. Et que peut faire le pauvre public, si ce n'est d'appliquer ces instructions et, en cas de relative unanimité, d'imposer ses sentiments personnels de bien et de mal au monde entier ?

Le mal mentionné ici n'est pas de ceux qui n'existent qu'en théorie; et on s'attendra peut-être à ce que je cite les cas particuliers où le public de cette époque et de ce pays investit à tort ses préférences du titre de lois morales. Je n'écris pas un essai sur les aberrations du sentiment moral actuel. C'est un sujet trop grave pour être discuté entre parenthèse et sous forme d'illustration. Toutefois, des exemples sont nécessaires pour montrer que le principe que je défends a une grande importance pratique et que je ne m'efforce pas d'élever une barrière contre des maux imaginaires. Il y a d'abondants exemples qui montrent que cette volonté d'étendre les limites de ce qu'on peut appeler la police morale jusqu'à ce qu'elle empiète sur la liberté la plus incontestablement légitime de l'individu, est de tous les penchants humains l'un des plus universels.

Comme premier exemple, considérez les antipathies que les hommes conçoivent du simple fait que des personnes d'opinions religieuses différentes ne pratiquent pas leurs observances - et surtout leurs abstinences - religieuses. Pour prendre un exemple 
un peu trivial, rien dans la croyance ou dans la pratique des chrétiens n'attise plus la haine des musulmans que de les voir manger du porc. Il y a peu d'actes qui inspirent plus franc dégoût aux chrétiens et aux Européens que n'en inspire aux musulmans cette manière particulière de satisfaire sa faim. C'est d'abord une offense à leur religion ; mais cette circonstance n'explique nullement le degré ou la forme de leur répugnance; car le vin est également interdit par leur religion, et si les musulmans jugent mal d'en boire, ils ne trouvent pas cela dégoûtant. Leur aversion pour la chair de la « bête impure » a ceci de particulier qu'elle ressemble à une antipathie instinctive, que l'idée d'impureté, une fois qu'elle a imprégné les sentiments, semble toujours inspirer la répulsion - et cela, même chez ceux dont les habitudes personnelles sont loin d'être scrupuleusement pures -, et dont le sentiment d'impureté religieuse chez les Hindous est un exemple remarquable. Supposez maintenant que dans un peuple à majorité musulmane, celle-ci veuille interdire de manger du porc dans tout le pays. Il n'y aurait là rien de bien neuf pour les pays musulmans ${ }^{1}$. Serait-ce là exercer légitimement l'autorité morale de l'opinion publique ? Et sinon, pourquoi ? Cette coutume est réellement révoltante pour un tel public ; il croit sincèrement que Dieu l'interdit et l'abhorre. On ne pourrait pas davantage censurer cette interdiction comme une persécution religieuse. Même religieuse d'origine, elle ne serait pas une persécution religieuse, étant donné qu'aucune religion ne fait un devoir de manger du porc. Le seul motif de condamnation possible serait que le public n'a pas à se mêler des goûts personnels et des intérêts privés du public.

Un peu plus près de nous, la majorité des Espagnols considèrent comme une marque grossière d'impiété, et comme l'offense la plus grave envers l'Être suprême, de lui vouer un culte différent de celui des catholiques romains ; et aucun autre culte public n'est permis sur le sol espagnol. Pour tous les peuples d'Europe méridionale, un clergé marié est non seulement irréligieux, mais impudique, indécent, grossier, dégoûtant. Que pensent les protestants de ces sentiments parfaitement sincères et de la tentative de les imposer aux non-catholiques ? Cependant si les hommes peuvent légitimement interférer dans leur liberté réciproque dans ce qui n'affecte pas les intérêts d'autrui, sur quel principe cohérent exclure ces cas ? Ou qui peu blâmer des gens pour leur désir de détruire ce qu'ils considèrent comme un scandale aux yeux de Dieu et des hommes ? Il n'y a pas d'arguments plus puissants pour interdire ce qu'on considère comme une immoralité personnelle que supprimer ces pratiques telles qu'elles apparaissent aux yeux de ceux qui les jugent impies; et à moins de vouloir adopter la logique des persécuteurs, et dire que nous pouvons persécuter les autres parce que nous avons raison, et qu'ils ne doivent pas nous persécuter parce qu'ils ont

1 Le cas des Parsis de Bombay est un curieux exemple à cet égard. Quand les membres de cette tribu industrieuse et entreprenante, descendante des adorateurs du feu perses, fuirent leur pays natal devant les Califes et arrivèrent en Inde occidentale, les souverains hindous acceptèrent de les tolérer à condition de ne pas manger de bœuf. Quand plus tard ces contrées tombèrent sous la domination des conquérants, les Parsis obtinrent la prolongation de cette indulgence à condition de renoncer au porc. Ce qui ne fut d'abord que soumission à l'autorité devint une seconde nature, si bien que les Parsis d'aujourd'hui s'abstiennent à la fois de bœuf et de porc. Bien que leur religion ne l'exige pas, cette double abstinence s'est imposée avec le temps comme une coutume de leur tribu ; et en Orient, la coutume est une religion. 
tort, il faut bien nous garder d'admettre un principe qui, imposé chez nous, nous paraîtrait une injustice flagrante.

On peut objecter, quoiqu'à tort, aux exemples précédents, qu'ils sont tirés de circonstances impossibles chez nous - puisqu'il est peu vraisemblable dans ce pays que l'opinion se mette à imposer l'abstinence de certaines viandes, ou à empêcher les gens de rendre leur culte, de se marier ou non, selon leur croyance ou leur inclination. En revanche, l'exemple suivant sera tiré d'une atteinte à la liberté dont la menace est loin d'être écartée. Partout où les puritains sont devenus suffisamment puissants comme en Nouvelle-Angleterre et en Grande-Bretagne au temps de la République ils se sont efforcés avec un succès considérable de réprimer les amusements publics et privés, particulièrement la musique, la danse, le théâtre, les jeux publics ou tout autre réunion en vue de divertissements. Il y a toujours dans notre pays un grand nombre de gens dont les notions de morale et de religion condamnent ces divertissements; et comme ces personnes appartiennent surtout à la classe moyenne - devenue aujourd'hui la puissance sociale et politique dominante du royaume - il est fort possible que cette opinion jouisse un jour d'une majorité au parlement. Comment réagira le reste de la communauté en voyant réglementer ses divertissements selon les sentiments moraux et religieux des stricts calvinistes et méthodistes ? Ne prierait-elle instamment ces hommes d'une piété si importune de s'occuper de leurs affaires ? C'est là précisément ce qu'il faut dire à tout gouvernement ou à tout public qui a la prétention de priver tout le monde des plaisirs qu'il condamne. Mais si le principe de la prétention est admis, on ne peut objecter raisonnablement à ce que la majorité ou tout autre pouvoir dominant dans le pays l'applique selon ses vues ; et tout le monde doit être prêt à se conformer à l'idée d'une république chrétienne, telle que la comprenait les premiers colons de la Nouvelle-Angleterre, qui craignaient qu'une secte religieuse semblable à la leur ne parvienne un jour à regagner le terrain perdu, comme ce fut souvent le cas des religions qu'on croyait en décadence.

Supposons maintenant une autre situation peut-être plus susceptible de se réaliser que la précédente. Il y a, de l'aveu de chacun, une forte tendance dans le monde à se diriger vers une constitution démocratique de la société, accompagnée ou non par des institutions politiques populaires. On affirme que dans le pays où cette tendance s'est manifestée le plus complètement -les États-Unis, qui ont la société et le gouvernement les plus démocratiques - le sentiment de la majorité, auquel déplaît le moindre signe d'un train de vie trop luxueux pour qu'elle puisse jamais l'égaler, agit comme. une loi somptuaire assez efficace, et que dans maintes parties de l'Union, il est réellement difficile à une personne disposant d'un revenu très important de le dépenser sans encourir la réprobation populaire. Bien que de telles affirmations soient sans doute des représentations très exagérées des faits existants, l'état de choses qu'elles décrivent est non seulement concevable et possible, mais le résultat probable de l'union du sentiment démocratique et de la notion que le public a un droit de veto sur la manière dont les gens dépensent leurs revenus. Maintenant nous n'avons plus qu'à supposer une diffusion considérable d'opinions socialistes pour voir qu'il peut devenir infâme aux yeux de la majorité de posséder davantage qu'une quantité très limitée de 
biens ou qu'un revenu quelconque non acquis par un travail manuel. Des opinions semblables à celles-ci dans leur principe dominent déjà parmi la classe ouvrière et pèsent d'une façon oppressive sur ceux qui dépendent avant tout de l'opinion de cette classe, à savoir ses propres membres. Il est notoire que les mauvais ouvriers - majoritaires dans beaucoup de branches de l'industrie - croient fermement qu'ils devraient recevoir le même salaire que les bons, et que nul ne devrait être autorisé, sous prétexte de travailler à la pièce ou autrement, à gagner plus en faisant montre de plus d'habileté et de zèle que les autres. Et ils utilisent une police morale, et physique à l'occasion, pour intimider les bons ouvriers et les empêcher de recevoir une rémunération plus importante pour de meilleurs services, ainsi que pour décourager les patrons de la leur donner. Si le public a la moindre juridiction sur les affaires privées, je ne vois pas pourquoi ces gens auraient tort ni pourquoi il faudrait blâmer le public particulier d'un individu de prétendre à la même autorité sur sa conduite individuelle que celle que l'opinion publique impose aux gens en général.

Mais trêve de suppositions : de grossières usurpations sont perpétrées aujourd'hui dans le domaine de la liberté privée, et d'autres, plus grandes encore, avec l'aide de ces opinions qui revendiquent le droit illimité du public non seulement d'interdire par la loi tout ce qu'il juge mauvais, mais encore, pour mieux atteindre ce but, d'interdire un certain nombre de choses qu'il juge innocentes.

Sous prétexte de lutter contre l'intempérance, les habitants d'une colonie anglaise et de presque la moitié des États-Unis se sont vu interdire par la loi tout usage de boissons alcoolisées autre que médical; car interdire la vente d'alcool - du reste, on l'entendait bien ainsi -, c'est en interdire l'usage. Et bien que l'impossibilité matérielle d'appliquer cette loi ait causé son abrogation dans plusieurs États qui l'avaient adoptée, y compris celui qui lui avait donné son nom, nombre de philanthropes déclarés mènent une campagne active pour promouvoir une loi similaire dans notre pays. L'association formée dans ce but, « l'Alliance », comme ils l'appellent, a acquis quelque notoriété par la publicité donnée à une correspondance entre son secrétaire et l'un des très rares hommes publics anglais à maintenir que les opinions d'un politicien devraient se fonder sur des principes. La part de lord Stanley dans cette correspondance est propre à renforcer les espoirs qu'avaient déjà placés en lui ceux qui savent combien sont rares, parmi les acteurs de la vie politique, ces qualités qu'il a parfois manifestées en public. Le porte-parole de l'Alliance qui « déplorerait profondément la reconnaissance de tout principe susceptible d'être détourné pour justifier le sectarisme et la persécution » entreprend de nous montrer « la large et infranchissable barrière » qui sépare de tels principes de ceux de l'association. « Toutes les questions relatives à la pensée, à l'opinion, à la conscience, me semblent », dit-il, " se situer hors de la sphère législative. En revanche, tout ce qui appartient au domaine des actes sociaux, des habitudes, des relations, me paraît uniquement du ressort d'un pouvoir discrétionnaire de l'État, et non de l'individu, de sorte que cela tombe dans la sphère de la législation. » Nulle mention n'est faite ici d'une troisième classe d'actes, différente des deux citées ci-dessus, à savoir les actions et les habitudes qui ne sont pas sociales, mais individuelles, bien que ce soit dans celles-ci que se classe la consommation de 
boissons alcoolisées. Il est pourtant vrai que la vente des boissons alcoolisées est un commerce, et que le commerce est un acte social. Or, l'infraction reprochée n'est pas la liberté du vendeur, mais celle de l'acheteur et du consommateur, puisque ]'État pourrait tout autant lui interdire de boire du vin que de le mettre dans l'impossibilité de s'en procurer. Le secrétaire déclare pourtant : « En tant que citoyen, je revendique le droit de légiférer partout où mes droits sociaux subissent l'assaut de l'acte social d'un autre. " Voici maintenant la définition de ces " droits sociaux »: "S'il y a une chose qui empiète sur mes droits sociaux, c'est bien le commerce des boissons alcoolisées. il détruit mon droit élémentaire à la sécurité en créant et en stimulant constamment le désordre social. Il empiète sur mon droit à l'égalité en tirant profit de la création d'une misère que je paye par mes impôts. Il infirme mon droit à un libre développement moral et intellectuel en parsemant ma route de dangers et en affaiblissant et démoralisant la société, dont j'ai le droit d'attendre aide et secours mutuels. » Cette théorie des « droits sociaux » telle que jamais sans doute on ne l'avait distinctement formulée, se réduit à ceci : tout individu a un droit social absolu d'exiger que tout autre individu agisse en tout exactement comme il le devrait; quiconque manque tant soi peu à son devoir viole mon droit social et m'autorise à demander à la législature réparation de ce grief. Un principe aussi monstrueux est infiniment plus dangereux que tout empiétement isolé sur la liberté: il n'est pas de violation de la liberté qu'il ne puisse justifier. Il ne reconnaît aucun droit à une liberté quelconque, sauf peut-être à celle de nourrir des opinions secrètes sans jamais les révéler, car dès qu'une opinion que je juge nuisible franchit les lèvres de quelqu'un, elle viole tous les « droit sociaux » que m'attribue l'Alliance. Cette doctrine accorde à tous les hommes un droit acquis mutuel sur la perfection morale, intellectuelle et même physique de l'autre, que chaque plaignant peut définir selon son propre critère.

Un autre exemple important d'empiétement illégitime sur la liberté légitime de l'individu, qui n'est pas une simple menace, mais qui a depuis longtemps pris triomphalement effet, est celui de la législation du Sabbat. Sans doute, la coutume de s'abstenir des occupations ordinaires un jour par semaine, autant que le permettent les exigences de la vie, est hautement salutaire, bien que ce ne soit un devoir religieux que pour les Juifs. Et comme cette coutume ne peut être observée sans le consentement général des classes ouvrières - dans la mesure où il suffit que quelques-uns travaillent pour imposer aux autres la même nécessité -, il est peut-être juste d'admettre que la loi garantisse à chacun l'observation générale de la coutume en suspendant un jour donné les principales opérations de l'industrie. Mais cette justification, fondée sur l'intérêt direct qu'ont les autres à ce que chacun observe cet usage, ne s'applique pas à ces occupations privées auxquelles une personne juge bon de consacrer son temps de loisir; par ailleurs, elle ne s'applique pas non plus le moins du monde aux restrictions légales visant les divertissements. Il est vrai que l'amusement des uns est le travail des autres ; mais le plaisir, pour ne pas dire l'utile récréation, d'une majorité de gens vaut bien le travail d'une minorité, pourvu que leur occupation soit choisie librement et puisse être librement abandonnée. Les ouvriers ont parfaitement raison de penser que si tout le monde travaillait le dimanche, on donnerait le travail de sept jours pour le salaire de six; mais tant que la majorité des opérations est suspendue, le 
petit nombre de ceux qui doit continuer de travailler pour le plaisir des autres obtient un surcroît de salaire proportionnel ; et nul n'est obligé de continuer de travailler ainsi s'il préfère le loisir au gain. Si l'on cherche un autre remède, on pourrait le trouver dans l'établissement d'un jour de congé dans la semaine pour cette classe particulière de personnes. Par conséquent, la seule raison qui reste pour justifier les restrictions sur les amusements du dimanche, c'est dire qu'ils sont répréhensibles du point de vue religieux, motif de législation contre lequel on ne saurait protester trop énergiquement. «Deorum injuriae Diis curae. » Il reste à prouver que la société ou l'un de ses fonctionnaires a reçu d'en haut la mission de venger toute offense supposée envers le Tout-puissant, qui ne soit pas aussi un tort infligé à nos semblables. L'idée qu'il est du devoir d'un homme de veiller à ce qu'un autre soit religieux est la cause de toutes les persécutions religieuses jamais perpétrées; et si on l'admettait, elle les justifierait pleinement. Quoique le sentiment qui transparaît dans les fréquentes tentatives d'arrêter le trafic des trains le dimanche, de fermer les musées, etc., n'ait pas la cruauté des anciens persécuteurs, l'état d'esprit qu'elles signalent est fondamentalement le même. C'est une détermination à ne pas tolérer que les autres fassent ce que leur permet leur religion, et cela parce que ce n'est pas permis par la religion du persécuteur. C'est croire que non seulement Dieu déteste l'acte du mécréant, mais qu'il ne nous tiendra pas non plus pour innocents si nous le laissons agir en paix.

Je ne puis m'empêcher d'ajouter à ces preuves du peu de cas qu'on fait généralement de liberté humaine celle du langage de franche persécution qui explose dans la presse de ce pays partout où elle prête attention au phénomène remarquable du mormonisme. On pourrait en dire long sur ce fait inattendu et instructif, qu'une prétendue révélation et une religion reposant sur cette base, fruit d'une imposture palpable, qui n'est pas même soutenue par le prestige des qualités extraordinaires chez son fondateur, soit partagée par des centaines de milliers de personnes et devenue le fondement d'une société dans le siècle des journaux, du chemin de fer et du télégraphe électrique. Ce qui nous concerne ici, c'est que cette religion, comme beaucoup d'autres et de meilleures, ait ses martyrs : que son prophète et son fondateur, à cause de sa doctrine, ait été mis à mort par la populace, que plusieurs de ses partisans aient perdu la vie pour les mêmes violences illégales, que leur secte ait été bannie de leur pays d'origine, et que, maintenant qu'elle est bien isolée au milieu du désert, beaucoup de nos compatriotes déclarent ouvertement qu'il serait juste (mais peu commode) d'envoyer une expédition contre les Mormons et de les contraindre par la force à se conformer aux opinions des autres. L'article de la doctrine mormone qui inspire le plus l'antipathie, laquelle passe outre les barrières ordinaires de la tolérance, est l'autorisation de la polygamie. Bien que celle-ci soit permise aux musulmans, aux Hindous et aux Chinois, elle semble exciter une animosité implacable lorsqu'elle est pratiquée par des gens qui parlent anglais et qui se disent chrétiens. Personne ne désapprouve plus profondément que moi cette institution mormone, pour ces mêmes raisons et aussi parce que, loin d'être comprise dans le principe de liberté, elle constitue une infraction directe à celui-ci, rivant simplement les chaînes d'une moitié de la communauté, et dispensant l'autre moitié de toute réciprocité d'obligation envers la première. Quoi qu'il en soit, il faut rappeler que, de la part des femmes concernées 
qui en paraissent les victimes, cette relation est tout aussi volontaire que dans toute autre forme d'institution matrimoniale. Et aussi surprenant que ce fait puisse paraître, il s'explique par les idées communes et les habitudes du monde: on apprend aux femmes que le mariage est la seule chose nécessaire pour elles ; ce qui explique dès lors que beaucoup d'entre elles préfèrent épouser un homme qui a beaucoup d'autres femmes à ne pas se marier du tout. D'autres pays n'ont pas à reconnaître de telles unions ou à dispenser une partie de leurs citoyens de suivre leurs propres lois en faveur des opinions mormones. Mais quand les dissidents ont concédé aux sentiments hostiles des autres bien plus qu'on ne pouvait en toute justice l'exiger, quand ils ont quitté leur pays où leurs doctrines étaient inacceptables pour s'établir dans un coin perdu de la terre qu'ils ont été les premiers à rendre habitable, il est difficile de voir au nom de quels principes, si ce n'est ceux de la tyrannie, on peut les empêcher d'y vivre à leur guise, pourvu qu'ils n'agressent pas les autres nations et qu'ils laissent toute liberté de partir aux mécontents.

Un écrivain moderne, de grand mérite à certains égards, proposait récemment (pour reprendre ses propres termes) non pas une croisade, mais une civilisade contre cette communauté polygame, et cela pour mettre fin à ce qui lui semblait être un pas en arrière dans la marche de la civilisation. Je vois la chose de même; mais je ne sache pas qu'aucune communauté ait le droit d'en forcer une autre à être civilisée. Tant que les victimes de la mauvaise loi ne demandent pas l'aide des autres communautés, je ne puis admettre que des personnes sans rapport aucun avec elles puissent intervenir et exiger la cessation d'un état de choses qui semble satisfaire toutes les parties intéressées, sous prétexte que c'est un scandale pour des gens vivant à quelques milliers de miles de là, et qui n'y ont aucune part et aucun intérêt. Qu'ils envoient des missionnaires, si bon leur semble, pour prêcher contre elle; et qu'ils opposent au progrès de telles doctrines dans leur propre pays des moyens équitables (or, imposer le silence aux novateurs n'en est pas un). Si la civilisation a vaincu la barbarie quand la barbarie dominait le monde, il est excessif de craindre qu'elle puisse revivre et conquérir la civilisation après avoir été défaite. Pour qu'une civilisation succombe ainsi à son ennemi vaincu, elle doit d'abord avoir dégénéré au point que ni ses prêtres, ni ses maîtres officiels, ni personne n'aient la capacité ou ne veuillent prendre la peine de la défendre. Si tel est le cas, plus vite on se débarrassera d'une telle civilisation, mieux ce sera. Elle ne pourra aller que de mal en pis, jusqu'à ce qu'elle soit détruite et régénérée (comme l'Empire romain d'Occident) par d'énergiques Barbares. 


\section{Chapitre V}

\section{Applications}

Les principes affirmés dans ces pages doivent être plus généralement admis comme base en vue d'une discussion des détails, avant qu'une application systématique puisse être tentée avec quelque chance de succès dans les différents champs de la politique et de la morale. Les quelques observations que je me propose de faire sur des questions de détails visent à illustrer les principes plutôt que d'en déduire les conséquences. Je n'offre pas tant des applications que des échantillons d'applications susceptibles d'éclairer davantage le sens et les limites des deux maximes qui constituent toute la doctrine de cet essai, et d'aider le jugement à maintenir l'équilibre entre elles dans les cas où l'on hésite à appliquer l'une ou l'autre.

Ces maximes sont les suivantes : premièrement, l'individu n'est pas responsable de ses actions envers la société, dans la mesure où elles n'affectent les intérêts de personne d'autre que lui-même. Pour leur propre bien, les autres peuvent avoir recours aux conseils, à l'instruction, à la persuasion et à la mise à l'écart: c'est là la seule façon pour la société d'exprimer légitimement son aversion ou sa désapprobation de la 
conduite d'un individu. Deuxièmement, pour les actions portant préjudice aux intérêts d'autrui, l'individu est responsable et peut être soumis aux punitions sociale et légale, si la société juge l'une ou l'autre nécessaire à sa propre protection.

En premier lieu, il ne faut surtout pas croire que, parce qu'il peut seul la justifier dans certains cas, un risque de dommage aux intérêts d'autrui puisse toujours justifier l'intervention de la société. Dans de nombreux cas, un individu, en poursuivant un but légitime, cause nécessairement et donc légitimement de la peine ou des pertes à d'autres, ou alors il intercepte un bien qu'ils pouvaient raisonnablement espérer obtenir. De telles oppositions d'intérêts entre individus proviennent souvent de mauvaises institutions, mais elles sont inévitables tant que celles-ci perdurent ; et certaines d'entre elles seraient inévitables sous n'importe quelles institutions. Quiconque réussit dans une profession où abondent les concurrents, ou bien à un concours, quiconque est préféré à l'autre dans une lutte pour un objet qu'ils désirent tous deux, celui-là tire profit de l'échec des autres, de la vanité de leurs efforts et de leur déception. Mais on admet communément qu'il vaut mieux dans l'intérêt général de l'humanité que les hommes poursuivent leurs buts sans s'arrêter à ce genre de conséquences. En d'autres termes, la société ne reconnaît aux compétiteurs déçus aucun droit légal ou moral à l'immunité devant ce type de souffrance, et elle ne se sent appelée à intervenir que lorsque les moyens de succès employés sont de ceux que l'intérêt général ne saurait permettre, à savoir: la fraude, la duperie et la violence.

Ainsi le commerce est acte social. Quiconque met en vente quoi que ce soit se lance dans une activité qui affecte les intérêts d'autrui et de la société en général ; et par suite, sa conduite tombe en principe sous la juridiction de la société. C'est pourquoi on estimait autrefois qu'il était du devoir des gouvernements, dans tous les cas importants, de fixer les prix et de réglementer les procédés de fabrication. Mais c'est seulement aujourd'hui, après une longue lutte, qu'on reconnaît que le seul moyen de garantir à la fois des prix bas et des produits de bonne qualité, c'est de laisser les producteurs et les vendeurs parfaitement libres, sans autre contrôle que l'égale liberté pour les acheteurs de se fournir ailleurs. Telle est la doctrine dite de « libre-échange », qui repose sur des bases différentes, mais non moins solides que le principe de liberté individuelle défendu dans cet essai. Les restrictions imposées au commerce ou à la production commerciale sont en effet des contraintes ; et toute contrainte, en tant que contrainte, est un mal. Mais les contraintes en question affectent seulement cet aspect de la conduite humaine que la société a le droit de contraindre, et si elles sont condamnables, c'est uniquement parce qu'elles ne produisent pas vraiment les résultats escomptés. Le principe de la liberté n'étant pas impliqué dans la doctrine du libreéchange, il ne l'est pas davantage dans les questions qui se posent sur les limites de cette doctrine, telles que, par exemple, la part de contrôle public susceptible d'être admise pour empêcher la fraude par falsification des marchandises, ou les précautions sanitaires ou les mesures de protection à imposer pour les ouvriers employés à des travaux dangereux. De telles questions n'impliquent des considérations de liberté que dans la mesure où il vaut toujours mieux laisser les gens livrés à eux-mêmes, caeteris paribus, que de les contrôler; mais il est indéniable qu'en principe, ils peuvent être 
légitimement contrôlés à ces fins. D'autre part, il y a les questions relatives à l'intervention dans le commerce, qui sont essentiellement, elles, des questions de liberté, telles que la loi du Maine mentionnée plus haut, l'interdiction d'importer de l'opium en Chine, la restriction sur la vente des toxiques - bref, tous les cas où le but de l'intervention est de rendre certains produits difficiles ou impossibles à obtenir. Ces interventions sont contestables non pas tant parce qu'elles empiètent sur la liberté du producteur ou du vendeur, mais parce qu'elles empiètent sur la liberté de l'acheteur.

L'un de ces exemples, celui de la vente des toxiques, pose une nouvelle question: celle des justes limites de ce qu'on peut appeler les fonctions de la police. Jusqu'où peut-on légitimement empiéter sur la liberté pour prévenir des crimes ou des accidents ? C'est l'une des fonctions incontestées du gouvernement que de prendre des précautions contre le crime avant qu'il ne soit perpétré, au même titre que de le découvrir et de le punir après coup. Toutefois, il est beaucoup plus aisé d'abuser de la fonction préventive du gouvernement au détriment de la liberté que d'abuser de sa fonction punitive ; car il n'est guère d'aspect de la liberté d'action légitime d'un être humain dont on ne puisse pas dire, et cela honnêtement, qu'il favorise davantage une forme ou une autre de délinquance. Néanmoins, si une autorité publique, ou même une personne privée, voient quelqu'un se préparer évidemment à commettre un crime, rien ne la force à observer sans rien faire et d'attendre que le crime soit commis, mais elle peut intervenir pour l'empêcher. Si l'on n'achetait de poison ou si l'on ne s'en servait jamais que pour empoisonner, il serait juste d'en interdire la fabrication et la vente. On peut cependant en avoir besoin à des fins non seulement inoffensives, mais utiles, et des restrictions ne peuvent être imposées dans un cas sans opérer dans l'autre. De plus, c'est le rôle de l'autorité publique que de prévenir les accidents. Si un fonctionnaire ou quelqu'un d'autre voyait une personne sur le point de traverser un pont reconnu dangereux et qu'il soit trop tard pour la prévenir du risque qu'elle court, il pourrait alors l'empoigner et la faire reculer de force, et cela sans réellement violer sa liberté, car la liberté consiste à faire ce qu'on désire, et cette personne ne désire pas tomber dans la rivière. Néanmoins, quand il n'y a pas de certitude, mais un simple risque de danger, seule la personne elle-même peut juger de la valeur du motif qui la pousse à courir ce risque. Dans ce cas, par conséquent (à moins qu'il ne s'agisse d'un enfant, d'une personne délirante ou dans un état d'excitation ou de distraction l'empêchant de réfléchir normalement), on devrait se contenter, selon moi, de l'avertir du danger et ne pas l'empêcher par la force de s'y exposer. De telles considérations, appliquées à une question comme la vente des toxiques, peuvent nous aider à décider lequel des divers modes de régulation possibles est contraire ou non au principe. Par exemple, on peut imposer sans violation de liberté une précaution telle que d'étiqueter la drogue de façon à en spécifier le caractère dangereux: l'acheteur ne peut désirer ignorer les qualités toxiques du produit qu'il achète. Mais exiger dans tous les cas le certificat d'un médecin, rendrait parfois impossible et toujours chère l'obtention de l'article pour des usages légitimes. Selon moi, le seul moyen de prévenir les empoisonnements, et cela sans violer la liberté de ceux qui ont besoin de substances toxiques dans d'autres buts, consiste à fournir ce que Bentham appelle fort justement une « preuve préalable ». Rien n'est plus commun dans les contrats. Il est courant et 
justifié, lorsqu'on conclut un contrat, que la loi requiert, comme condition de sa valeur légale, l'observance de certaines formalités telles que les signatures, l'attestation des témoins, etc., afin qu'en cas de dispute ultérieure, on puisse avoir la preuve que le contrat a été réellement conclu, et que rien dans les circonstances ne l'invalidait. L'effet de ce dispositif est de mettre de grands obstacles aux contrats fictifs, ou aux contrats faits dans des conditions qui, si elles étaient connues, les rendraient caducs. On pourrait imposer semblables précautions sur la vente des articles propres à servir d'instruments criminels. Par exemple, on pourrait exiger du vendeur qu'il inscrivît dans un registre la date exacte de la vente, le nom et l'adresse de l'acheteur, la qualité et la quantité précises vendues, ainsi que l'usage prévu de l'objet. Quand il n'y a pas de prescription médicale, on pourrait exiger la présence d'un tiers afin de prouver le fait contre l'acheteur s'il s'avérait par la suite que l'article ait été utilisé à des fins criminelles. De tels règlements ne constitueraient en général aucun obstacle matériel à l'obtention de l'article, mais un obstacle très considérable à en faire un usage illicite sans être découvert.

Le droit inhérent à la société d'opposer aux crimes qui la visent des mesures préventives, suggère les limites évidentes de cette idée que la mauvaise conduite purement privée n'offre pas matière à prévention ou à punition. L'ivresse, par exemple, n'est pas ordinairement un sujet normal d'intervention législative ; mais je trouverais parfaitement légitime qu'on impose une restriction spéciale, personnelle à un homme convaincu de quelque violence envers autrui sous l'influence de la boisson, et telle que si on le trouve ivre ensuite, il soit passible d'une amende, et que s'il commet un nouveau délit dans cet état, la punition reçue soit plus sévère. S'enivrer, pour une personne que l'ivresse pousse à nuire à autrui, est un crime envers les autres. De même l'oisiveté - sauf si la personne est à la charge du public, ou si son oisiveté constitue une rupture de contrat - ne peut sans tyrannie faire l'objet de punitions légales. Mais si par oisiveté, ou par une autre raison facilement évitable, un homme manque à ses devoirs légaux envers autrui, comme d'entretenir ses enfants, ce n'est pas un acte de tyrannie que le forcer à remplir ses obligations en travaillant si on ne trouve pas d'autres moyens.

En outre, il y a beaucoup d'actes directement dommageables à leurs auteurs qui ne devraient pas être légalement interdits, mais qui, commis en publie, deviennent une violation des bonnes mœurs sociales, tombent ainsi dans la catégorie des offenses envers autrui et peuvent être justement interdits. C'est le cas des atteintes à la décence, sur lesquelles il est inutile de s'appesantir, d'autant moins qu'elles n'ont qu'un rapport indirect avec notre sujet, puisqu'on peut objecter à la publicité d'un acte, même si celui-ci n'est blâmable en lui-même pour personne.

Il y a une autre question à laquelle il faut trouver une réponse en accord avec les principes posés ici. Dans les cas de conduite personnelle tenus pour blâmables, mais que le respect de la liberté empêche de prévenir ou de punir, parce qu'alors le mal qui en résulte retombe entièrement sur l'agent - doit-on avoir la même liberté de conseiller ou d'inciter à faire ce que fait librement l'agent ? La question n'est pas sans 
difficulté. Le cas d'une personne qui en incite une autre à accomplir un acte n'est pas strictement un cas de conduite personnelle. Prodiguer des conseils à quelqu'un ou le pousser à agir est un acte social et peut par conséquent, comme toute action qui affecte autrui en général, être estimé soumis au contrôle social. Mais un peu de réflexion corrige cette première impression en montrant que, si le cas n'entre pas strictement dans la définition de la liberté individuelle, on peut néanmoins lui appliquer les raisons sur lesquelles se fonde le principe de la liberté. Si l'on doit permettre aux gens, dans ce qui les concerne seuls, d'agir comme bon leur semble à leurs risques et périls, c'est qu'ils doivent également être libres de se consulter l'un l'autre sur ce qu'il convient de faire, d'échanger des opinions ainsi que de donner et recevoir des suggestions. Il faut pouvoir conseiller tout ce qu'il est permis de faire. Mais la question devient douteuse lorsque l'instigateur tire un profit personnel de son conseil, lorsqu'il en fait métier pour vivre ou s'enrichir, pour promouvoir ce que la société et l'État considèrent comme un mal. Alors, effectivement, un élément de complication intervient, à savoir l'existence d'une classe de personnes dont l'intérêt est contraire à ce qui est considéré comme le bien public, et dont le mode de vie est basé sur l'opposition à ce bien. Est-ce ou non un cas d'intervention ? Ainsi la fornication et le jeu doivent être tolérés : mais est-on libre pour autant d'être souteneur ou tenancier d'une maison de jeu ? Le cas est un de ceux qui se situent à la frontière des deux principes, et l'on ne voit pas immédiatement duquel des deux il dépend. il y a des arguments de part et d'autre. Du côté de la tolérance, on peut dire qu'il ne peut pas être criminel de choisir pour métier, pour en vivre et s'enrichir, une activité qui serait admissible autrement ; que cet acte devrait être soit toujours permis, soit toujours interdit; que si les principes que nous avons défendus jusqu'ici sont vrais, la société, en tant que société, n'a pas à déclarer mauvais ce qui ne concerne que l'individu; qu'elle ne peut aller au-delà de la dissuasion; et qu'enfin une personne devrait être aussi libre de persuader qu'une autre de dissuader. En opposition à cela, on peut défendre l'idée que - quoique le public ou l'État ne puisse décider de manière autoritaire, en vue de réprimer ou de punir, que telle ou telle conduite purement personnelle est bonne ou mauvaise - ils sont parfaitement en droit de supposer que, s'ils jugent mauvais certains actes, alors le fait qu'ils le soient ou non est ouvert à la discussion ; ceci étant admis, le public et l'État ne peuvent faire mal en s'efforçant d'éliminer l'influence de sollicitations qui ne sont pas désintéressées, d'instigateurs qui ne sauraient être impartiaux, qui ont un intérêt personnel direct orienté d'un côté (le mauvais du point de vue de l'État), et qui avouent le promouvoir à des fins personnelles uniquement. On pourra avancer que rien ne sera perdu assurément, qu'aucun bien ne sera sacrifié, si l'on fait en sorte que les gens fassent spontanément leur choix, sagement ou sottement, mais autant que possible à l'abri des artifices de ceux qui stimulent leurs inclinations par intérêt personnel. Alors, dira-t-on, bien que le statut des jeux illicites soit absolument indéfendable - bien que tout le monde doive être libre de jouer chez soi, chez les autres, ou dans un lieu de rencontre fonctionnant sur cotisation et accessible aux seuls membres et à leurs invités -néanmoins, les maisons de jeu publiques ne devraient pas être autorisées. Il est vrai que l'interdiction n'est jamais efficace, et que, aussi tyrannique que soit la police, les maisons de jeu parviennent toujours à se maintenir sous d'autres prétextes ; mais on peut les contraindre à entourer leurs 
affaires d'un certain degré de secret et de mystère, afin que personne ne les connaisse, hormis ceux qui les recherchent ; et la société devrait se contenter de ce résultat. Ces arguments ont une force considérable. Je ne me risquerai pas à décider s'ils sont suffisants pour justifier l'anomalie morale consistant à punir le complice, quand l'instigateur est laissé en liberté (et qu'on doit le laisser libre), à mettre à l'amende ou en prison le souteneur, mais non le fornicateur -le tenancier de la maison de jeu, mais non le joueur. Et de tels motifs devraient encore moins entrer en ligne de compte dans les transactions commerciales courantes. Tout article acheté ou vendu peut donner lieu à des excès que les vendeurs ont un intérêt pécuniaire à encourager. Mais ce fait ne peut supporter aucun argument en faveur de la loi du Maine, par exemple, et cela parce que les marchands de boissons alcoolisées, malgré leur intérêt à ce qu'on en abuse, restent indispensables pour l'usage légitime de ces boissons. Cependant, l'intérêt de ces commerçants à favoriser l'intempérance est un mal réel qui justifie l'imposition de restrictions par l'État, ainsi que l'exigence de garanties qui, sans cette justification, seraient des violations de la liberté légitime.

Ce qui fait encore question, c'est de savoir si l'État, tout en tolérant une conduite qu'il estime contraire aux intérêts les plus précieux de l'agent, ne devrait pas néanmoins la décourager indirectement. Ne devrait-il pas lutter contre l'ivresse, par exemple, en augmentant le prix des alcools ou en limitant le nombre des points de vente pour qu'il soit plus difficile de s'en procurer ? Ici, comme dans la plupart des questions pratiques, il y a une foule de distinctions à faire. Taxer les alcools, dans le seul but de rendre leur obtention plus difficile, est une mesure qui diffère fort peu de leur interdiction totale, et qui ne se justifierait que si elle était justifiable. Toute augmentation est une interdiction pour ceux qui ne peuvent payer le nouveau prix; et pour ceux qui ont les moyens, c'est une façon de pénaliser leur volonté de satisfaire un goût particulier. Le choix de leurs plaisirs et leur manière de dépenser leurs revenus une fois qu'ils ont rempli leurs obligations légales et morales envers l'État et les individus, ne regardent qu'eux-mêmes et ne doivent dépendre que de leur seul jugement. À première vue, ces considérations semblent condamner le choix des alcools en tant que source particulière de revenus fiscaux. Mais il faut rappeler que la taxation à cette fin est absolument inévitable, que dans nombre de pays, cet impôt oit être en grande partie indirect, et que par conséquent l'État ne peut pas éviter de pénaliser l'usage de certains articles de consommation par des taxes qui, pour certains, peuvent être prohibitives. Il est donc du devoir de l'État de considérer, avant d'imposer des taxes, quelles sont les denrées dont les consommateurs peuvent le mieux se passer et, a fortiori, de choisir de préférence celles qui, selon lui, peuvent devenir nuisibles audelà d'une quantité très modérée. C'est pourquoi on peut admettre autant qu'approuver que les alcools fassent l'objet de l'imposition maximum (à supposer que l'État ait besoin de tous les revenus ainsi obtenus).

La question de savoir s'il faut faire de la vente de ces denrées un privilège plus ou moins exclusif, doit être résolue différemment selon les motifs auxquels est subordonnée la restriction. Dans tous les lieux publics, il faut la contrainte d'une police, et particulièrement dans les lieux de ce genre qui deviennent facilement le théâtre de 
délits contre la société. Il est donc opportun de limiter le droit de vente de ces marchandises (du moins pour la consommation sur place) à des personnes dont la respectabilité est connue ou garantie ; on doit, en outre, réglementer les heures d'ouverture et de fermeture en fonction des exigences de la surveillance publique, et retirer sa licence au tenancier si des troubles se produisent à plusieurs reprises avec sa complicité ou à cause de son incapacité, ou si son établissement devient un lieu de rendezvous pour comploter et préparer des infractions à la loi. Je ne vois pas d'autre restriction justifiable en principe. Par exemple, la limitation du nombre des brasseries et des débits de boisson dans le but express d'en diminuer les tentations, est non seulement un inconvénient pour tout le monde, sous prétexte que certains abuseraient de cette facilité, mais encore une mesure qui ne convient qu'à un état de société dans lequel les classes ouvrières sont traitées ouvertement comme des enfants ou des sauvages, et soumises à une éducation contraignante afin de préparer leur future admission aux privilèges de la liberté. Tel n'est pas le principe selon lequel les classes ouvrières sont gouvernées dans un pays libre, et quiconque estime la liberté à sa juste valeur ne consentira jamais à ce qu'elles soient gouvernées ainsi, à moins qu'après avoir tout fait pour les initier à la liberté et les gouverner comme des hommes libres, il s'avère en fin de compte qu'ils ne peuvent être gouvernés que comme des enfants. Le simple énoncé de l'alternative montre combien il est absurde de supposer que de tels efforts aient été faits dans tous les cas qui nous intéressent ici. C'est seulement parce que les institutions de ce pays forment un tissu de contradictions qu'on voit mettre en pratique des mesures propres au système despotique ou paternaliste, comme on l'appelle, tandis que la liberté générale de nos institutions ne permet pas d'exercer le contrôle nécessaire pour imposer la contrainte comme système moral.

Nous avons signalé dans un chapitre précédent de cet essai que la liberté de l'individu dans les choses qui ne concernent que lui implique une liberté correspondante pour un groupe d'individus de régler par consentement mutuel les choses qui les concernent ensemble et ne regardent personne d'autre. La question ne présente aucune difficulté tant que la volonté des personnes intéressées ne change pas ; mais comme elle peut changer, il est souvent nécessaire, même dans les choses où elles sont seules concernées, qu'elles prennent des engagements mutuels; et quand elles le font, il convient en règle générale que ces engagements soient tenus. Pourtant, il est probable que dans les lois de tous les pays, cette règle générale connaisse des exceptions. Non seulement les gens ne sont pas tenus de respecter des engagements qui violent les droits d'un tiers, mais on estime parfois qu'il suffit qu'un engagement leur soit dommageable à eux-mêmes pour les en dégager. Par exemple, dans ce pays et dans la plupart des pays civilisés, un engagement par lequel quelqu'un se vendrait ou consentirait à être vendu comme esclave serait nul et sans valeur sans appui de la loi ou de l'opinion. Le motif pour limiter ainsi le pouvoir d'un individu sur lui-même est évident, et on le perçoit très clairement dans ce cas extrême. La raison de ne pas intervenir (à moins que d'autres ne soient menacés) dans les actes volontaires d'une personne, c'est le respect pour sa liberté. Le choix volontaire d'un homme est la preuve que ce qu'il choisit ainsi est désirable, ou du moins supportable pour lui, et en fin de compte, on ne peut mieux pourvoir à son bien qu'en lui permettant de choisir 
ses propres moyens pour l'atteindre. Mais en se vendant comme esclave, un homme abdique sa liberté; après cet acte unique, il renonce à tout usage futur de sa liberté. Il détruit donc dans son propre cas le but même qui justifie la permission de disposer de lui-même. Il n'est plus libre, mais il est désormais dans une position telle qu'on ne peut plus présumer qu'il ait délibérément choisi d'y rester. Le principe de liberté ne peut exiger qu'il soit libre de n'être pas libre. Ce n'est pas la liberté que d'avoir la permission d'aliéner sa liberté. Ces raisons, dont la force est évidente dans ces cas particuliers, ont naturellement une application bien plus large ; cependant les nécessités de la vie leur imposent constamment des limites, car il nous faut toujours, non pas renoncer à notre liberté, mais consentir à la limiter d'une façon ou d'une autre. Toutefois, le principe qui requiert la liberté d'action la plus complète pour tout ce qui ne concerne que les agents, exige que ceux qui, liés l'un à l'autre pour des choses qui ne concernent aucun tiers parti, puissent se dégager de leur engagement. Et même sans cette libération volontaire, il n'y a peut-être aucun contrat, excepté un engagement financier, dont on puisse oser dire qu'on ne devrait jamais être libre de s'en rétracter. Le baron Wilhelm von Humboldt, dans l'excellent essai que j'ai déjà cité, affirme que selon lui, les engagements qui impliquent des relations ou des services personnels ne devraient jamais lier légalement au-delà d'un temps limité, et que le plus important de ces engagements, le mariage - dont la particularité est de manquer son but dès lors que les sentiments des deux partis ne s'accordent pas avec celui-ci devrait pouvoir être dissout par la simple volonté déclarée d'un des partenaires. Ce sujet est trop important et trop compliqué pour être discuté entre parenthèses, et je ne fais que l'effleurer à des fins d'illustration. Si la concision et la généralité de l'essai de Humboldt ne l'avaient pas obligé à se contenter d'énoncer sa conclusion sans en discuter les prémisses, nul doute qu'il eût reconnu qu'on ne peut trancher cette question sur des principes aussi simples que ceux auxquels il se confine. Quand quelqu'un, soit par une promesse expresse, soit par -sa conduite, en a encouragé une autre à compter qu'elle agira d'une certaine façon - à fonder des espérances, 4 faire des prévisions et à hasarder une part de sa vie sur cette supposition -, celui-ci s'est créé envers l'autre une nouvelle série d'obligations morales, lesquelles peuvent éventuellement être annulées, mais non pas ignorées. En outre, si la relation entre les deux parties contractantes a été suivie de conséquences pour d'autres - si elle a placé un tiers dans une position particulière, ou si comme dans le mariage, elle a donné naissance à des tiers -, les deux parties contractantes se sont créé des obligations envers ceux-ci, dont l'accomplissement sera grandement affecté par la continuation ou la rupture de la relation entre les parties originales du contrat. Il ne s'ensuit pas - et je ne saurais l'admettre que ces obligations aillent jusqu'à exiger l'accomplissement du contrat au prix du bonheur de la partie réticente ; mais elles sont un élément nécessaire de la question ; et même si, comme Humboldt le soutient, elles ne doivent faire aucune différence dans la liberté légale qu'ont les parties de se défaire de l'engagement (et je prétends qu'elles ne devraient pas en faire beaucoup), ces obligations font nécessairement une grande différence en ce qui concerne la liberté morale. L'individu doit tenir compte de toutes ces circonstances avant de se résoudre à franchir un pas qui peut tant affecter les intérêts d'autrui ; et s'il n'accorde pas la considération voulue à celles-ci, il est moralement responsable du tort causé. J'ai fait ces remarques évidentes afin de 
mieux illustrer le principe général de la liberté, et non parce qu'elles en disent davantage sur cette question qui, au contraire, est toujours discutée comme si l'intérêt des enfants était tout, et celui des adultes, rien.

J'ai déjà pu observer qu'à cause de l'absence de principes généraux reconnus, la liberté est souvent accordée là où elle devrait être refusée, et refusée là où elle devrait être accordée ; et l'un des cas où le sentiment de liberté est le plus fort dans le monde européen moderne, est de ceux où, selon moi, il est totalement déplacé. Une personne devrait être libre de mener ses propres affaires à son gré ; mais elle ne devrait pas être libre de faire ce qu'elle veut lorsqu'elle agit pour un autre, sous prétexte que ses affaires sont aussi les siennes. Tout en respectant la liberté de chacun dans ce qui le concerne prioritairement l'État est obligé de surveiller de près la façon dont l'individu use du pouvoir qu'on lui a octroyé sur d'autres. Cette obligation est presqu'entièrement négligée dans le cas des relations familiales - cas qui, par son influence directe sur le bonheur humain est plus important que tous les autres pris ensemble. Point n'est besoin de s'étendre ici sur le pouvoir à peu près despotique des maris sur les femmes, parce qu'il ne faudrait rien moins, pour extirper ce mal, qu'accorder aux femmes les mêmes droits et la même protection légale qu'à tout autre personne, et puis parce que, sur ce sujet, les défenseurs de l'injustice régnante ne se prévalent pas de l'excuse de la liberté, mais se posent ouvertement comme des champions du pouvoir. C'est dans le cas des enfants que le mauvais usage de l'idée de liberté empêche réellement l'État de remplir ses devoirs. On croirait presque que les enfants font littéralement partie d'un homme (et ce n'est pas seulement une métaphore), tant l'opinion est jalouse de la moindre intervention de la loi dans le contrôle absolu qu'il exerce sur eux, plus jalouse encore que du moindre empiétement sur sa liberté d'action privée, tant il est vrai que l'humanité attache généralement plus de prix au pouvoir qu'à la liberté. Prenons l'exemple de l'éducation. N'est-il pas axiomatique que l'État doive exiger et imposer l'éducation de ses jeunes citoyens, au moins jusqu'à un certain niveau ? Pourtant qui ne craint pas de reconnaître et de défendre cette vérité ? Presque personne ne niera en effet que l'un des devoirs les plus sacrés des parents (ou plutôt, selon la loi et l'usage, du père), c'est de donner à l'être humain qu'ils ont mis au monde une éducation qui lui permette de bien tenir son rôle dans la vie tant envers les autres qu'envers lui-même. Mais, tandis que l'on déclare unanimement que tel est le devoir du père, presque personne dans ce pays ne supportera l'idée qu'on l'oblige à remplir ce devoir. Au lieu d'exiger d'un homme qu'il fasse des efforts et des sacrifices pour assurer l'éducation de son enfant, on le laisse libre de refuser ou d'accepter cette éducation offerte gratuitement ! On ne reconnaît toujours pas que mettre un enfant au monde sans être certain de pouvoir lui fournir non seulement la nourriture nécessaire à son corps, mais encore l'instruction et l'exercice nécessaires à son esprit, on ne reconnaît pas que cela est un crime à la fois envers le malheureux rejeton et envers la société, et que si les parents ne satisfont pas à cette obligation, c'est l'État qui devrait veiller à ce qu'il en soit pourvu, et cela autant que possible à la charge des parents.

Si l'on admettait un jour le devoir d'imposer l'éducation universelle, il n'y aurait plus de difficultés quant à ce que l'État doit enseigner et sur la façon de l'enseigner - 
difficultés qui, pour le moment, constituent un véritable champ de bataille pour les sectes et les partis ; c'est ainsi qu'on perd du temps et de l'énergie à se quereller autour de l'éducation, au lieu de s'y consacrer. Si le gouvernement prenait la décision d'exiger une bonne éducation pour tous les enfants, il s'éviterait la peine de leur en fournir une. Il pourrait laisser aux parents le soin de faire éduquer leurs enfants où et comme ils le souhaitent, suivant les besoins de chacun, et se contenter de payer une partie des frais de scolarité des enfants les plus pauvres et de s'en charger complètement pour ceux qui n'ont personne d'autre pour y pourvoir. Les objections qu'on oppose avec raison à l'éducation publique ne portent pas sur le fait que l'État impose l'éducation, mais sur ce qu'il se charge de la diriger, ce qui est tout différent. Je réprouve autant que quiconque l'idée de laisser partiellement ou totalement l'éducation aux mains de l'État. Tout ce que j'ai dit de l'importance de l'individualité du caractère, ainsi que de la diversité des opinions et des modes de vie, implique tout autant la diversité de l'éducation. Une éducation générale dispensée par l'État ne peut être qu'un dispositif visant à fabriquer des gens sur le même modèle; et comme le moule dans lequel on les coulerait serait celui qui satisfait le pouvoir dominant au sein du gouvernement - prêtres, aristocratie ou majorité de la génération actuelle -, plus cette éducation serait efficace, plus elle établirait un despotisme sur l'esprit, qui ne manquerait pas de gagner le corps. Une éducation instituée et contrôlée par l'État ne devrait figurer tout au plus qu'à titre d'expérience parmi d'autres, qu'à titre d'exemple et de stimulant propre à maintenir les autres expériences à un bon niveau. À moins, bien sûr, que la société soit dans son ensemble si arriérée qu'elle ne puisse ou ne veuille se donner des institutions scolaires convenables sans que le gouvernement ne s'en charge. Dans ce cas seulement, pour choisir le moindre de ces deux grands maux, le gouvernement pourrait alors se charger des écoles et des universités, comme de constituer des sociétés par action dans un pays où les entreprises privées ne sont pas de taille à entreprendre de grands travaux industriels. Mais en général, si le pays dispose d'assez de personnes qualifiées pour enseigner sous les auspices du gouvernement, ces mêmes personnes pourraient tout autant enseigner dans un système privé, puisque leur rémunération serait garantie par une loi rendant l'éducation obligatoire, doublée d'une aide de ]'État destinée à ceux qui seraient incapables de prendre la dépense à leur charge.

Le seul moyen de faire respecter la loi serait d'imposer des examens publics à tous les enfants dès le plus jeune âge. On pourrait fixer un âge auquel tout enfant serait examiné pour vérifier qu'il (ou elle) sait lire. Si un enfant s'en montrait incapable, le père, à moins d'une excuse valable, pourrait recevoir une amende modérée, à acquitter au besoin sur son salaire, et l'enfant pourrait alors être envoyé à l'école à ses frais. L'examen pourrait avoir lieu une fois par an, sur un éventail de matières toujours plus large, afin de rendre obligatoire l'acquisition et (surtout) la mémorisation d'un minimum de connaissances générales. Au-delà de ce minimum, on instaurerait des examens facultatifs dans toutes les matières, en vertu desquels tous ceux qui seraient parvenus à un certain niveau de compétence auraient droit à un certificat. Pour empêcher l'État d'exercer ainsi trop d'influence sur l'opinion, la connaissance exigée pour passer un examen, même de haut niveau (au-delà des domaines purement instrumen- 
taux du savoir tels que les langues et leur pratique), on devrait se limiter exclusivement aux faits et à la science positive. Les examens sur la religion, la politique ou tout autre matière controversée ne porteraient pas sur la vérité ou la fausseté des opinions, mais sur le fait que telle ou telle opinion est défendue par tels arguments, par tels auteurs, écoles ou églises. Grâce à ce système, la génération montante ne serait pas plus mal pourvue qu'aujourd'hui face aux vérités controversées : les jeunes se rangeraient toujours parmi les anglicans ou parmi les membres d'une autre secte ; seulement, l'État veillerait à ce que dans les deux cas, ils fussent instruits. Rien n'empêcherait de leur enseigner la religion avec l'accord des parents, dans les écoles mêmes où ils reçoivent le reste de leur éducation. Toutes les tentatives de l'État pour fausser les conclusions de ses citoyens sur les questions controversées sont mauvaises ; mais l'État peut parfaitement proposer de garantir et de certifier qu'une personne possède le savoir requis pour tirer elle-même des conclusions dignes d'intérêt. Un étudiant en philosophie gagnerait à pouvoir passer un examen portant à la fois sur Locke et Kant, quel que soit celui qu'il préfère, et même s'il n'adhère à aucun des deux ; et il n'y a raisonnablement rien à redire à ce qu'on examine un athée sur les preuves du christianisme, pourvu qu'on ne l'oblige pas d'en faire profession de foi. Toutefois, il me semble que les examens dans les domaines supérieurs de la connaissance devraient être entièrement facultatifs. Ce serait accorder un pouvoir trop dangereux aux gouvernements que de leur permettre d'exclure qui bon leur semble de certaines professions - même de l'enseignement - sous prétexte d'un manque de qualifications. Et je pense avec Wilhelm von Humboldt que les grades ou les certificats publics de connaissances scientifiques ou professionnelles devraient être accordés à tous ceux qui se présentent à l'examen et le réussissent, mais qu'ils ne devraient donner sur les autres concurrents aucun autre avantage que la valeur qu'attache l'opinion publique à leur témoignage. Ce n'est pas dans le seul domaine de l'éducation que des idées de liberté mal utilisées occultent les obligations morales des parents et l'imposition d'obligations légales quand on aurait toujours les meilleures raisons de le faire. Le fait même de donner naissance à un être humain est l'une des actions qui entraîne le plus de responsabilités dans la vie. Prendre cette responsabilité - donner une vie qui peut s'avérer une bénédiction ou une malédiction - est un crime envers l'être à qui on la donne s'il n'a pas les chances ordinaires de mener une vie désirable. Et dans un pays trop peuplé ou en voie de le devenir, mettre au monde trop d'enfants, dévaluer ainsi le prix du travail par leur entrée en compétition, c'est faire grand tort à tous ceux qui vivent de leur travail. Ces lois qui, dans nombre de pays du Continent, interdisent le mariage aux couples qui ne peuvent pas prouver qu'ils ont les moyens de nourrir une famille, n'outrepassent pas le pouvoir légitime de l'État ; et par ailleurs, que de telles lois soient ou non bienvenues (question qui dépend principalement des circonstances et des sentiments locaux), on ne peut leur reprocher d'être des violations de la liberté. C'est grâce à de telles lois que l'État peut prévenir un acte funeste un acte dommageable pour autrui - qu'il faut soumettre à la réprobation ou au blâme social, même si l'on juge inopportun de le doubler d'une punition légale. Pourtant, les idées courantes de liberté, lesquelles se prêtent si aisément aux violations réelles de la liberté de l'individu dans les affaires qui ne concernent que lui, résisteraient presque à toute tentative de restreindre tant soi peu ses inclinations, et cela même lorsque leur 
satisfaction condamne sa progéniture à une vie de misère et de dépravation et cause à leur entourage de nombreuses souffrances. Si l'on compare ce mélange d'étrange respect et d'irrespect de l'humanité envers la liberté, on croirait presque que les hommes ont nécessairement le droit de nuire aux autres, et aucun droit de se satisfaire sans faire souffrir quelqu'un.

J'ai réservé pour la fin toute une série de questions sur les limites de l'intervention du gouvernement qui, quoiqu'étroitement liées au sujet de cet essai, n'en font pas rigoureusement partie. Ce sont les cas où les raisons contre cette intervention ne se fondent pas sur le principe de liberté ; la question ne porte plus sur la restriction des actions des individus, mais sur leur encouragement: on se demande si le gouvernement devrait faire ou donner les moyens de faire quelque chose pour leur bien, au lieu de les laisser s'en occuper individuellement ou en s'associant.

Les objections contre l'intervention du gouvernement, quand elle n'implique pas une violation de la liberté, peuvent être de trois sortes.

La première s'applique quand la chose à faire est susceptible d'être mieux faite par les individus que par le gouvernement. En général, personne n'est mieux à même de diriger une affaire, ou de décider par qui ou comment elle doit être conduite, que ceux qui y sont personnellement intéressés. Ce principe condamne les interventions, autrefois si fréquentes, des législateurs ou des fonctionnaires dans les opérations ordinaires de l'industrie. Mais cette aspect du sujet a été suffisamment développé par les économistes politiques et n'est pas particulièrement lié aux principes de cet essai.

La seconde objection se rattache plus étroitement à notre sujet. Dans de nombreux cas, bien que la moyenne des individus ne puissent pas faire certaines choses aussi bien que les fonctionnaires, il est néanmoins souhaitable que ce soit eux qui les fassent, et non pas le gouvernement, afin de contribuer à leur éducation intellectuelle, de fortifier leurs facultés actives, d'exercer leur jugement et de les familiariser avec les sujets dont on les laisse ainsi s'occuper. C'est là la principale, mais non l'unique recommandation du jugement par jury (pour les cas non politiques) des institutions libres et populaires à l'échelon local et municipal, d'entreprises industrielles et philanthropiques par des associations volontaires. Ce ne sont pas là des questions de liberté, et elles ne se rapportent que de loin à ce sujet ; mais ce sont davantage des questions de développement. Il ne nous appartient pas ici de nous étendre sur l'utilité de toutes ces choses en tant qu'aspects de l'éducation de la nation, puisqu'elles font partie en vérité de l'éducation particulière du citoyen, la partie pratique de l'éducation politique d'un peuple libre. Elles tirent l'homme du cercle étroit de l'égoïsme personnel et familial pour le familiariser avec les intérêts communs et la direction des affaires communes ; elles l'habituent à agir sur des motifs publics et semi-publics, et à orienter sa conduite à des fins qui le rapprochent des autres au lieu de l'en isoler. Sans ces habitudes et ces facultés, une constitution libre ne peut ni fonctionner ni se perpétuer, comme le montre trop souvent la nature transitoire de la liberté politique dans les pays où elle ne se fonde pas sur une base assez solide de libertés locales. La direction 
des affaires purement locales par les localités, et celle des grandes entreprises industrielles par l'union de ceux qui les financent volontairement se recommandent en outre par tous les avantages qui, comme nous l'avons montré dans cet essai, sont inhérents au développement individuel et à la diversité des façons d'agir. Les opérations du gouvernement tendent à être partout les mêmes. En revanche, les individus et les associations volontaires produisent une immense et constante variété de tentatives et d'expériences. Ce que l'État peut faire utilement, c'est de faire office de dépositaire et diffuseur actif des expériences résultant des nombreux essais. Sa tâche est de permettre à tout expérimentateur de bénéficier des expériences d'autrui, au lieu de ne tolérer que les siennes.

La dernière et la plus forte raison de restreindre l'intervention du gouvernement est le mal extrême que cause l'élargissement sans nécessité de son pouvoir. Toute fonction ajoutée à celle qu'exerce déjà le gouvernement diffuse plus largement son influence sur les espoirs et les craintes, et transforme davantage les éléments actifs et ambitieux du public en parasites ou en comploteurs. Si les routes, les chemins de fer, les banques, les compagnies d'assurances, les grandes compagnies à capital social, les universités et les établissements de bienfaisance étaient autant de branches du gouvernement; si, de plus, les corporations municipales et les conseils locaux, avec tout ce qui leur incombe aujourd'hui, devenaient autant de départements de l'administration centrale; si les employés de toutes ces diverses entreprises étaient nommés et payés par le gouvernement et n'attendaient que de lui leur avancement, toute la liberté de la presse et toute la constitution démocratique n'empêcheraient pas ce pays ni aucun autre de n'être libre que de nom. Et le mal serait d'autant plus grand que la machine administrative serait construite plus efficacement et savamment, et qu'on aurait recours aux procédés les plus habiles pour se procurer les mains et les cerveaux les plus qualifiés pour la faire fonctionner. En Angleterre, on a proposé dernièrement de sélectionner tous les membres de l'administration gouvernementale sur concours, afin de placer à ces postes les personnes les plus intelligentes et les plus instruites parmi les candidats; et on a beaucoup dit et écrit pour et contre cette proposition. L'un des arguments sur lesquels ses adversaires ont le plus insisté, c'est que l'emploi de fonctionnaire permanent de l'État n'offre pas de perspective de recevoir une rémunération suffisante et de jouer un rôle assez important pour attirer les meilleurs talents, lesquels trouveront toujours des carrières plus attrayantes dans les professions libérales, au service de compagnies ou d'autres corps publics. On n'aurait pas été surpris que cet argument vÎnt de partisans de la proposition comme une réponse à sa difficulté principale. Venant de ses adversaires, elle est pour le moins curieuse. Ce qu'on avance comme une objection est la soupape de sécurité du système en question. Car si tous les meilleurs talents du pays pouvaient être attirés au service du gouvernement, une proposition visant à ce résultat aurait assurément de quoi inquiéter. Si toutes les affaires de la société qui nécessitent une organisation concertée, ou des vues larges et englobantes, étaient entre les mains de l'État, et si toutes les fonctions gouvernementales étaient universellement remplies par les hommes les plus capables, alors toute la culture au sens large, toute l'intelligence pratique du pays (à l'exception de l'intelligence purement spéculative), seraient concentrées en une bureaucratie nombreuse, 
bureaucratie dont le reste de la communauté attendrait tout: les conseils et les ordres pour les masses, l'avancement personnel pour les intelligents et les ambitieux. Être admis dans les rangs de cette bureaucratie, et en gravir les échelons une fois admis, tels seraient les seuls objets d'ambition. Sous ce régime, non seulement le public extérieur est mal qualifié par manque d'expérience pratique pour contrôler et critiquer, le système bureaucratique, mais, même si les hasards du fonctionnement naturel d'institutions despotiques ou démocratiques portent au sommet un ou plusieurs dirigeants réformateurs, aucune réforme contraire aux intérêts de la bureaucratie ne peut être adoptée. Telle est la triste condition de l'empire russe, comme le montrent les compte rendus de ceux qui ont pu l'observer. Le Tsar lui-même est impuissant contre le corps bureaucratique; il peut envoyer chacun de ses membres en Sibérie, mais il ne peut gouverner sans eux ni contre leur volonté. Ils peuvent mettre un veto tacite sur tous les décrets, simplement en s'abstenant de les appliquer. Dans des pays d'une civilisation plus avancée et d'un esprit plus insurrectionnel, les gens, habitués à attendre que l'État fasse tout pour eux - ou du moins à ne rien faire par eux-mêmes sans que l'État leur en ait non seulement accordé la permission, mais indiqué la marche à suivre -, ces gens tiennent naturellement l'État pour responsable de tout ce qui leur arrive de fâcheux, et lorsque les maux excèdent leur patience, ils se soulèvent contre le gouvernement et font ce qu'on appelle une révolution; après quoi, quelqu'un d'autre, avec ou sans l'autorité légitime de la nation, saute sur le trône, donne ses ordres à la bureaucratie, et tout reprend comme avant, sans que la bureaucratie ait changé et que personne soit capable de la remplacer.

Un peuple habitué à mener ses propres affaires offre un spectacle tout différent. En France, où une grande partie des gens ont fait leur service militaire et où beaucoup d'entre eux ont eu au moins le grade de sous-officier, il se trouve dans toutes les insurrections populaires quelques personnes compétentes pour en prendre le commandement et improviser un plan d'action passable. Ce que sont les Français dans les affaires militaires, les Américains le sont dans toute sorte d'affaires civiles : laissezles sans gouvernement, et n'importe quel groupe d'Américains est capable d'en improviser un et de mener cette affaire ou tout autre affaire civile, avec assez d'intelligence, d'ordre et de décision. Voilà comment devrait être tout peuple libre : il ne se laissera jamais asservir par aucun homme ou groupe d'hommes parce qu'il est capable de s'emparer et de tenir les rênes de l'administration centrale. Aucune bureaucratie ne peut espérer contraindre un tel peuple à faire ou à subir ce qui ne lui plaît pas. Mais là où la bureaucratie fait tout, rien de ce à quoi elle est réellement hostile ne peut être fait. La constitution de tels pays est une combinaison de l'expérience et des talents pratiques concentrée en un corps discipliné, destiné à gouverner les autres ; et plus l'organisation est parfaite en elle-même, mieux elle réussit à attirer et éduquer dans son sens les gens les plus brillants de toutes les classes de la société, plus l'asservissement de tous, y compris des membres de la bureaucratie, est complet. Car les gouvernants sont autant les esclaves de leur organisation et de leur discipline que les gouvernés ne le sont des gouvernants. Un mandarin chinois est tout autant l'outil et la créature du despotisme que le plus humble cultivateur. Un Jésuite est l'esclave de son 
ordre au plus haut point d'avilissement, bien que l'ordre lui-même existe de par le pouvoir collectif et l'importance de ses membres.

Il ne faut pas oublier non plus que l'absorption de toutes les grandes intelligences du pays par la classe gouvernante est fatale tôt ou tard à l'activité et au progrès intellectuel de cette classe elle-même. Liés comme le sont ses membres à faire fonctionner un système qui, comme tous les systèmes, procède dans une large mesure par des règles fixes, le corps des fonctionnaires est continuellement tenté de sombrer dans une indolente routine ; ou s'ils sortent de temps à autre du système, c'est pour se lancer dans quelque embryon de projet qui a frappé l'imagination d'un des membres influents de ce corps ; et le seul moyen de contrôler ces tendances très proches, bien qu'apparemment opposées, le seul moyen de maintenir les intelligences de ce corps à un bon niveau, c'est de rester ouvert à la critique vigilante, indépendante et formée elle aussi de grandes intelligences. C'est pourquoi il faut pouvoir former de telles compétences en dehors du gouvernement et leur fournir les occasions et l'expérience nécessaires pour concevoir un jugement correct dans les affaires pratiques. Si nous voulons avoir en permanence un corps de fonctionnaires habile et efficace - et pardessus tout susceptible de créer le progrès et disposé à l'adopter - et si nous ne voulons pas que notre bureaucratie dégénère en " pédantocratie », il ne faut pas que ce corps absorbe les emplois qui forment et cultivent les facultés requises pour gouverner les hommes.

Savoir où commencent ces maux si redoutables pour la liberté et le progrès humain, ou plutôt savoir où ils commencent à l'emporter sur les bienfaits, lesquels naissent de l'usage collectif de la force sociale et des directives de ses chefs officiels et visent à supprimer les obstacles à notre bien-être ; bref, garantir autant que possible les avantages de la centralisation politique et intellectuelle, sans pour autant détourner dans les voies officielles une trop grande proportion de l'activité générale - voilà une des questions les plus difficiles de l'art de gouverner. C'est dans une large mesure une question de détails, où les considérations les plus nombreuses et les plus variées doivent être prises en compte, et où l'on ne peut poser de règles absolues. Mais je crois que le principe pratique sur lequel repose notre salut, l'idéal à ne pas perdre de vue, le critère de jugement de tous les dispositifs inventés pour vaincre la difficulté, peut s'exprimer ainsi : la plus grande dissémination de pouvoir conciliable avec l'efficacité; mais la plus grande centralisation possible de l'information et sa diffusion plus grande à partir du centre. Ainsi il y aurait dans l'administration municipale - comme dans les États de la Nouvelle-Angleterre - un partage très soigneux entre les fonctionnaires de chaque localité de toutes les affaires qu'on n'aurait pas avantage à laisser aux mains des personnes directement intéressées ; mais à côté de cela, il y aurait dans chaque département des affaires locales, une superintendance, formant une branche du gouvernement général. L'organe de cette superintendance concentrerait, comme en un foyer, toute la variété des informations et expériences provenant de la direction de cette branche des affaires publiques dans toutes les localités, ainsi que de tout ce qu'on fait d'analogue dans les pays étrangers et de ce qu'on peut tirer des principes généraux de la science politique. Cet organe central aurait le droit de savoir tout ce 
qui se fait, et sa mission serait de rendre disponibles ailleurs les connaissances acquises dans un endroit. Émancipés des préjugés mesquins et des vues étroites d'une localité de par sa position élevée et l'étendue de la sphère de ses observations, ses conseils auraient du même coup davantage d'autorité; mais son pouvoir réel, en tant qu'institution permanente, devrait se limiter, selon moi, à obliger les fonctionnaires à se conformer aux lois établies pour les diriger. Pour tout ce qui n'est pas prévu dans les règles générales, ces fonctionnaires devraient être laissés libres d'exercer leur propre jugement et d'en répondre devant leurs mandants. Pour la violation des règles, ils seraient responsables devant la loi, et les règles elles-mêmes seraient édictées par le législatif, l'autorité administrative centrale ne veillant qu'à leur application; et en cas de mauvaise application, l'autorité en appellerait, selon la nature du cas, soit au tribunal pour faire respecter la loi, soit aux électeurs pour renvoyer les fonctionnaires qui n'auraient pas appliqué cette loi selon son esprit. Telle est, dans son ensemble, la superintendance centrale que le Bureau de la loi des pauvres est censée exercer sur les administrateurs du Conseil des pauvres dans tout le pays. Quelque soit l'usurpation de pouvoir que commette le Bureau dans ce domaine, elle est juste et nécessaire, puisqu'il s'agit de corriger les habitudes de mauvaise administration dans les questions qui intéressent non seulement les localités, mais toute la communauté, puisque nulle localité n'a le droit de se transformer par la déficience de son administration en un nid de paupérisme, susceptible de gagner d'autres localités et de détériorer la condition morale et physique de toute la communauté ouvrière. Bien que les pouvoirs de coercition administrative et de législation subordonnée que possède le Bureau de la loi des pauvres (mais qu'il n'exerce qu'avec parcimonie étant donné l'état de l'opinion sur le sujet), soient parfaitement justifiables là où il y va d'intérêts nationaux de première importance, ils seraient totalement déplacés pour la surveillance d'intérêts purement locaux. Mais un organe central d'information et d'instruction pour toutes les localités seraient également précieux dans tous les départements de l'administration. Un gouvernement ne saurait se priver de cette sorte d'activité qui n'empêche pas, mais aide et stimule au contraire les efforts et le développement individuels. Le mal commence quand, au lieu de stimuler l'activité et la force des individus et des associations, le gouvernement substitue sa propre activité à la leur ; quand, au lieu d'informer, de conseiller, et à l'occasion de dénoncer, il les enchaîne à leur travail, ou leur ordonne de s'effacer pendant qu'il fait leur travail à leur place. La valeur d'un État, à la longue, c'est la valeur des individus qui le composent ; et un État qui sacrifie les intérêts de leur élévation intellectuelle à un peu plus d'art administratif ou à l'apparence qu'en donne la pratique - dans le détail des affaires ; un État qui rapetisse les hommes pour en faire des instruments dociles entre ses mains, même en vue de bienfaits, un tel État s'apercevra qu'avec de petits hommes, rien de grand ne saurait s'accomplir, et que la perfection de la machine à laquelle il a tout sacrifié n'aboutit finalement à rien, faute de cette puissance vitale qu'il lui a plu de proscrire pour faciliter le jeu de la machine. 